\title{
Parents' role in enabling the participation of their child with a physical disability : Actions, challenges and needs
}

Citation for published version (APA):

Piskur, B. (2015). Parents' role in enabling the participation of their child with a physical disability : Actions, challenges and needs. [Doctoral Thesis, Maastricht University]. Datawyse / Universitaire Pers Maastricht. https://doi.org/10.26481/dis.20150617bp

Document status and date:

Published: 01/01/2015

DOI:

10.26481/dis.20150617bp

Document Version:

Publisher's PDF, also known as Version of record

\section{Please check the document version of this publication:}

- A submitted manuscript is the version of the article upon submission and before peer-review. There can be important differences between the submitted version and the official published version of record.

People interested in the research are advised to contact the author for the final version of the publication, or visit the DOI to the publisher's website.

- The final author version and the galley proof are versions of the publication after peer review.

- The final published version features the final layout of the paper including the volume, issue and page numbers.

Link to publication

\footnotetext{
General rights rights.

- You may freely distribute the URL identifying the publication in the public portal. please follow below link for the End User Agreement:

www.umlib.nl/taverne-license

Take down policy

If you believe that this document breaches copyright please contact us at:

repository@maastrichtuniversity.nl

providing details and we will investigate your claim.
}

Copyright and moral rights for the publications made accessible in the public portal are retained by the authors and/or other copyright owners and it is a condition of accessing publications that users recognise and abide by the legal requirements associated with these

- Users may download and print one copy of any publication from the public portal for the purpose of private study or research.

- You may not further distribute the material or use it for any profit-making activity or commercial gain

If the publication is distributed under the terms of Article $25 \mathrm{fa}$ of the Dutch Copyright Act, indicated by the "Taverne" license above, 


\section{PARENTS' ROLE IN ENABLING THE PARTICIPATION OF THEIR CHILD WITH A PHYSICAL DISABILITY Actions, challenges and needs}

Barbara Piškur 
ISBN: 9789461594372

Production: Datawyse | Universitaire Pers Maastricht Illustration: Jaime Langeweg, student Communication \& Media Design, Zuyd Hogeschool 


\title{
Parents' role in enabling the participation of their child with a physical disability
}

\author{
Actions, challenges and needs
}

\author{
Dissertation \\ to obtain the degree of Doctor \\ at Maastricht University, \\ on the authority of the Rector Magnificus, Prof.dr. L.L.G Soete \\ in accordance with the decision of the Board of Deans, \\ to be defended in public \\ on Wednesday, 17 June 2015, at 16.00 hours
}

by

Barbara Piškur

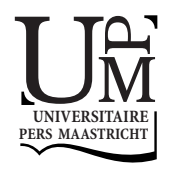


Promotoren

Prof.dr. Anna JHM Beurskens

Prof.dr. Rob JEM Smeets

Prof.dr. Marian J Jongmans (Utrecht University)

\section{Co-promotor}

Dr. Marjolijn Ketelaar (University Medical Center Utrecht and De Hoogstraat Rehabilitation)

\section{Manuscript commission}

Prof.dr. Klasien Horstman (chair)

Prof.dr. Jan-Willem Gorter (McMaster University, Canada)

Prof.dr. Maria WJ Jansen

Dr. Niina Kolehmainen (Newcastle University, UK)

Prof.dr. Luc JI Zimmermann 


\section{Contents}

$\begin{array}{lll}\text { CHAPTER } 1 \text { General introduction } & 7\end{array}$

$\begin{array}{lll}\text { PART I } & \text { LITERATURE INQUIRY } & 21\end{array}$

CHAPTER 2 Parents' actions, challenges, and needs while enabling participation of children with a physical disability: A scoping review

CHAPTER 3 Participation and social participation Are they distinct concepts?

PART II MIXED METHODS INQUIRY

63

CHAPTER 4 What do parents need to enhance participation of their school-aged child with a physical disability? A cross-sectional study in the Netherlands

CHAPTER 5 Daily actions, challenges, and needs among Dutch parents while supporting the participation of their child with a physical disability at home, at school, and in the community: A qualitative diary study

CHAPTER 6 The lived experience of parents enabling participation of their child with a physical disability at home, at school and in the community: An Interpretative Phenomenological Analysis 101

CHAPTER 7 Summary and general discussion 125

CHAPTER 8 Valorisation 151

Nederlandse samenvatting (Summary in Dutch) 159

Appendix 1 169

Acknowledgements

Curriculum Vitae 185 
"Inclusion is communion. No one becomes included by receiving hand-outs, even if these hand-outs are given by public bodies and with public resources. No one becomes included by being treated by a program in which he or she is no more than a number or a statistic. Inclusion is ... to participate in a process of changing one's own life and collective life".

Cezar Busatto [1] 
CHAPTER 1

General introduction 

Taking care of a child is one of the complex tasks every parent hopes to succeed in [2]. Parents are the constant factor in a child's life [3] and for most parents caring for a child is an experience full of triumphs and joy as well as challenges and stress [4]. Parent involvement is a crucial force in children's development, learning, and success at school and in life [5]. As child development is primarily seen as a social process, the child's family is the central social context where this development occurs. In particular parents or primary care givers, have a major influence on child development by for example making decisions on choosing their child's friends or peer groups [6]. Also parents of children with a physical disability play an important role in the development of their child.

United Nation agencies roughly calculate that $10 \%$ of the world's population, currently $650,000,000$, is born with or acquires a disability within lifetime $[7,8]$. Of this 650 million, UNICEF has estimated that around one quarter or 150 million are children. In 2012, Tierolf et al. [9] showed that in the Netherlands there are between 109.000 and 129.000 children with a disability (not including children with psychiatric problems), accounting for about 3,5\% of all children between 0 and 17 years. Within this group, $70 \%$ has a physical disability [9]. According to the Netherlands Organization for Applied Scientific Research (TNO), 5\% of Dutch children between 4 and 15 years has a severe physical disability [10]. Based on these data, it can be estimated that in the Netherlands around 150.000 parents of children with a physical disability daily take care for their child at home, at school and in the community.

The following paragraphs highlight concepts that relate to parents' role while taking care of their child with a physical disability.

\section{Participation}

Participation is seen as an important outcome in the field of childhood disability [11] and mentioned as a core principle in several European policy reports (e.g., the European Health Policy: Health 2020 [12], the Europe Disability Action Plan 2006 - 2015 [13], and the Europe 2020 Strategy [14]. Participation is every child's right [15], vital to the child's health [16], and associated with the child's well-being [17, 18], quality of life, and development [19]. Since its publication in 2001, the definition of participation "a person's involvement in life situations", as described in the International Classification of Functioning, Disability and Health (ICF) [20], is the most frequently used in rehabilitation and research. For children, participation domains of involvement in everyday activities, as described in the ICF - Children and Youth (IFC-CY) [21], include 'learning and applying knowledge', 'general tasks and demands', 'communication', 'mobility', 'self-care', 'do- 
mestic life', 'interpersonal interactions and relationships', 'major life areas', 'community', 'social and civic life'. Regardless of its common use, the ICF definition of participation has been critically evaluated for its limitations, concerning issues as the meaning of involvement and the subjective experience of participation [22-25].

In particular, for children, being involved in life situations with other people is of great importance; children engage in formal activities organized by schools, sports clubs or hobby associations and informal activities initiated by peers, friends, or other social contacts $[11,26]$. Several authors use the term social participation, emphasizing the importance of engagement in social situations [27-30]. Social participation refers to the relationships with family members, peers, community members, local institutions, and at the broadest level, with society [31-33]. A growing interest in social participation can be witnessed as the concept is used in several recent policy reports (e.g., the revised European Social Charter [34]).

Despite the interest in the concepts of participation and social participation, it remains unclear how those concepts relate to each other. As both concepts are regarded as vital for child development, these concepts should be distinctly defined and clearly should be described how they are intertwined for the purpose of practice and research.

\section{Children with a physical disability}

Children with a physical disability participate less frequently in almost all activities compared to children without physical disabilities $[35,36]$, and experience more difficulties in participating across a wide range of domains essential to daily life [37]. The degree of participation of children with a physical disability is associated with several variables, such as gross motor functioning and communication skills [38]. As a result, these children have difficulty building relationships, and often feel socially isolated [39-41]. Through interaction with members of social networks, children gain knowledge, learn skills, express creativity, determine meaning of life, and form friendships [32, 42]. In addition, participation of children in social networks prepares them to become competent within the particular cultural or ecological context in which they live [43]. Consequently, they are better equipped for adult life including work, marriage, and recreation [33].

In the last twenty years, the view on disability in our society has changed [44, 45] due to the prohibition of any discrimination on the ground of disability (Article 21- The Charter of Fundamental Rights) $[46,47]$ and the shift from a medical to a social model of disabil- 
ity [7]. Taking that perspective, any situation in which children with a disability participate less than their peers without a disability is not satisfactory [8].

\section{Family-centred service}

In the Netherlands, as well as in Europe, children with a physical disability that is neurological and non-progressive in nature (e.g., Cerebral palsy, Spina bifida) and their parents represent the major group in paediatric rehabilitation [48]. A shift in the paradigm of paediatric rehabilitation is the recognition that families have the expertise to care for their own children $[49,50]$. Family-centred service (FCS), also named Family-centred care or Family centred practice [50-53] is described as a set of values, attitudes, and approaches to services for children with special needs and their families. It recognizes that each family is unique, a constant in the child's life, and that parents are the experts in the child's abilities and needs [50,54]. In FCS, a family works in partnership with service providers to make informed decisions about the services and supports the child and family are able to receive $[54,55]$. There is recognition that collaboration with and support for parents have a positive influence on the contribution of parents to their child's participation [56]. Recently, as children are seen as equal partners in the process of paediatric rehabilitation, the approach has been adapted into Child \& Family-Centred Service - CFCS [57].

Also, in the Netherlands, Family-Centered Care has become widely accepted as part of the philosophy in paediatric rehabilitation [58-61]. However, it still appears that current paediatric practice does not fall in line with the core principles of FCS $[6,62]$, and that parents do not always receive the support or collaboration that is meaningful to them $[63,64]$.

Situations like this are regarded as not acceptable, as parents have long been positioned as playing a central role in rehabilitation process [65].

\section{Parents' role in facilitating participation of children with a physical disability}

Scorgie et al. [66] illustrated that most parents of a child with a physical disability are able to find a way to support their child in daily life. However, caring for a child with a disability can be demanding $[67,68]$. Discussions among Dutch parents of a child with a physical disability on social media illustrate that parents experience that caring for a child goes with a lot of organization and effort, as quoted in the following Tweet: 


\section{Wie heeft enig idee wat er allemaal aan geregel en gedoe komt kijken bij zorg voor mensen met beperking? Dat alléén is soms al een dagtaak!}

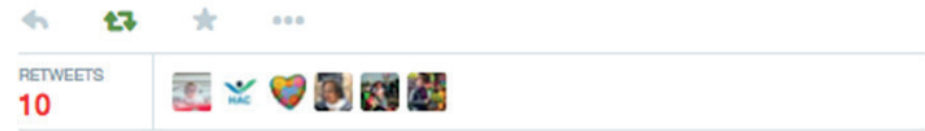

23:21 - 26 okt. 2014

Translation: "Who has any idea of the amount of organization and effort required in caring for people with a disability? That in itself is a day's work".

A large amount of studies with parents of children with a disability has been conducted [68-73]. However, most studies looked at the impact of having a child with a disability on parents' life (e.g., parental mental health or parent personal stress). A few studies $[74,75]$ investigated the relationship between child physical functioning and family needs; others [11, 76] looked mainly at the relationship between parents' factors such as socio-economic status and parents' activity orientation and child's participation. According to Lalvani \& Polvere [77], there is a dominating medical perspective in research concerning children with a physical disability. This perspective tends to look for negative outcomes or patterns of dysfunction; the perspectives of families of children with disabilities are usually not represented in this research [77, 78]. Parents, in particular, positively influence participation of their child with a disability. In the last 15 years, some studies described actions and strategies of parents of a child with a physical disability to support their child in daily life; for example by encouraging other people to accept their child with a disability [79] or by facilitating contacts outside of the family [80]. Studies also showed that these parents experience challenges or problems; insufficient school support, lack of acceptance and financial burden are among the examples $[81,82]$. Research [83] suggests that the difficulties parents encounter in daily life seriously affect the efforts they undertake to support their child to participate.

Despite these studies, we still do not know enough what parents of children with a physical disability do in their daily life to support their child's participation, what they might come across and what needs they might have while supporting child's activities at home, at school or in the community. Understanding parents' actions, challenges and needs is fundamental to take further steps in designing better strategies to improve participation of children with a physical disability. To reach understanding, the most 
relevant is to capture the perspectives of these parents themselves; parents' views and voice in the development of services and their evaluation of 'what works' need to be central [84].

In conclusion, participation is seen as a key principle in paediatric rehabilitation, research and policy. Children with a physical disability are participating less in almost all activities of daily life compared to their peers without a disability. A situation as portrayed above is not acceptable since participation is a fundamental right for all children. Parents of children with a physical disability do support their child's participation and are, within paediatric rehabilitation, regarded as experts on their child's abilities and needs. Nevertheless, there is very little understanding of what parents actually do, what they come across and what their needs are in relation to their child's participation. Indepth knowledge about parents' role regarding participation of their child with a physical disability would enable professionals to achieve meaningful collaboration with parents.

\section{Aims}

The overall aim of this thesis is to generate new knowledge and insights into parents' actions, challenges, and needs while enhancing the participation of their child with a physical disability. In addition, this research project took the motto "Nothing About Us Without Us" as a guiding principle. Hence, the research team involved service users in several ways; as a co-researcher, worked in cooperation with the Dutch association of people with a physical disability (i.e. the BOSK) and consulted a parent panel.

The specific objectives of this thesis were:

- To explore the scientific literature and define gaps about the scope of parents' actions, challenges, and needs while enabling participation of their child with a physical disability (scoping review study).

- To critically discuss the current scientific literature on the concepts of participation and social participation (discussion paper).

- To provide an extensive description of parents' needs and explore which factors are associated with these needs (cross-sectional study).

- To describe parents' actions, challenges and needs while enabling their child's participation at home, at school and in the community (diary study).

- To perform an in-depth exploration by interviews and gain understanding of parents' thoughts, feelings and concerns as experienced while reflecting on their actions, challenges, and needs in enabling their child's participation at home, at school and in the community (phenomenological study). 


\section{Outline of the study}

The outline of the thesis (chapter 2-6) is presented in the following figure (Figure 1).

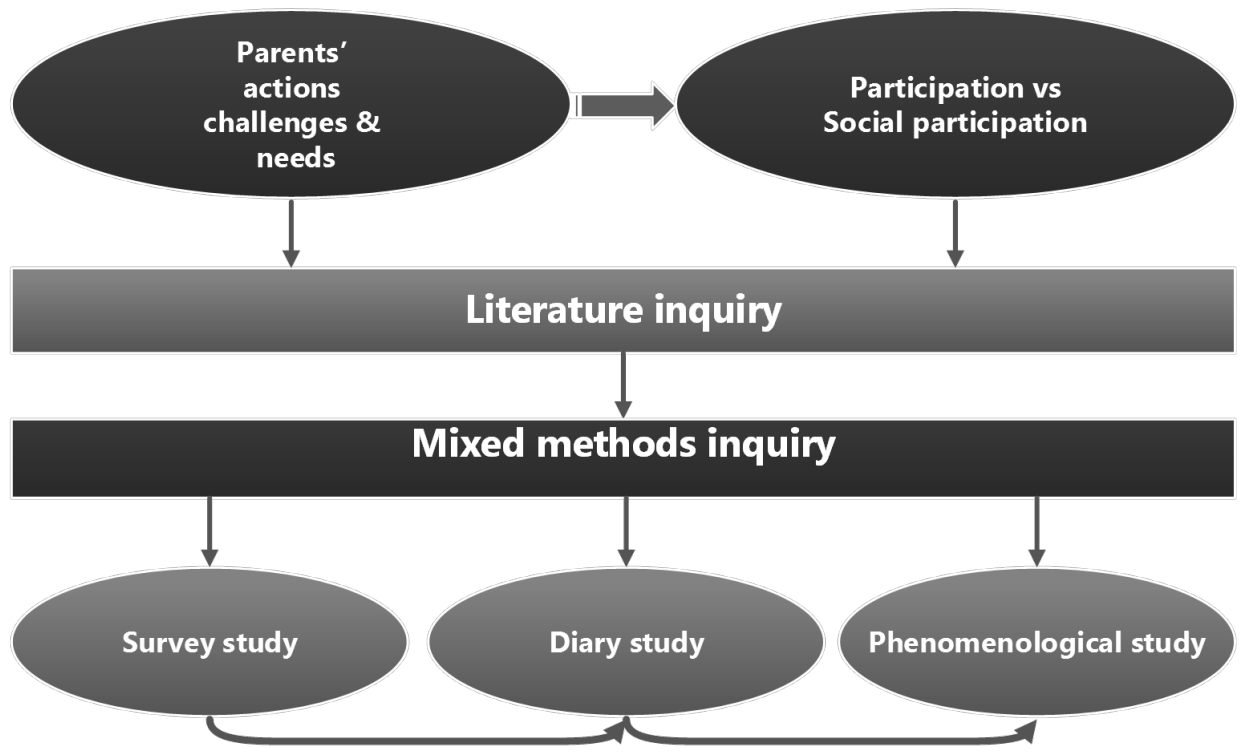

Figure 1: Outline of the study

Part I called literature inquiry focuses on understanding of the earlier work through providing an overview and exploration of the literature on the key concepts of the thesis. Chapter 2 presents a scope in the literature on parent's actions, challenges and needs while enabling their child's participation and provides a thematic framework while in Chapter 3 the differences and similarities of the concepts of participation and social participation as described in the literature are discussed and a possible direction for the improvement of the definition of participation is provided.

Part II - mixed methods inquiry, using sequential data collection approach, provides a detailed picture using different research methods to better understand these complex research phenomena [85-87]. Three empirical studies were conducted with the Dutch parents of a child with a physical disability that is neurological and non-progressive in nature (e.g. Cerebral palsy, Spina bifida). The child had to be between 4 and 12 years old, still living at home and participating in regular or special education. Chapter 4 gives an overview of the number, domains and priority of needs as expressed by parents in supporting the participation of their school-aged child with a physical disability. Additionally, the possible associations between the factors (perceived parental general 
health, family socio-economic status, child's gross motor function level) and the number of needs are identified. Chapter 5 provides a description of parents' own daily actions, challenges, and needs while supporting their child with a physical disability at home, at school, and in the community as illustrated in diaries. In addition, on the basis of the literature and data of this qualitative research a refined preliminary thematic framework is presented. In Chapter 6, an in-depth exploration and understanding of parents' thoughts, feelings and concerns as they reflect on their actions, challenges, and needs while enabling their child's participation at home, at school and in the community is given.

The thesis concludes in Chapter 7 with a summary and general discussion of the main findings with a focus on implications for service providers (elaborated in the Valorisation - Chapter 8), as well as theoretical and methodological considerations of the studies. 


\section{LITERATURE}

1. Busatto C: Solidary Governance for Creating Inclusive Societies, In: A contribution to the Expert Group Meeting: Creating Inclusive Society: Practical Strategies to Promote Social Integration. Paris; 2007.

2. Akister J, Johnson K: The Parenting Task: Parent's Concerns and Where They Would Seek Help. Journal of Family Social Work 2004, 8(2):53-64.

3. Sameroff AJ, Fiese BH: Transactional regulation: The developmental ecology of early intervention. In: Handbook of early childhood intervention edn. Edited by Shonkoff JP, Meisels SJ. New York: Cambridge University Press; 2000: 135-159.

4. Resch JA, Mireles G, Benz MR, Grenwelge C, Peterson R, Zhang D: Giving parents a voice: A qualitative study of the challenges experienced by parents of children with disabilities. Rehabilitation Psychology 2010, 55(2):139-150.

5. Patrikakou EN: The Power of Parent Involvement: Evidence, Ideas, and Tools for Student Success. In. Lincoln, IL: Center on Innovation \& Improvement, DePaul University; 2008.

6. Barbour $\mathrm{CH}$, Barbour NH, Scully P: Families, Schools, and Communities: Building Partnerships for Educating Children 5edn: Pearson; 2010.

7. WHO: World Report on Disability. In.: WHO; 2011.

8. Vosters N, Petrina R, Heemskerk I: Inclusief: werken aan zorg en welzijn voor iedereen: Coutinho; 2013.

9. Tierolf B, Oudenampsen D: Kinderen met een handicap in Tel: Kerngegevens per provincie, gemeente en wijk. In. Utrecht; 2013.

10. Kooiker SE: Jeugd met beperkingen: Rapportage gehandicapten 2006, In. Den Haag: Sociaal en Cultureel Planbureau; 2006.

11. King G, Law M, Hanna S, King S, Hurley P, Rosenbaum P, Kertoy M, Petrenchik T: Predictors of the Leisure and Recreation Participation of Children With Physical Disabilities: A Structural Equation Modeling Analysis. Children's Health Care 2006, 35(3):209-234.

12. Organization WH: The new European policy for health -Health 2020: First WHO European Conference on the New European Policy for Health - Health 2020. In. Jerusalem, Israel. Geneva:: World Health Organization; 2011.

13. Europe Co: Council of Europe Action Plan to promote the rights and full participation of people with disabilities in society: Improving the quality of life of people with disabilities in Europe 2006-2015. In. Strasbourg: Council of Europe; 2006.

14. Commission. E: Europe 2020: A strategy for smart, sustainable and inclusive growth. In. Brusssels: European Commission; 2010.

15. Nations U: Geneva: UN; 2006.

16. Hart R: Childrens prticipation, the theory and practice of involving young citizens in community development and environmental care, London: Earthscan Publications Ltd.; 1997.

17. Maton KI, Schellenbach CJ, Leadbeater BJ, Solarz AL: Investing in Children, Youth, Families, and Communities: Strengths-Based Research and Policy. Washington, DC: American Psychological Association. ; 2004.

18. Dahan-Oliel N, Shikako-Thomas K, Majnemer A: Quality of life and leisure participation in children with neurodevelopmental disabilities: a thematic analysis of the literature. Quality of Life Research 2012, 21(3):427-439.

19. Brown M, Gordon WA: Impact of impairment on activity patterns of children. Arch Phys Med Rehabil 1987, 68(12):828-832.

20. World Health Organization: International classification of functioning disability and health. In. Geneva: ICF; 2001.

21. World Health Organization: Geneva: World Health Organization; 2007.

22. Perenboom R, Chorus A: Measuring participation according to the International Classification of Functioning, Disability and Health (ICF). Disabil Rehabil 2003, 25(11/12):577 - 587. 
23. Hemmingsson $\mathrm{H}$, Jonsson $\mathrm{H}$ : An occupational perspective on the concept of participation in the international classification of functioning, disability and health-some critical remarks. Am J Occup Ther 2005, 59(5):569 - 576.

24. Wade D, Halligan P: New wine in old bottles: the WHO ICF as an explanatory model of human behaviour. Clin Rehabil 2003, 17(4):349 - 354.

25. Ueda S, Okawa Y: The subjective dimension of functioning and disability: what is it and what is it for? Disability and Rehabilitation 2003, 25(11-12):596-601.

26. King G, Petrenchik T, DeWit D, McDougall J, Hurley P, Law M: Out-of-school time activity participation profiles of children with physical disabilities: a cluster analysis. Child: Care, Health \& Development 2010, 36(5):726-741.

27. Coster W: Occupation-centered assessment of children. The American Journal Of Occupational Therapy: Official Publication Of The American Occupational Therapy Association 1998, 52(5):337-344.

28. Hjelle KM, Vik K: The ups and downs of social participation: experiences of wheelchair users in Norway. Disability \& Rehabilitation 2011, 33(25/26):2479-2489.

29. Pellerin C, Rochette A, Racine E: Social participation of relatives post-stroke: The role of rehabilitation and related ethical issues. Disability and Rehabilitation: An International, Multidisciplinary Journal 2011, 33(13-14):1055-1064.

30. Koster M, Pijl S, Nakken H, Van Houten E: Social participation of students with special needs in regular primary education in the Netherlands. Int J Disabil Dev Educ 2010, 57(1):59 - 75.

31. Lewis M, Feiring C, Brooks-Gunn J: Young children's social networks as a function of age and dysfunction. Infant Mental Health Journal 1988, 9(2):142-157.

32. Palisano R, Almarsi N, Chiarello L, Orlin M, Bagley A, Maggs J: Family needs of parents of children and youth with cerebral palsy. Child Care Health Dev 2009, 36(1):85 - 92.

33. Kang L, Palisano RJ, Orlin MN, Chiarello LA, King GA, Polansky M: Determinants of social participation-with friends and others who are not family members--for youths with cerebral palsy. Physical Therapy 2010, 90(12):1743-1757.

34. Council of Europe: Revised European Social Charter: 5th National Report on the implementation of the Revised European Social Charter submitted by The Government of the Netherlands. In.: Council of Europe; 2012.

35. Imms C, Reilly S, Carlin J, Dodd K: Diversity of participation in children with cerebral palsy. Dev Med Child Neurol 2008, 50(5):363 - 369.

36. Bult M, Verschuren O, Gorter J, Jongmans M, Piskur B, Ketelaar M: Cross-cultural validation and psychometric evaluation of the Dutch language version of the Children's Assessment of Participation and Enjoyment (CAPE) in children with and without physical disabilities. Clin Rehabil 2010, 24(9):843 - 853.

37. Lyons A, O' Connell L: The SPARCLE Project: Study of PARticipation and quality of life of Children with cerebral palsy Living in Europe. In.: SPARCLE: Enable Ireland; 2010.

38. Bult M, Verschuren $O$, Jongmans $M$, Lindeman $E$, Ketelaar $M$ : What influences participation in leisure activities of children and youth with physical disabilities? A systematic review. Res Dev Disabil 2011, 32(5):1521 - 1529.

39. Frostad $\mathrm{P}, \mathrm{Pijl} \mathrm{S}$ : Does being friendly help in making friends? The relation between the social position and social skills of pupils with special needs in mainstream education. Eur J Spec Needs Educ 2007, 22(1):15 30.

40. Law M, Dunn W: Perspectives on understanding and changing the environments of children with disabilities. Phys Occup Ther Pediatr 1993, 13(3):1 - 17.

41. La Greca AM: Social consequences of pediatric conditions: fertile area for future investigation and intervention. Journal Of Pediatric Psychology 1990, 15(3):285-307.

42. Dijkers M, Whiteneck G, El-Jaroudi R: Measures of social outcomes in disability research. Arch Phys Med Rehabil 2000, 81(12, Part B):S63 - S80. 
43. Tietjen AM: Children's Social Networks and Social Supports in Cultural Context. In: Children's Social Networks and Social Supports in Cultural Context. edn.

44. Barnes C: Understanding disability and the importance of design for all. Journal of Accessibility and Design for All 2011, 1(1).

45. Williams- Findlay R: Is there evidence to support the view that the language and subject matter selected by the Times and the Guardian in relation to disabled people has changed over the last twenty years? Leeds, UK: The University of Leeds.

46. Solemne P, al. E: Charter of fundamental rights of the European Union. In: (2000/C 364/01).

47. Convention on the Rights of Persons with Disabilities

48. Cans C: Surveillance of cerebral palsy in Europe: a collaboration of cerebral palsy surveys and registers. Developmental Medicine \& Child Neurology 2000, 42(12):816-824.

49. Nijhuis BJ, Reinders-Messelink HA, de Blécourt AC, Olijve WG, Groothoff JW, Nakken H, Postema K: A review of salient elements defining team collaboration in paediatric rehabilitation. Clinical Rehabilitation 2007, 21(3):195-211.

50. King S, Teplicky R, King G, Rosenbaum P: Family-centered service for children with cerebral palsy and their families: a review of the literature. Semin Pediatr Neurol 2004, 11(1):78 - 86.

51. Rosenbaum P, King S, Law M, King G, Evans J: Family-centred service. Phys Occup Ther Pediatr 1998, 18(1):1 - 20.

52. Kuo DZ, Houtrow AJ, Arango P, Kuhlthau KA, Simmons JM, Neff JM: Family-Centered Care: Current Applications and Future Directions in Pediatric Health Care. Matern Child Health J 2012(16):297-305.

53. Schoot T: Client-centred care: Balancing between perspectives of clients and nurses in home care. Maastricht: Maastricht University: Universitaire Pers Maastricht; 2006.

54. Bamm E, Rosenbaum P: Family-centered theory: origins, development, barriers, and supports to implementation in rehabilitation medicine. Arch Phys Med Rehabil 2008, 89(8):1618 - 1624.

55. Espe-Sherwindt M: Family-centred practice: collaboration, competency and evidence. Support for Learning 2008, 23(3):136-143.

56. Heiman T: Parents of Children with Disabilities: Resilience, Coping, and Future Expectations. Journal of Developmental and Physical Disabilities 2002, 14(2):159-171.

57. Rodger S: Occupation Centred Practice with Children: A Practical Guide for Occupational Therapists: Wiley-Blackwell; 2010.

58. Meihuizen-de Regt MJ, de Moor JMH, Mulders AHM: Kinderrevalidatie: Van Gorcum; 2009.

59. VRIN, VRA: Toekomstperspectief kinderrevalidatie in Nederland. In. Utrecht; 2000.

60. Siebes RC, Maassen GH, Wijnroks L, Ketelaar M, van Schie PE, Gorter JW, Vermeer A: Quality of paediatric rehabilitation from the parent perspective: validation of the short Measure of Processes of Care (MPOC20) in the Netherlands. Clinical Rehabilitation 2007, 21(1):62-72.

61. RN, VRA: Landelijk Innovatieprogramma Kinderrevalidatie 2006-2010, . In.: Stuurgroep Vooronderzoek Landelijk Innovatieprogramma Kinderrevalidatie; 2005.

62. Gorter JW, Visser-Meily A, Ketelaar M: The relevance of family-centred medicine and the implications for doctor education. Medical Education 2010, 44(4):332-334.

63. Nijhuis BJ, Reinders-Messelink HA, de Blécourt AC, Boonstra AM, Calamé EH, Groothoff JW, Nakken H, Postema K: Goal setting in Dutch paediatric rehabilitation. Are the needs and principal problems of children with cerebral palsy integrated into their rehabilitation goals? Clinical Rehabilitation 2008, 22(4):348363.

64. Pickering D, Busse M: An audit of disabled children's services - what value is MPOC-SP? Dovepress: open access to scientific and medical research 2010(2): 13-22

65. Faber R, Mulders A, Tol-de Jager vM: Kinderrevalidatie. In. Utrecht: Revalidatie Nederland; 2010.

66. Scorgie K, Wilgosh L, Sobsey D: The Experience of Transformation in Parents of Children with Disabilities: Theoretical Considerations. Developmental Disabilities Bulletin 2004, 32(1):84-110. 
67. Hatzmann J, Maurice-Stam H, Heymans H, Grootenhuis M: A predictive model of Health Related Quality of life of parents of chronically ill children: the importance of care-dependency of their child and their support system. Health and Quality of Life Outcomes 2009, 7(1):72.

68. Parkes J, Caravale B, Marcelli M, Franco F, Colver A: Parenting stress and children with cerebral palsy: a European cross-sectional survey. Developmental Medicine \& Child Neurology 2011, 53(9):815-821.

69. Hung J, Wu Y, Chiang Y, Wu W, Yeh C: Mental health of parents having children with physical disabilities. Chang Gung Med J 2010, 33(1):82-91.

70. Ketelaar M, Volman MJM, Gorter JW, Vermeer A: Stress in parents of children with cerebral palsy: what sources of stress are we talking about? Child: Care, Health and Development 2008, 34(6):825-829.

71. Skok A, Harvey D, Reddihough D: Perceived stress, perceived social support, and wellbeing among mothers of school-aged children with cerebral palsy. Journal of Intellectual and Developmental Disability 2006, 31(1):53-57.

72. Lach LM, Kohen DE, Garner RE, Brehaut JC, Miller AR, Klassen AF, Rosenbaum PL: The health and psychosocial functioning of caregivers of children with neurodevelopmental disorders. Disabil Rehabil 2009, 31(9):741-752.

73. Murphy N, Christian B, Caplin D, Young P: The health of caregivers for children with disabilities: caregiver perspectives. Child Care Health Dev 2007, 33(2):180 - 187.

74. Perrin EC, Lewkowicz C, Young MH: Shared vision: concordance among fathers, mothers, and pediatricians about unmet needs of children with chronic health conditions. Pediatrics 2000, 105(1 Pt 3):277-285.

75. Hendriks AHC, De Moor JMH, Oud JHL, Savelberg MMHW: Perceived changes in well-being of parents with a child in a therapeutic toddler class. Research in Developmental Disabilities 2000, 21(6):455-468.

76. La Torre G, Masala D, De Vito E, Langiano E, Capelli G, Ricciardi W: Extra-curricular physical activity and socioeconomic status in Italian adolescents. BMC Public Health 2006, 6:22.

77. Lalvani P, Polvere L: Historical perspectives on studying families of children with disabilities: A case for critical research Disability Studies Quarterly 2013, 33(3).

78. Ferguson PM: A Place in the Family: An Historical Interpretation of Research on Parental Reactions to Having a Child with a Disability, Journal of Special Education 2002, 36 (3).

79. Turnbull A, Pereira L, Blue-Banning M: Parents' facilitation of friendships between their children with a disability and friends without a disability. J Assoc Persons Severe Handicaps 1999, 24(2):85 - 99.

80. Bedell G, Khetani M, Cousins M, Coster W, Law M: Parent perspectives to inform development of measures of children's participation and environment. Arch Phys Med Rehabil 2011, 92(5):765 - 773.

81. Lundy HF: Parental Stress, Socioeconomic Status, Satisfaction with Services, and Family Quality of Life among Parents of Children Receiving Special Education Services. Georgia State University; 2011.

82. Brown RI, Schalock RL, Brown I: Quality of Life: Its Application to Persons With Intellectual Disabilities and Their Families-Introduction and Overview. Journal of Policy and Practice in Intellectual Disabilities 2009, $6(1): 2-6$.

83. Brown I, Anand S, Fung WLA, Isaacs B, Baum N: Family Quality of Life: Canadian Results from an International Study. Journal of Developmental and Physical Disabilities 2003, 15(3):207-230.

84. Network NQI: Principles for engaging with families: A framework for local authorities and national organisations to evaluate and improve engagement with families. In. London: Early Learning Partnership: Parental Engagement Group; 2010.

85. Creswell JW: Research design: Qualitative, quantitative, and mixed methods approaches: Thousand Oaks: Sage; 2009.

86. Betzner AE: Pragmatic and Dialectic Mixed Method Approaches: An Empirical Comparison. In. Ann Arbor, Minnesota, University of Minnesota; 2008.

87. Cronholm S, Hjalmarsson A: Experiences from sequential use of mixed methods. Electronic Journal of Business Research Methods 2011, 9(2):87-95. 



\section{PART I LITERATURE INQUIRY}





\section{CHAPTER 2}

Parents' actions, challenges, and needs while enabling participation of children with a physical disability

A scoping review

Published as: Piškur, B, Beurskens, A.J.H.M., Jongmans, M. J., Ketelaar, M., Norton, M, Frings, C, Hemmingsson, H \& Smeets, R.J.E.M. (2012). Parents' actions, challenges, and needs while enabling participation of children with a physical disability: a scoping review. BMC Pediatrics, 12: 177. 


\begin{abstract}
Background: Paediatric rehabilitation considers Family-centred service (FCS) as a way to increase participation of children with a physical disability in daily life. An important principal is that parents greatly contribute to their child's participation at school, at home, and in the community. However, it is unclear what kind of information is available from literature about what parents actually do to support their child's participation and what problems and needs they experience? Hence, the aim of this study was to provide an overview of the actions, challenges, and needs of parents in enabling participation of their child with a physical disability that is neurological and nonprogressive in nature.
\end{abstract}

Methods: Scoping review with extensive literature search (September 2011) and a thematic analysis to synthesize findings.

Results: Fourteen relevant articles revealed two major themes: 'parents enable and support performance of meaningful activities' and 'parents enable, change and use the environment'. Each theme holds a number of actions (e.g. choosing the right type of meaningful activities for facilitating social contacts) and challenges (e.g. negative attitudes of other people). Less information is available about the needs of parents.

Conclusions: This study indicates that parents apply a broad range of strategies to support participation of their children. They experience many challenges, especially as a result of constraints in the social and physical environments. However, this review also shows that little is known about needs of parents in facilitating participation. As Familycentered service (FCS) philosophy is all about the needs of the child and the family, it is essential to further investigate the needs of the parents and to understand if and to what extent they wish to be supported in enabling their child's participation in daily life. 


\section{BACKGROUND}

The concept of participation is important in the field of childhood disability [1]. Participation has been defined by the International Classification of Functioning, Disability and Health (ICF) as "a person's involvement in life situations" [2]. For children, involvement includes participation in everyday activities, such as recreational, leisure, school, and household activities [3]. Participation is an important outcome for the health of adults and children [4-7]. Furthermore, children's participation at home, at school, and in the community relates to well-being, quality of life, and development $[5,8-10]$. Several authors use the term social participation for participation, emphasizing the importance of engagement in social situations [11-13]. Through participation in different social contexts, children gather knowledge and skills needed to interact, play, work, and live with other people $[14,15]$.

Several publications [16-18] consider participation to be a fundamental right for children; the more meaningful a child's participation is, the more he or she develops a sense of identity and becomes confident and competent to deal with peers, adults, and the extended society. For these reasons, the enhancement of participation is a key topic of the revised European Social Charter [19]. The ICF operationalizes participation as what an individual does in his or her current environment and the individual's ability to execute a task or an action in real life situations [2]. Others [20,21] stressed that in addition to performance, engagement in activities is part of participation. For example, several studies $[22,23]$ show people might consider themselves to be engaged and participate in activities without actually performing them.

The degree of participation of children with a physical disability is associated with several variables, such as gross motor function, communicative skills, and environments [24]. Children with a physical disability experience participation restrictions. They participate less frequently in almost all activities compared to children without physical disabilities $[25,26]$. As a result, they have decreased opportunities building relationships and often feel socially isolated [27-29]. It is commonly known that accessible or accommodating facilities enable participation of children with physical disabilities [30].

The support of the social environment is equally important: parents, peers, teachers, community-members, and friends. Parents, in particular, greatly influence participation at school, at home and in the community [31]. They undertake many actions to improve their children's participation in daily life [31,32]. Understanding the actions of parents and also their challenges and needs will contribute to how society can support these parents and thereby enable the participation of children with physical disabilities. Paediatric rehabilitation, aiming for optimal participation [33,34], could benefit from this understanding to improve Family-centered services (FCS). In FCS, the family is seen as an expert on the child's abilities and needs, and professionals work in partnership 
with the family $[34,35]$. Paediatric rehabilitation considers FCS as a way to increase participation of children with a physical disability in daily life.

However, it is unclear what kind of information is available in literature about what parents live through, do, and what kind of problems and needs they have in supporting their child's participation? For these reasons, a scoping review was conducted in order to systematically map the research done in this area, as well as to identify any existing gaps in knowledge. Scoping review can be undertaken as a stand-alone project, especially where an area is complex or has not yet been comprehensively reviewed [36]. The following research question was formulated: What is known from the literature about parents' actions, challenges, and needs while enabling participation of their children with a physical disability? It was decided to focus on parents of children belonging to the major group of paediatric rehabilitation clients in the Netherlands, as well as, in Europe [37]; children with physical disabilities that are neurological and non-progressive in nature (e.g. cerebral palsy, spina bifida).

\section{METHODS}

\section{Scoping reviews}

For this review, the methodological framework of Arksey \& O'Malley [38] was applied. This framework consisted of the following main phases: design and search for relevant studies, selection of studies, charting the data, and the collation, summarization, and reporting of the results. Similar steps used for mixed-method systematic reviews were followed [39]; typically in scoping reviews, the appraisal and inclusion of evidence is not limited by the methodological quality of that evidence $[38,40]$.

\section{Search terms and search strategies}

This review focused on the actions, challenges, and needs of parents having a child between 0-18 years of age with a physical disability resulting from a neurological cause (e.g. cerebral palsy, spina bifida). An initial orientation search was conducted to extract the key search terms. The search strategies used the following formula: parents AND children AND diagnose OR physical disability AND need OR wish OR problem OR action OR strategy AND social participation. Search terms for "parents" included MeSH terms like "parents", "caregivers", or "single parent" in combination with free-text terms such as "parenting" or "grown-up". Search terms for "children" included the MeSH term "child" combined with free-text terms such as "children" or "scholar". Search terms for "physical disability" included MeSH terms such as "disabled children" combined with free-text terms such as "physical impairment" or "physical dysfunction". Diagnostic 
labels were also added to the search process. MeSH terms like "cerebral palsy" or "spinal dysraphism" were combined with free-text terms such as "infantile cerebral paralysis" or "spina bifida". Expressions that focus on parents' actions, challenges, and needs were searched with free-text terms like "action", "challenge", "demand", "wish", "desire", "need", or "problem". MeSH terms like "social participation" and "social environment" were combined with free-text terms like "participation", "social competence", or "formal participation".

During September 2011, the databases for PubMed, Psychology and Behavioral Sciences Collection, and PsycINFO were searched with no restrictions to the publication date. In addition, a manual search of articles in four journals (American Journal of Occupational Therapy, British Journal of Occupational Therapy, Canadian Journal of Occupational Therapy, Scandinavian Journal of Occupational Therapy) together with an Internet browser search (scholar.google.com) using the key search terms ("parents", "children", "cerebral palsy [and other diagnoses]", "physical disability", "need", "wish", "problem", "action", "strategy", "social participation", "participation") was conducted to locate and extract any additional publications or grey literature.

\section{Study selection criteria}

A four-stage process was used to identify selection criteria for study reviews. First, because parents' actions, challenges, and needs were the subject of this scoping review, parents were the primary target population of in the study in order to meet the selection criteria. Further, any studies showing parents' opinions or experiences, or both, towards the participation of their child with a physical disability were of particular interest in the review process. Second, to limit the scope of the review, studies also had to include only parents of children between 0 and 18 years of age having a physical disability that was deemed non-progressive and of neurological origin (e.g. cerebral palsy, spina bifida). If a study also included parents of children with other kinds of disabilities, that group had to be the minority of the study population. Third, studies were required to focus on those particular actions, challenges, or needs of parents that enabled participation of their children in daily activities at home, at school and the community. Participation could refer to the actual performance of activities or the engagement in activities. A "need" is described as a motivating force that compels action for its satisfaction [41] or a lack of something wanted [42]. An "action" was considered as the process of doing something, especially when dealing with a problem or difficulty [43]. A "challenge" is often threatening, provocative, stimulating, or inciting [44] and can be perceived as a problem that is defined as a gap between the existing state and a desired state [41]. Fourth, no restrictions were imposed regarding the type of design or year of 
publication for studies reviewed. The original language of each study, however, was limited to English, German, and Dutch.

\section{Study selection}

Three reviewers (BP, MN, CAF) independently evaluated and scored each study using the inclusion criteria described above. They recorded their evaluation by labelling each as either relevant (R), irrelevant (I), doubtful (D), or double (DO). Next, study abstracts were divided into three equal groups and assessed independently by the three reviewers. This step was followed by a cross-check by BP of 40 abstracts to check for consistency. Next, full-text articles were reviewed by BP and cross-checked by MN and ACF. In case of disagreement, a fourth person (AJHMB) stepped in to reach a consensus.

\section{Charting the data}

In scoping reviews, the process employed in the selection and charting of data generally includes studies that use mixed methodologies. This requires a subsequent synthesis, grounded within interpretative, narrative, and descriptive analytical methods [40,4547]. A data-charting form was developed to determine which variables to extract. This form provided for descriptive entries (e.g., study design) and for specific narrative information (e.g., actions, challenges, needs in relation to supporting participation). The three reviewers independently charted the data and discussed the results.

\section{Collating, summarizing, and reporting the results}

Data collation and summarization was done in two steps, as recommended methodological procedures found in the literature $[38,40]$. A descriptive summary of each study was made, consisting of the following elements: author, year, country, aim of the study, study design and population, and principal findings (see Table 1). Narrative synthesis was used to summarize evidence from 3 streams (quantitative descriptive, mixed methods, and qualitative studies) involving a qualitative, thematic analysis [46-49]. Codes and labels were formatted in the findings section of each article. Labels were ordered and discussed by the three reviewers. This resulted in themes that define the scope of the study, including the reviewers' interpretation of the data. 
Table 1: Descriptive summary of the relevant studies

\begin{tabular}{|c|c|c|c|c|c|}
\hline & $\begin{array}{l}\text { Author, Year, } \\
\text { and Country }\end{array}$ & Aim of the Study & Study Design & $\begin{array}{l}\text { Description of Study } \\
\text { Population }\end{array}$ & $\begin{array}{l}\text { Focus on Social } \\
\text { Participation, } \\
\text { Participation, or } \\
\text { Activity }\end{array}$ \\
\hline & $\begin{array}{l}\text { Heah T, Case T, } \\
\text { McGuire B, } \\
\text { Law M } \\
2007 \\
\text { Canada }\end{array}$ & $\begin{array}{l}\text { Parent/child experiences } \\
\text { regarding } \\
\text { - what successful } \\
\text { participation means to } \\
\text { children and families } \\
\text { - what support and what } \\
\text { hinders participation }\end{array}$ & $\begin{array}{l}\text { Qualitative research } \\
\text { Phenomenological } \\
\text { approach } \\
\text { Semi-structured } \\
\text { interviews }\end{array}$ & $\begin{array}{l}8 \text { parents ( } 1 \text { father, } 7 \\
\text { mothers) and } 8 \text { children } \\
\text { ( } 5 \text { - } 16 \text { years; } 5 \text { boys, } 3 \text { girls) } \\
\text { with physical disability } \\
\text { (neurological and / or } \\
\text { musculoskeletal disabilities) }\end{array}$ & $\begin{array}{l}\text { Participation in } \\
\text { everyday } \\
\text { occupations }\end{array}$ \\
\hline 51 & $\begin{array}{l}\text { Antle BJ, Mills } \\
\text { W, Steele C, } \\
\text { Kalnins I, } \\
\text { Rossen B } \\
2007 \\
\text { Canada }\end{array}$ & $\begin{array}{l}\text { Gain insight into parental } \\
\text { health promotion efforts } \\
\text { within the family context } \\
\text { where there is an } \\
\text { adolescent with a physical } \\
\text { disability }\end{array}$ & $\begin{array}{l}\text { Qualitative research } \\
\text { Long interview } \\
\text { Method }\end{array}$ & $\begin{array}{l}15 \text { parents ( } 11 \text { two-parent } \\
\text { and } 4 \text { single parent families) } \\
\text { and } 15 \text { children (11-16 } \\
\text { years; } 13 \text { boys, } 2 \text { girls) with } \\
\text { a diagnosis of physical } \\
\text { disability (Cerebral palsy: 7, } \\
\text { Spina Bifida: 3, Muscular } \\
\text { dystrophy 3, other } \\
\text { conditions:2) }\end{array}$ & $\begin{array}{l}\text { Play, leisure, } \\
\text { and educational } \\
\text { activities }\end{array}$ \\
\hline 52 & $\begin{array}{l}\text { Missiuna C, } \\
\text { Moll S, King S, } \\
\text { King G, Law M } \\
2007 \\
\text { Canada }\end{array}$ & $\begin{array}{l}\text { To explore parent } \\
\text { perspectives regarding the } \\
\text { early experiences of their } \\
\text { children with } \\
\text { Developmental } \\
\text { Coordination Disorder }\end{array}$ & $\begin{array}{l}\text { Qualitative research } \\
\text { Phenomenological } \\
\text { approach } \\
\text { In-depth interviews }\end{array}$ & $\begin{array}{l}13 \text { parents of children with } \\
\text { Developmental } \\
\text { Coordination Disorder (6-14 } \\
\text { years; } 10 \text { boys, } 3 \text { girls) }\end{array}$ & $\begin{array}{l}\text { Play, leisure, } \\
\text { and educational } \\
\text { activities }\end{array}$ \\
\hline 53 & $\begin{array}{l}\text { Missiuna C, } \\
\text { Moll S, Law M, } \\
\text { King S, King G } \\
2006 \\
\text { Canada }\end{array}$ & $\begin{array}{l}\text { Explore the early } \\
\text { experiences and } \\
\text { participation patterns of } \\
\text { children with } \\
\text { Developmental } \\
\text { Coordination Disorder, as } \\
\text { perceived and reported by } \\
\text { the parents. }\end{array}$ & $\begin{array}{l}\text { Qualitative research } \\
\text { Phenomenological } \\
\text { approach } \\
\text { Semi-structured } \\
\text { interviews }\end{array}$ & $\begin{array}{l}13 \text { parents ( } 2 \text { fathers, } 13 \\
\text { mothers; } 13 \text { two-parent } \\
\text { families) and } 13 \text { children } \\
\text { (6- } 14 \text { years; } 10 \text { boys, } 3 \text { girls) } \\
\text { with diagnosis of } \\
\text { Developmental } \\
\text { Coordination Disorder }\end{array}$ & $\begin{array}{l}\text { Play, leisure, } \\
\text { and educational } \\
\text { activities }\end{array}$ \\
\hline 54 & $\begin{array}{l}\text { Bedell GM, } \\
\text { Cohn ES, } \\
\text { Dumas HM } \\
2005 \\
\text { USA }\end{array}$ & $\begin{array}{l}\text { Describe parents' } \\
\text { perspectives about the } \\
\text { strategies they use to } \\
\text { promote social } \\
\text { participation of their } \\
\text { school-age child with Acute } \\
\text { Brain Injury }\end{array}$ & $\begin{array}{l}\text { Qualitative research } \\
\text { Semi-structured } \\
\text { interviews (content } \\
\text { and constant- } \\
\text { comparison analysis) }\end{array}$ & $\begin{array}{l}16 \text { Parents ( } 3 \text { fathers and } \\
16 \text { mothers; } 15 \text { two-parent } \\
\text { and } 1 \text { single parent families) } \\
\text { and children ( } 5-15 \text { years; } 6 \\
\text { boys, } 10 \text { girls) with Acute } \\
\text { Brain Injury }\end{array}$ & $\begin{array}{l}\text { Social } \\
\text { participation }\end{array}$ \\
\hline 55 & $\begin{array}{l}\text { Huang Y P, } \\
\text { Kellett U, St. } \\
\text { John W } \\
2011 \\
\text { Taiwan }\end{array}$ & $\begin{array}{l}\text { Describe a range of } \\
\text { challenging care-giving } \\
\text { experiences of Taiwanese } \\
\text { mothers providing for their } \\
\text { children with cerebral palsy }\end{array}$ & $\begin{array}{l}\text { Qualitative research } \\
\text { Hermeneutic } \\
\text { Phenomenological }\end{array}$ & $\begin{array}{l}15 \text { Mothers of children with } \\
\text { Cerebral palsy ( } 8 \text { months- } \\
14 \text { years) }\end{array}$ & $\begin{array}{l}\text { Activities of } \\
\text { daily living and } \\
\text { educational } \\
\text { activities }\end{array}$ \\
\hline
\end{tabular}




\begin{tabular}{|c|c|c|c|c|c|}
\hline & $\begin{array}{l}\text { Author, Year, } \\
\text { and Country }\end{array}$ & Aim of the Study & Study Design & $\begin{array}{l}\text { Description of Study } \\
\text { Population }\end{array}$ & $\begin{array}{l}\text { Focus on Social } \\
\text { Participation, } \\
\text { Participation, or } \\
\text { Activity }\end{array}$ \\
\hline 56 & $\begin{array}{l}\text { Bennett K, } \\
\text { Hay D } \\
2007 \\
\text { Australia }\end{array}$ & $\begin{array}{l}\text { (Cerebral palsy). } \\
\text { Test the hypothesized } \\
\text { model to determine } \\
\text { individual, family, and } \\
\text { teacher characteristics } \\
\text { associated with social skills } \\
\text { development in children } \\
\text { with physical disabilities }\end{array}$ & $\begin{array}{l}\text { Quantitative research } \\
\text { Descriptive study }\end{array}$ & $\begin{array}{l}212 \text { parents and children } \\
\text { (5-12 years) with a physical } \\
\text { disability; } 170 \text { teachers in } \\
\text { mainstream schools }\end{array}$ & $\begin{array}{l}\text { Educational } \\
\text { activities }\end{array}$ \\
\hline 57 & $\begin{array}{l}\text { Hewitt-Taylor J } \\
2008 \\
\text { UK }\end{array}$ & $\begin{array}{l}\text { Reports the parents views } \\
\text { of their children's } \\
\text { experiences in relation to } \\
\text { these activities }\end{array}$ & $\begin{array}{l}\text { Qualitative research } \\
\text { Semi-structured } \\
\text { interviews }\end{array}$ & $\begin{array}{l}14 \text { parents and } 14 \text { children } \\
\text { (18 months- } 18 \text { years) }\end{array}$ & $\begin{array}{l}\text { Play and } \\
\text { educational } \\
\text { activities }\end{array}$ \\
\hline 58 & $\begin{array}{l}\text { Buran CF, } \\
\text { Sawin K, } \\
\text { Grayson P, } \\
\text { Criss S } \\
2009 \\
\text { USA }\end{array}$ & $\begin{array}{l}\text { Survey the parents of } \\
\text { children with Cerebral palsy } \\
\text { and report their needs for } \\
\text { information, services, and } \\
\text { access to treatment }\end{array}$ & $\begin{array}{l}\text { Quantitative } \\
\text { research- } \\
\text { Descriptive study }\end{array}$ & $\begin{array}{l}475 \text { families receiving } \\
\text { services at a } \\
\text { multidisciplinary Cerebral } \\
\text { palsy Clinic; children (mean } \\
\text { age } 8 \text { years } 11 \text { months; } 266 \\
\text { girls, } 209 \text { boys) }\end{array}$ & $\begin{array}{l}\text { Recreational } \\
\text { activities }\end{array}$ \\
\hline 59 & $\begin{array}{l}\text { Meehan DR } \\
2005 \\
\text { USA }\end{array}$ & $\begin{array}{l}\text { Describe the experience of } \\
\text { mothering a 3-6 year old } \\
\text { child with hemiparesis }\end{array}$ & $\begin{array}{l}\text { Qualitative research } \\
\text { Phenomenological } \\
\text { approach } \\
\text { Interviews }\end{array}$ & $\begin{array}{l}5 \text { Mothers ( } 5 \text { two-parent } \\
\text { families) and children (3-6 } \\
\text { years; } 4 \text { boys, } 1 \text { girl)with a } \\
\text { diagnosis of hemiparesis }\end{array}$ & Leisure activities \\
\hline 60 & $\begin{array}{l}\text { Lawlor K, } \\
\text { Mihaylov B, } \\
\text { Welsh S, Jarvis } \\
\text { S, Colver A } \\
2006 \\
\text { UK }\end{array}$ & $\begin{array}{l}\text { Identify features of } \\
\text { environments that facilitate } \\
\text { or restrict participation }\end{array}$ & $\begin{array}{l}\text { Qualitative research } \\
\text { In-depth interviews }\end{array}$ & $\begin{array}{l}12 \text { Parents ( } 3 \text { fathers, } 5 \\
\text { mother, } 1 \text { grandmother) } \\
\text { and children ( } 5-17 \text { years; } 6 \\
\text { boys and } 6 \text { girls) with } \\
\text { Cerebral palsy }\end{array}$ & $\begin{array}{l}\text { Participation as } \\
\text { defined by the } \\
\text { International } \\
\text { Classification of } \\
\text { Function }\end{array}$ \\
\hline 61 & $\begin{array}{l}\text { Vogts N, } \\
\text { Mackey A, } \\
\text { Ameratunga S, } \\
\text { Stott NS } \\
2010 \\
\text { New Zealand }\end{array}$ & $\begin{array}{l}\text { To pilot the use to the Craig } \\
\text { Hospital Inventory of } \\
\text { Environmental Factors } \\
\text { (CHIEF) questionnaire to } \\
\text { ascertain information } \\
\text { regarding barriers to } \\
\text { participation }\end{array}$ & $\begin{array}{l}\text { Mix-methods: } \\
\text { Quantitative data } \\
\text { with Qualitative } \\
\text { feedback }\end{array}$ & $\begin{array}{l}32 \text { Parents and children } \\
\text { ( } 6-16 \text { years, } 15 \text { boys and } 7 \\
\text { girls) with Cerebral palsy }\end{array}$ & $\begin{array}{l}\text { Participation as } \\
\text { defined by the } \\
\text { International } \\
\text { Classification of } \\
\text { Function }\end{array}$ \\
\hline 62 & $\begin{array}{l}\text { Hewitt-Taylor J } \\
2009 \\
\text { UK }\end{array}$ & $\begin{array}{l}\text { Gain understanding of } \\
\text { parent's views regarding } \\
\text { the social inclusion of their } \\
\text { children who have complex } \\
\text { and continuing health } \\
\text { needs }\end{array}$ & $\begin{array}{l}\text { Qualitative research } \\
\text { Semi-structured } \\
\text { interviews }\end{array}$ & $\begin{array}{l}14 \text { parents ( } 2 \text { fathers, } 12 \\
\text { mothers; } 12 \text { two- parent } \\
\text { families, } 2 \text { single parent } \\
\text { families) and } 14 \text { children } \\
\text { (18 months- } 18 \text { years) with } \\
\text { complex health needs } \\
\text { (learning problems as well }\end{array}$ & Leisure activities \\
\hline
\end{tabular}




\begin{tabular}{|c|c|c|c|c|c|}
\hline & $\begin{array}{l}\text { Author, Year, } \\
\text { and Country }\end{array}$ & Aim of the Study & Study Design & $\begin{array}{l}\text { Description of Study } \\
\text { Population }\end{array}$ & $\begin{array}{l}\text { Focus on Social } \\
\text { Participation, } \\
\text { Participation, or } \\
\text { Activity }\end{array}$ \\
\hline 63 & $\begin{array}{l}\text { Palisano RJ, } \\
\text { Almarsi N, } \\
\text { Chiarello LA, } \\
\text { Orlin MN, } \\
\text { Bagley A, } \\
\text { Maggs J } \\
2009 \\
\text { USA }\end{array}$ & $\begin{array}{l}\text { Identify (1) differences in } \\
\text { the number and types of } \\
\text { family needs based on the } \\
\text { child's age and gross motor } \\
\text { function level; (2) the most } \\
\text { frequent expressed family } \\
\text { needs; and ( } 3 \text { ) needs that } \\
\text { differ based on gross motor } \\
\text { function level }\end{array}$ & $\begin{array}{l}\text { Quantitative research } \\
\text { Cross-sectional } \\
\text { analytical design }\end{array}$ & $\begin{array}{l}\text { as health problems) } \\
501 \text { parents ( } 389 \text { mothers, } \\
59 \text { fathers, } 25 \\
\text { grandmothers, } 28 \text { others) } \\
\text { and children ( } 2-21 \\
\text { years)with Cerebral palsy }\end{array}$ & $\begin{array}{l}\text { Physical } \\
\text { activities }\end{array}$ \\
\hline
\end{tabular}

The numbers in Table 1 correspond with the numbers in the reference list and the numbers in Figure 2

\section{RESULTS}

In total, 2,768 articles were identified as potentially relevant from the search in the following databases: PubMed, Psychology and Behavioral Sciences Collection, and PsycINFO. After screening the titles, 892 articles appeared to be relevant. Screening of abstracts resulted in 240 potentially relevant articles. In addition to these, the grey literature and manual search yielded an additional 133 articles. All 373 articles were then evaluated on a full-text level, resulting in a final total of 14 articles relevant for charting (See Figure 1).

\section{Descriptive summary of the studies}

The majority of the 14 relevant articles remaining after application of selection criteria were conducted in Canada and the United States followed by the United Kingdom (See Table 1). Parents of children aged between $0-18$ years had participated in the included studies. All articles had been published between 2005 and 2011. Ten articles consisted of qualitative studies; three of quantitative descriptive studies, and one article used a mixed method approach. The study population in eleven articles included parents having a child afflicted with a physical disability and children themselves. In two articles, only the parents of a child with a physical disability were included, and in one article, the study population involved the parents, the child with a physical disability, and their teacher. 


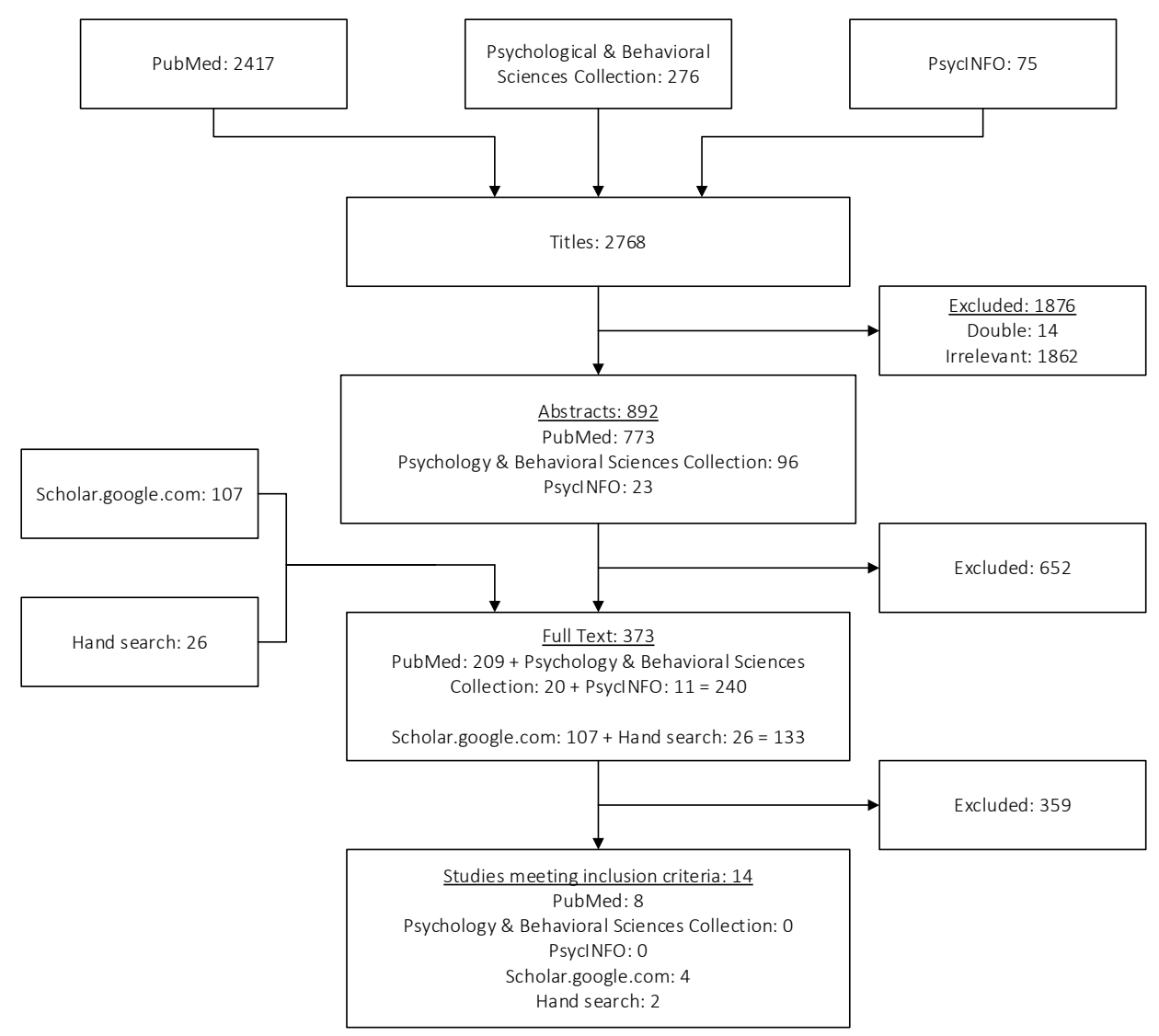

Figure 1: Flowchart of study selection.

\section{Narrative summary of the studies}

Results of the qualitative thematic analysis were organized along two major themes: (1) parents enable and support performance of meaningful activities, and (2) parents enable, change, and use the environment. In Figure 2, the actions, challenges, and needs are graphically presented. 


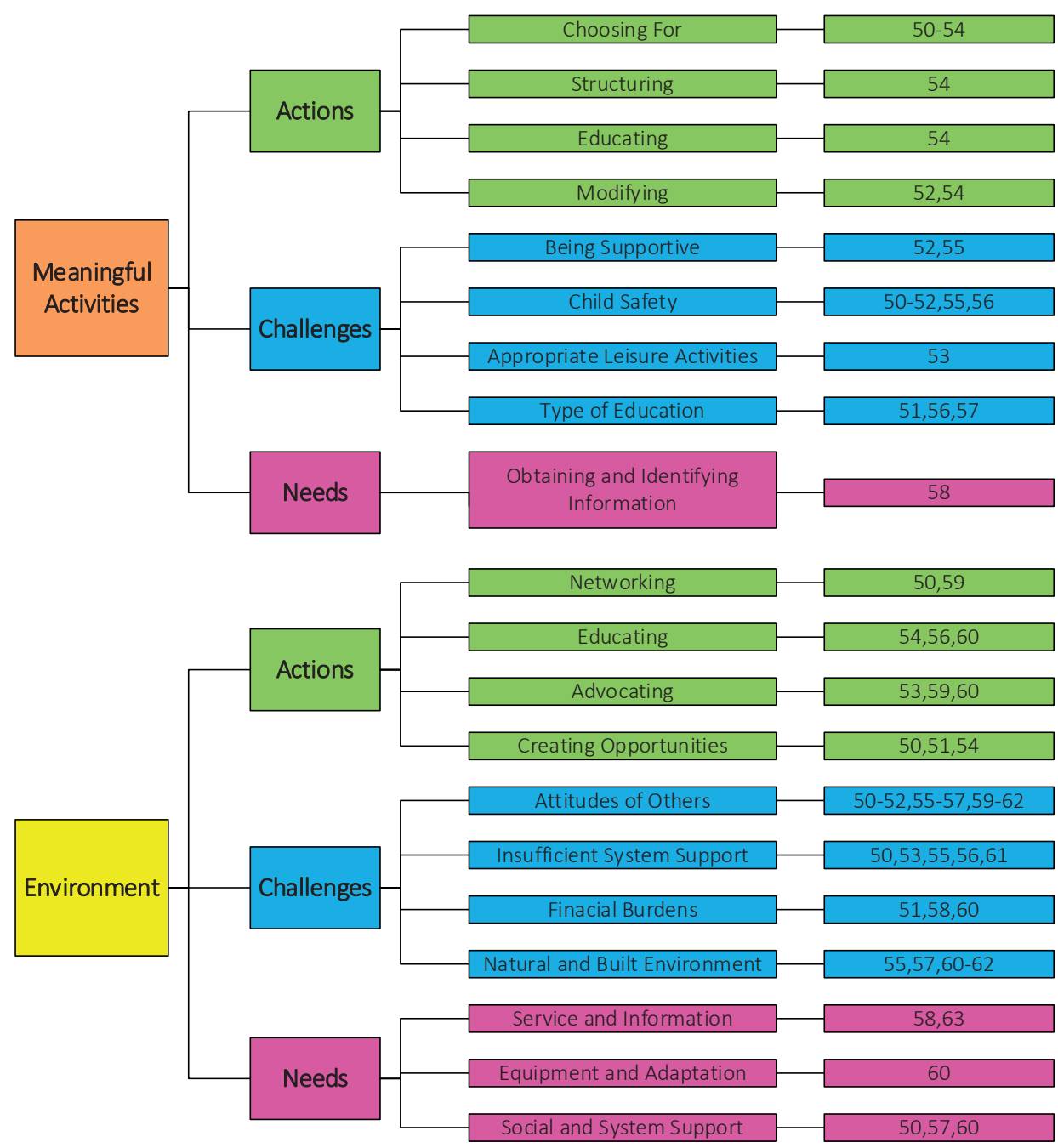

Figure 2: Flowchart of results based on thematic analysis.

\section{Parents enable and support performance of meaningful activities}

This theme is about actions, challenges, and needs of parents in relation to helping their child with a physical disability to engage or be involved in meaningful activities in order to enable participation. Here, the term meaningful relates to the subjective perception of parents about the meaning of activities regarding participation of the child. Five out of 14 studies demonstrated the following actions or strategies: "choosing for", "structuring", "educating", and "modifying" activities. 
"Choosing for" refers to the action by which parents make choices for or with the child about the kinds of activities in which he or she will engage. Heah et al. [50] found that parents had strong convictions that their children should experience a variety of activities in order to choose those that are particularly meaningful. Parents attributed different meanings to activities: having fun, feeling successful, doing and being with others, and doing things yourself [50]. In the study of Antle et al. [51], parents stressed the importance of exploring physical activities in order for their child to stay healthy and to develop self-confidence and discipline. Missiuna et al. [52] provided similar examples of parents who decided to enrol their child with a physical disability in recreational activities or in team sports in order to be better engaged with their peers. Occasionally, however, parents chose to limit or avoid sports activities if these activities proved to be too demanding in relation to their child's physical abilities, or to reduce the frustration levels of both parents and their child $[51,53,54]$. In some cases, mainstream education includes activities that are too demanding for a child with a physical disability. In one example [50], when parents noticed their child was at risk of falling behind his or her peers, they choose another type of educational institution.

"Structuring" refers to the way in which parents apply strategies to organize the day so that enough time is left for a child to engage in meaningful activities. One article addressed this specific action. In a study of Bedell et al. [54], in order to promote participation, mothers composed strategies that incorporated the daily needs of the family with that of the child by orchestrating activities and routines that enhanced the child's participation and experience. Specific strategies were not further described.

"Educating" is about teaching and coaching a child on how to solve problems while performing new or difficult activities. One study [54] showed examples of how parents enabled their child's participation by using several types of cognitive and behavioral strategies to improve performance. Modelling, showing, or describing the process, using trial and error, or repeating activities in the same or different contexts, were among the strategies found to be useful and valuable. Parents educated their child about how to deal with peers at school who engaged in behaviors, such as teasing [54]. Further, parents stimulated the learning process by setting limits, by being very consistent, or by using cues that supported their child's ability to perform meaningful activities.

"Modifying" stands for adaptations of activities to support the child's independence and social interaction. Missiuna et al. [52] provided examples by which parents helped their child perform everyday activities more effectively. One such example putting on a jacket for playing outdoors - was facilitated by buying clothes without buttons. Parents indicated that this was especially important when performance was interfering with a child's routine situations during school time. In another example given 
by Bedell et al. [54], parents broke down difficult household activities into smaller tasks, such as involving their child in parts of the laundry process.

While creating opportunities for their child to engage in meaningful activities, parents experienced various challenges. These included "being supportive in a correct manner", "coping with child safety", "choosing the most appropriate leisure activities", and "selecting the best type of education". Such types of challenges were discussed in six of the 14 studies.

Two studies $[52,55]$ illustrated the challenge of "being supportive in a correct manner" during performance of difficult activities. Parents did not know how to help their child once he or she became angry while doing a homework assignment [52]. Huang et al. [55] showed that parents struggled between encouraging their child's independence versus maintaining their responsibilities as parents.

"Coping with child safety" is another important challenge for parents. Studies by Heah et al. [50] and Missiuna et al. [52] demonstrated parents' vigilance when children went out with friends, such as playing in the park or attending a party. The more severe the child's disability, the more alert and involved his or her parents were [56]. Often, parents became overprotective, as described in the studies of Antle at al. [51] and Huang et al. [55].

Parents faced other challenges in addition to home and school activities, such as "choosing the most appropriate leisure activities" that fit the child's abilities while bringing a sense of accomplishment. For example, Missiuna et al. [53] described parents' struggles with physical leisure activities. Parents sought to avoid tasks in which the child experienced repeated failure, even taking the risk that by withholding their child from team sports, opportunities for peer connections might become more limited.

"Selecting the best type of education" to support their child's future is yet another challenge confronting parents. The study reviews indicated that parents believed that an appropriate education was an important condition for future success. Antle et al. [51] found many worries among parents about the future of their children: worries about having a career, about being financially independent, and about being able to live on their own and having friends. While some parents believed that a mainstream school is the best way to succeed in society, others were afraid their child would be too different from their peers in such a school system [56,57].

Only one study [58] addressed the needs of parents in "identifying and obtaining information" about meaningful activities for their child. Concerns encompassed the need of obtaining more information about the availability of recreational and entertainment activities, as well as information about education and special education. 


\section{Parents enable, change and use the environment}

This theme is about actions, challenges, and needs of parents while using, enabling, and changing the social and physical environment at home, school, and in the community to support the participation of their child with a physical disability. In addressing this theme, seven studies described actions or strategies: "networking", "educating", "advocating", and "creating opportunities".

"Networking" refers to the establishing of connections with people with similar experiences, who understand the parents' situation, and who are willing to support them. Heah et al. [50] and Meehan [59] illustrated that, in connecting with other parents of children with a disability, parents became more informed about community programs and suitable activities for their children. In addition, these connections provided parents with a feeling of belonging to a group with shared interests [59]. Further, Heah et al. [50] reported that parents identified and organized a wide range of social support (friends, family, or support workers) with the aim of increasing the participation of their child in community activities and social interactions. For example, one set of parents engaged a support worker to escort their child outside of the house to be with friends.

"Educating" is defined as the giving of instructions to others on how to support the activity performance of their child. Explaining to a teacher how to make educational activities more suitable to their children [56], or providing a teacher with written strategies are two examples of how parents helped to educate school staff [54]. Similar strategies were used for extended family members and services, such as respite care [60].

"Advocating" refers to the competing of resources, supports, and services within the system. Examples are given by Missiuna et al. [53], Meehan [59], and Lawlor et al. [60], in which parents actively advocated for additional services at school, like the presence of a teacher-assistant while taking an exam, or they spoke up for their child's best interest, or they fought for extra resources during leisure activities. To get appropriate support for their child, parents promote awareness about the child's abilities, strengths, and needs in an attempt to change peoples' attitudes toward their disability.

"Creating opportunities", as an action, means the creation of events by parents in order to shape opportunities for their child to get acquainted with other children. Heah et al. [50] and Antle et al. [51] described how parents often organized meetings with others to create opportunities and situations for their child to meet friends. Parents worried about their child being alone at parties. To cope, some parents held dual parties: one for themselves and one for the children [51]. Additionally, Bedell et al. [54] showed that parents purposefully selected certain peers to visit or play with their child after school in order to increase the chances for developing a solid friendship. 
Twelve studies addressed several parents' challenges related to the theme of "enable, change, and use of the environments". These comprised challenges such as the "attitudes of others", "insufficient system support", "financial burdens", "lack of time", and "barriers in both the natural and built environments".

The "attitudes of others" refers to the experience by which parents faced negative attitudes of other children or adults towards their child with a physical disability. The fact that parents have to deal with these attitudes is shown by the many worries and concerns that were expressed in several of the 14 research studies. Parents worried that their child would not be accepted by peers, or would be teased or hurt emotionally or physically [50,51,56,57,59]. Missiuna et al. [52] and Vogts et al. [61] also found that parents harbored concerns about their child being criticized by their teacher for not performing at the expected level. Negative attitudes, comments, and prejudice of others influenced the joy of being together as a family and thereby, impacted the participation of their child $[55,60,62]$.

"Insufficient system support" pertains to the challenges stemming from unsupportive social structures. Six research papers addressed challenges related to the school system. Bennett \& Hay [56] documented parents' concerns about the lack of help their children received from teachers and about the insufficient qualifications those teachers had in educating children with physical disabilities. Furthermore, studies by Vogts et al. [61], Missiuna et al. [53], Heah et al. [50], and Huang et al. [55] indicated that support and help at school was clearly not sufficient for children with disabilities. Additionally, in the study of Heah et al. [50], parents expressed that community programs do not provide enough opportunities for children with disabilities to play with others.

"Financial burden" illustrates the challenges faced by families in dealing with monetary constraints to support the participation of their child. Antle et al. [51] reported that parents with low incomes experienced stress when they lacked the resources necessary to enrol their child in recreational activities. Conversely, other parents discovered that their income was too high to receive financial support from the government and too low for addressing their child's needs [58]. Parents were often unaware of other financial support programs to which they were entitled [60].

A "barrier in the natural and built environment" refers to the physical accessibility of buildings and public places. Hewitt-Taylor [62] gave examples of challenges confronting parents in non-user-friendly shops, cinemas, and public toilets. Similar challenges were also experienced in parks, public transport, and parking facilities -- all noted as not being user-friendly for children with a physical disabilities [57,60-62]. Also, schools, playgrounds, and leisure facilities in neighbourhoods were often inaccessible to children with a physical disability $[55,61]$. These environmental barriers present many challenges for parents to find appropriate outdoor activities for their child to play with other children. 
Five studies addressed parents' needs regarding enabling environments: "service and information", "equipment and adaptations", and "social and system support".

"Service and information needs" refers to parents' needs for available centers and services in the community suitable for providing leisure activities for children with a physical disability. Palisano et al. [63] showed that parents sought out extra support persons or services to help them locate appropriate community camps, sports, recreational, social, and leisure activities. Furthermore, Buran et al. and Palisano et al. [58,63] illustrated how parents require more written information than is generally available about services available in their community.

"Equipment and adaptation" refers to the need for adequate equipment that is designed to support independence and participation in activities, while reducing the level of care. A study by Lawlor et al. [60] referred to the parents' needs for more userfriendly designs of transport systems and parking facilities, as those facilities are vital for attending leisure activities, school sessions, and hospital appointments.

"Social and system support" refers to the needs of parents for more expansive social networks and accessible leisure centers to enable the participation of their children. In several studies $[50,57,60]$ parents also expressed the need for extra support from grandparents by bringing their child to leisure activities or to school, ensuring that parents would be able to continue to work.

\section{DISCUSSION}

The purpose of this scoping review was to explore what is known in the literature about parents' actions, challenges, and needs while enabling participation of their children with a physical disability. Fourteen articles, all published after 2004, were included in the review.

The findings of this scoping review reveal that parents of children with a physical disability use, enable, and change the social and physical environment to facilitate participation. Further, they facilitate their child to engage or perform in meaningful activities. The most cited actions in the 14 studies reviewed are "choosing for" meaningful activities for their child, "advocating" for the child, "educating" the social environment, and "networking" with other people. The present study illustrates further that, in supporting participation, parents often face challenges in the environment such as "attitudes of other people", "insufficient system support", and "barriers in both the natural and built environments". Parents of children with a physical disability frequently experience difficulty in finding suitable educational systems and meaningful activities for their children that support their child's participation outside of the home. Ten out of 14 articles demonstrated parents' challenges with the "attitudes of other people" at school and in the community. Only a small number of studies discussed parents' needs in ena- 
bling participation; "social and system support" needs are the most often reported, followed by the needs for "services and information".

There is a debate in the literature about the concept of participation $[11,64]$. The International Classification of Functioning, Disability and Health (ICF) definition of participation used in this scoping review has been criticized in the literature $[20,65,66]$ for not including a personal meaning. Perenboom \& Chorus [67] stress the importance of fulfillment of personal goals and societal roles for participation, although their study found that several measurement instruments for participation only focused on the actual performance of activities. In the present study, it is unclear whether the meaning parents attribute to certain activities is congruent with the personal meaning their child is experiencing. Furthermore, Perenboom \& Chorus [67] argue that being autonomous to some extent or being able to control your own life, is part of participation. Participation can exist even if one is not actually doing things themselves. Some authors $[68,69]$ assigned the importance of engagement and motivation to the definition of participation. In our review, studies were included if they focused on parents enabling participation of their child in daily activities, regardless of whether the child actually performed or was engaged in the activity.

The results of this study may be hampered by limitations. Although a number of free-text and MeSH terms were used for addressing physical disabilities, there is a possibility that non-reviewed studies may have used other terms with similar intent or meaning. In addition, we may have missed studies due to database selection bias. This review did not specifically focus on literature in the fields of education or special education. Nevertheless, there is only a small chance that some studies were missed, as we conducted extensive manual searching (including the literature lists of included articles) and additional searches using scholar.google.com. This study does not only present a descriptive summary of the findings, but the thematic analysis also led to a synthesis that leads to further understanding of parents' actions, challenges, and needs. Most studies were conducted in western societies, like the United States and Canada. As social and cultural contexts differ in countries and regions, the results of this study may be influenced by cultural bias.

Similar findings of actions have been found in studies with other populations, e.g. parents of children with Down syndrome, young people with epilepsy, and young adults with physical disabilities [70-72]. Bedell et al. [72] gave examples of parents educating others and Reid et al. [70] showed examples of parents advocating for equal rights. In a study of parents' perceptions of their children with developmental coordination disorder (DCD), Segal et al, [73] found that physical activity is an important facet of social life, as impaired performance could lead to participation restriction. In many of the studies in the present review, parents were greatly concerned with enrolling their child in physical or recreational activities in order to enhance participation. 
Challenges of parents have also been presented in studies with other populations. Bedell et al. [72] and Reid et al. [70] presented similar challenges of parents integrating their young adults in appropriate leisure activities, changing the attitudes of others, and dealing with insufficient system support. These findings also relate to theories about social stigma, as described by Goffman [74]. Social stigma is a severe social disapproval of, or personal discontent with, a person on the grounds of his unique characteristics distinguishing him from others in society [74]. Negative attitudes have an undesirable effect on children, leading to negative consequences such as low self-esteem and reduced participation [75].

In paediatric rehabilitation, Family-centered service (FCS) is seen as a best practice [34]. FCS requires active family involvement in all stages of the rehabilitation process. Knowledge about what parents do, experience, and need in enhancing their child's participation is crucial in developing tools and strategies for FCS. The number of studies conducted in this area is still rather low. The 14 included articles indicate that parents do perform many actions and experience many challenges in enhancing participation. Most of these actions and challenges seem to focus on the environment. Altering the environment might be the main determinant of change in enabling childrens' participation. Professionals engaged in FCS could question whether they pay enough attention on supporting the parents in this endeavour.

This review shows that little information is available about parents needs in supporting participation of their child with a physical disability. As FCS is all about the needs of families, more research is necessary to gain further understanding of what parents really need and how they would like to be empowered in enhancing participation of their child. Furthermore, FCS can be improved if more knowledge is available about the relationship between characteristics of contexts, families, parents and children, and the actions, challenges, and needs of parents.

\section{CONCLUSIONS}

This review shows that parents apply a broad range of strategies to support participation of their children. They experience many challenges, especially as a result of constraints in the social and physical environments. However, this review also displays that little is known about needs of parents in facilitating participation. Further investigation into the needs of parents is warranted to understand if and to what extent they wish to be supported in enabling their child's participation in daily life. 


\section{Acknowledgements}

This research project was financially supported by Zuyd University of Applied Sciences.

The authors wish to thank Prof. Dr. H. Polatajko, University of Toronto and Dr. R. Daniëls, Zuyd University of Applied Sciences for their valuable contributions to this study. 


\section{LITERATURE}

1. King GA, Law M, King S, Hurley P, Hanna S, Kertoy M, Rosenbaum P. Measuring children's participation in recreation and leisure activities: Construct validation of the CAPE and PAC. Child Care Health Dev. 2007;33(1):28-39.

2. World Health Organization. International classification of functioning, disability and health. Geneva: World Health Organization; 2001.

3. World Health Organization. International classification of functioning, disability and health. Children and youth version. Geneva: World Health Organization; 2007.

4. Dahan-Oliel N, Gelinas I, Mazer B. Social participation in the elderly: what does the literature tell us? Crit Rev Physic Rehabil Med. 2008;20(2):159-176. doi: 10.1615/CritRevPhysRehabilMed.v20.i2.40.

5. Chiao C, Weng L-J, Botticello AL. Social participation reduces depressive symptoms among older adults: an 18-year longitudinal analysis in Taiwan. BMC Publ Health. 2011;11:292.

6. Eyssen IC, Steultjens MP, Dekker J, Terwee CB. A systematic review of instruments assessing participation: challenges in defining participation. Arch Phys Med Rehabil. 2011;92(6):983-997.

7. McConachie H, Colver AF, Forsyth RJ, Jarvis SN, Parkinson KN. Participation of disabled children: how should it be characterised and measured? Disabil Rehabil. 2006;28(18):1157-1164.

8. Dijkers MPJM, Whiteneck G, El-Jaroudi R. Measures of social outcomes in disability research. Arch Phys Med Rehabil. 2000;81(12, Part B):S63-S80.

9. Barnes C, Mercer G. Exploring disability: a sociological introduction. 2nd. Cambridge: Polity Press; 2010.

10. Lee HY, Jang S-N, Lee S, Cho S-I, Park E-O. The relationship between social participation and self-rated health by sex and age: a cross-sectional survey. Int J Nurs Stud. 2008;45(7):1042-1054.

11. Hjelle KM, Vik K. The ups and downs of social participation: experiences of wheelchair users in Norway. Disabil Rehabil. 2011;33(25/26):2479-2489.

12. Koster M, Pijl SJ, Nakken H, Van Houten E. Social participation of students with special needs in regular primary education in the Netherlands. Int J Disabil Dev Educ. 2010;57(1):59-75.

13. Pellerin C, Rochette A, Racine E. Social participation of relatives post-stroke: the role of rehabilitation and related ethical issues. Disabil Rehabil. 2011;33(13-14):1055-1064.

14. Law M. Participation in the occupations of everyday life. Am J Occup Ther. 2002;56(6):640-649.

15. Bedell GM, Dumas HM. Social participation of children and youth with acquired brain injuries discharged from inpatient rehabilitation: A follow-up study. Brain Inj. 2004;18(1):65-82.

16. United Nations. General comment on implementing rights in early childhood. Geneva: UN; 2006. CotRot, vol. CRC/C/GC/7/Rev 1.

17. Mégret $F$. The disabilities convention: human rights of persons with disabilities or disability rights? Hum Rights Q. 2008;30(2):494-516.

18. Rosenbaum P, King S, Law M, King G, Evans J. Family-centred service. Phys Occup Ther Pediatr. 1998;18(1):1-20.

19. Council of Europe. Revised European social charter: 5th national report on the implementation of the revised European social charter submitted by the government of the Netherlands. Strasbourg: Council of Europe; 2012.

20. Hemmingsson $\mathrm{H}$, Jonsson $\mathrm{H}$. An occupational perspective on the concept of participation in the international classification of functioning, disability and health-some critical remarks. Am J Occup Ther. 2005;59(5):569-576.

21. Wilcock A. Making sense of what people Do: historical perspectives. J Occup Sci. 2003;10(1):4-6.

22. Pereira $E$, nia, la Cour $K$, Jonsson $H$, Hemmingsson $H$. The participation experience of children with disabilities in Portuguese mainstream schools. Br J Occup Ther. 2010;73(12):598-606.

23. Leven NVT, Jonsson $H$. Doing and being in the atmosphere of the doing: environmental influences on occupational performance in a nursing home. Scand J Occup Ther. 2002;9(4):148-155. 
24. Bult MK, Verschuren O, Jongmans MJ, Lindeman E, Ketelaar M. What influences participation in leisure activities of children and youth with physical disabilities? A systematic review. Res Dev Disabil. 2011;32(5):1521-1529.

25. Imms C, Reilly S, Carlin J, Dodd K. Diversity of participation in children with cerebral palsy. Dev Med Child Neurol. 2008;50(5):363-369.

26. Bult MK, Verschuren O, Gorter JW, Jongmans MJ, Piskur B, Ketelaar M. Cross-cultural validation and psychometric evaluation of the Dutch language version of the Children's Assessment of Participation and Enjoyment (CAPE) in children with and without physical disabilities. Clin Rehabil. 2010;24(9):843-853.

27. Frostad P, Pijl SJ. Does being friendly help in making friends? The relation between the social position and social skills of pupils with special needs in mainstream education. Eur J Spec Needs Educ. 2007;22(1):1530.

28. Blum RW, Resnick MD, Nelson R, St Germaine A. Family and peer issues among adolescents with spina bifida and cerebral palsy. Pediatrics. 1991;88(2):280-285.

29. Law M, Dunn W. Perspectives on understanding and changing the environments of children with disabilities. Phys Occup Ther Pediatr. 1993;13(3):1-17.

30. Welsh B, Jarvis S, Hammal D, Colver A. How might districts identify local barriers to participation for children with cerebral palsy? Public Health. 2006;120(2):167-175.

31. Turnbull AP, Pereira L, Blue-Banning MJ. Parents' facilitation of friendships between their children with a disability and friends without a disability. J Assoc Persons Severe Handicaps. 1999;24(2):85-99.

32. Rodger S, Ziviani J. Occupational therapy with children: understanding children's occupations and enabling participation. Malden: Blackwell Publishing; 2006.

33. Bamm EL, Rosenbaum P. Family-centered theory: origins, development, barriers, and supports to implementation in rehabilitation medicine. Arch Phys Med Rehabil. 2008;89(8):1618-1624.

34. King S, Teplicky R, King G, Rosenbaum P. Family-centered service for children with cerebral palsy and their families: a review of the literature. Semin Pediatr Neurol. 2004;11(1):78-86.

35. Law M, Hanna S, King G, Hurley P, King S, Kertoy M, Rosenbaum P. Factors affecting family-centred service delivery for children with disabilities. Child Care Health Dev. 2003;29(5):357-366.

36. Mays N, Roberts E, Popay J. Synthesising research evidence. London: Routledge; 2001. pp. 188-220.

37. Cans C. Surveillance of cerebral palsy in Europe: a collaboration of cerebral palsy surveys and registers. Dev Med Child Neurol. 2000;42(12):816-824.

38. Arksey H, O'Malley L. Scoping studies: towards a methodological framework. Int J Soc Res Methodology: Theory \& Pract. 2005;8(1):19-32.

39. Oliver S, Harden A, Rees R, Shepherd J, Brunton G, Garcia J, Oakley A. An emerging framework for including different types of evidence in systematic reviews for public policy. Eval: Int J Theory, Res Pract. 2005;11(4):428-446.

40. Levac D, Colquhoun H, O'Brien K. Scoping studies: advancing the methodology. Implement Sci. 2010;5(1):1-9.

41. Problem. 2011. http://www.BusinessDictionary.com.

42. Need. 2011. http://www.Dictionary.com.

43. Action. 2011. http://www.Dictionary.cambridge.org.

44. Challenge. 2011. http://www.Merriam-webster.com.

45. Barnett-Page E, Thomas J. Methods for the synthesis of qualitative research: a critical review. BMC Med Res Methodology. 2009;9:59. doi: 10.1186/1471-2288-9-59.

46. Mays N, Pope C, Popay J. Systematically reviewing qualitative and quantitative evidence to inform management and policy-making in the health field. J Health Serv Res Policy. 2005;10:6-20.

47. Thomas J, Harden A. Methods for the thematic synthesis of qualitative research in systematic reviews. BMC Med Res Methodology. 2008;8:45.

48. Boyatzis RE. Transforming qualitative information: Thematic analysis and code development. Thousand Oaks, CA US: Sage; 1998. 
49. Braun V, Clarke V. Using thematic analysis in psychology. Qualitative Res Psychology. 2006;3(2):77-101.

50. Heah T, Case T, McGuire B, Law M. Successful participation: the lived experience among children with disabilities. Canadian J Occup Ther. 2007;74(1):38-47.

51. Antle BJ, Mills W, Steele C, Kalnins I, Rossen B. An exploratory study of parents' approaches to health promotion in families of adolescents with physical disabilities. Child Care Health Dev. 2007;34(2):185193.

52. Missiuna C, Moll S, King S, King G, Law M. A trajectory of troubles: parents' impressions of the impact of developmental coordination disorder. Phys Occup Ther Pediatr. 2007;27(1):81-101.

53. Missiuna C, Moll S, Law M, King S, King G. Mysteries and mazes: Parents' experiences of children with developmental coordination disorder. Canadian J Occup Ther. 2006;73(1):7-17.

54. Bedell GM, Cohn ES, Dumas HM. Exploring parents' use of strategies to promote social participation of school-age children with acquired brain injuries. Am J Occup Ther. 2005;59(3):273-284.

55. Huang Y-P, Kellett U, St John W. Being concerned: caregiving for Taiwanese mothers of a child with cerebral palsy. J Clin Nurs. 2012;21(1/2):189-197.

56. Bennett KS, Hay DA. The role of family in the development of social skills in children with physical disabilities. Int J Disabil Dev Educ. 2007;54(4):381-397.

57. Hewitt-Taylor J. Parents' views of their children who have complex health needs. Paediatr Nurs. 2008;20(8):20-23.

58. Buran CF, Sawin K, Grayson P, Criss S. Family needs assessment in cerebral palsy clinic. J Specialists Pediatr Nurs. 2009;14(2):86-93.

59. Meehan DR. Mothering a 3- to 6-year-old child with hemiparesis. J Neurosci Nurs. 2005;37(5):265-271.

60. Lawlor K, Mihaylov S, Welsh B, Jarvis S, Colver A. A qualitative study of the physical, social and attitudinal environments influencing the participation of children with cerebral palsy in northeast England. Pediatr Rehabil. 2006;9(3):219-228.

61. Vogts N, Mackey AH, Ameratunga S, Stott NS. Parent-perceived barriers to participation in children and adolescents with cerebral palsy. J Paediatr Child Health. 2010;46(11):680-685.

62. Hewitt-Taylor J. Children with complex, continuing health needs and access to facilities. Nurs Stan. 2009;23(31):35-41.

63. Palisano RJ, Almarsi N, Chiarello LA, Orlin MN, Bagley A, Maggs J. Family needs of parents of children and youth with cerebral palsy. Child Care Health Dev. 2009;36(1):85-92.

64. Badley EM. Enhancing the conceptual clarity of the activity and participation components of the international classification of functioning, disability, and health. Soc Sci Med. 2008;66(11):2335-2345.

65. Wade DT, Halligan P. New wine in old bottles: the WHO ICF as an explanatory model of human behaviour. Clin Rehabil. 2003;17(4):349-354.

66. Häggström A, Lund ML. The complexity of participation in daily life: a qualitative study of the experiences of persons with acquired brain injury. J Rehabil Med. 2008;40(2):89-95.

67. Perenboom RJM, Chorus AMJ. Measuring participation according to the International Classification of Functioning, Disability and Health (ICF). Disabil Rehabil. 2003;25(11/12):577-587.

68. Eriksson L, Granlund M. Conceptions of participation in students with disabilities and persons in their close environment. J DevPhysDisabil. 2004;16(3):229-245.

69. Kolehmainen N, Francis JJ, Ramsay CR, Owen C, McKee L, Ketelaar M, Rosenbaum P. Participation in physical play and leisure: developing a theory- and evidence-based intervention for children with motor impairments. BMC Pediatr. 2011;11:100.

70. Reid A, Imrie H, Brouwer E, Clutton S, Evans J, Russell D, Bartlett D. "If I knew then what I know now": parents' reflections on raising a child with cerebral palsy. Phys Occup TherPediatr. 2011;31(2):169-183.

71. Lewis SA, Noyes J, Mackereth S. Knowledge and information needs of young people with epilepsy and their parents: Mixed-method systematic review. BMC Pediatr. 2010;10:103.

72. Bedell GM, Khetani M, Cousins M, Coster WJ, Law MC. Parent perspectives to inform development of measures of children's participation and environment. Arch Phys Med Rehabil. 2011;92(5):765-773. 
73. Segal R, Mandich A, Polatajko H, Valiant Cook J. Stigma and its management: A pilot study of parental perceptions of the experiences of children with developmental coordination disorder. Am J Occup Ther. 2002;56(4):422-428.

74. Goffman E. Stigma: Notes on the management of spoiled identity. New York: Prentice-Hall; 1963.

75. Thornicroft G, Rose D, Kassam A. Discrimination in health care against people with mental illness. Int Rev Psychiatry. 2007;19(2):113-122. 



\section{CHAPTER 3}

\section{Participation and social participation}

Are they distinct concepts?

Published as: Piškur B, Daniëls R, Jongmans MJ, Ketelaar $M$, Smeets RJEM, Norton $M$, Beurskens AJHM: Participation and social participation: are they distinct concepts? Clinical Rehabilitation 2014, 28(3):211-220. 


\section{Abstract}

Introduction: The concept of participation has been extensively used in health and social care literature since the World Health Organization introduced its description in the International Classification of Functioning, Disability and Health (ICF) in 2001. More recently, the concept of social participation is frequently used in research articles and policy reports. However, in the ICF, no specific definition exists for social participation, and an explanation of differences between the concepts is not available.

Aim: The central question in this discussion article is whether participation, as defined by the ICF, and social participation are distinct concepts. This article illustrates the concepts of participation and social participation, presents a critical discussion of their definitions, followed by implications for rehabilitation and possible future directions.

Discussion: A clear definition for participation or social participation does not yet exist. Definitions for social participation differ from each other and are not sufficiently distinct from the ICF definition of participation. Although the ICF is regarded an important conceptual framework, it is criticised for not being comprehensive. The relevance of societal involvement of clients is evident for rehabilitation, but the current ICF definition of participation does not sufficiently capture societal involvement.

Conclusion: Changing the ICF's definition of participation towards social roles would overcome a number of its shortcomings. Societal involvement would then be understood in the light of social roles. Consequently, there would be no need to make a distinction between social participation and participation. 


\section{Background}

The concept of participation has been extensively used in the health and social care literature [1-5]. Participation, believed to contribute to health and well-being $[3,6,7]$, became a central concept of several policy papers [8-11]. In rehabilitation, participation is considered as the most relevant outcome $[3,12,13]$. More recently, the concept of social participation is frequently used in research articles $[14,15]$ and is a core principle in European policy reports [16, 17]. Several authors [18-21] consider social participation as an indicator of health, well-being and positive social behaviours. Social participation is seen as an important condition for children's development, as children gather knowledge and develop social skills while interacting with other people [3, 22]. For the elderly, social participation is regarded as a key determinant of successful and healthy aging [23]. The introduction of the International Classification of Functioning, Disability and Health (ICF) [24] had a major impact on the use and understanding of the concept of participation in health care. However, a specific definition for social participation does not exist within the ICF, nor is there a description of how both concepts differ. The central question in this discussion article is whether participation, as defined by the ICF, and social participation are distinct concepts. To answer this question, this article will illustrate the concepts of participation and social participation, present a critical discussion of their definitions, followed by implications for rehabilitation and possible future directions. Examples from paediatrics will be used to highlight issues.

\section{Concepts of participation and social participation}

The World Health Organisation initially had the concept handicap within its International Classification of Impairment, Disabilities and Handicaps (ICIDH). Handicap was replaced with participation when discussions about participation, originated by the normalisation movement in the 1960s, emerged. These were initiated by Scandinavian countries as a response to human rights infringements that promoted the deinstitutionalisation and implementation of organised services facilitating community reintegration and the performance of activities of people with disabilities [25]. Since the 1990s, the concept of participation has been frequently used in the literature. The need for participation has appeared from an ideological shift in how society looks upon people with disabilities [25], which considers a disability as a socially created problem and not as an attribute of an individual [26].

The concept of participation gained more attention when the World Health Organization [27] introduced its description in the ICF in 2001. The ICF became an important conceptual framework in rehabilitation to describe health-related states [24]; its core 
components body functions and structures, activities and participation, environmental factors and personal factors provided a global and collective language for health and disability [28-30]. Participation became a source for a better understanding of the possible impact of impairments and disabilities on the life of an individual person [31]. The ICF defines participation as 'involvement in a life situation' or as "the lived experience" of people in the actual context in which they live' [24] while the activity is defined as 'the execution of a task or action by an individual'.

The components of activity and participation have some overlap. Both components together are divided in a single list of nine domains; each domain consists of several sub-domains that cover the full range of life areas from basic learning or watching to composite areas, such as interpersonal interactions and relationships or work and employment. In addition to the general ICF classification, a child- and youth-specific classification called the ICF for Children and Youth was developed; core domains were added to cover child- and youth-specific areas of life, like play [32]. In addition to the description of the sub-domains, the ICF uses two qualifiers for activities and participation [24, 28]. A 'capacity' qualifier that specifies what a person can do independently of context, i.e. the best ability to execute a task or an action in a standardised environment. This qualifier aims to indicate the highest probable level of functioning that a person may reach in a given domain at a given moment (with or without assistive devices). The second qualifier 'performance' specifies what a person does do in the current environment, which includes a societal context $[24,28]$. This 'real life'" environment has an impact on performance. For example, a child with cerebral palsy may have sufficient primary school capacities (in a standardised environment), but may not go to a regular school owing to the physical environment, the denial of access to services, discrimination or stigma.

Social participation has been discussed since the 1960s. However, a commonly accepted definition of social participation is still lacking [33]. Authors have frequently been using the concept of social participation interchangeably with participation [34-36]. Further, authors use social participation in relation to concepts of social integration, social inclusion or social activity [15]. While the first authors consider participation and social participation as synonyms, the latter seem to differentiate between the two concepts. We identified three ways that authors may refer to social participation as a separate entity: as consumer participation, social activity and levels of involvement in society.

To begin with, social participation as consumer participation, derives from authors connected to social inclusion and the rights-based movement. The Institute for Social Participation describes social participation as (the right for) 'meaningful involvement in 
decision-making about health, policy and planning, care and treatment, and the wellbeing of self and the community' [37]. According to the Institute for Social Participation, [37] three components are central in their description of social participation that enable people to experience self-determined modes of social engagement: the references to the concepts of social capital and social inclusion, the individual's human right to experience self-determined modes of engagement in all aspects of society and the societal responsibility to provide conditions necessary for the above. The emphasis on active involvement in contributing to society is central to this perspective on social participation. Although the World Health Organization did not mention social participation in the ICF manual, [24] the website of the World Health Organization [38] describes social participation from a similar angle: '... a way to contribute to a broader society by working with, consulting and empowering communities.' This kind of social participation also referred to as consumer participation or community engagement, [39-41] can take place at a micro-level (e.g. partner in the delivery of care), meso-level (e.g. engagement in service and information planning) or macro-level (e.g. part of health system consumer councils) of society.

The use of the concept of social participation as a synonym for social activity is witnessed by authors in several research areas, like Koster et al. [42] and Shattuck et al. [43]. These authors restrict social participation to interactions between people. Koster et al., [42 p.135], conducted a literature review in the area of primary education and described social participation as the presence of positive social contact/interaction between pupils and their classmates, acceptance of pupils by their classmates, social relationships/friendships between pupils and their classmates and the pupils' perception that they are accepted by their classmates.

Other authors operationalised social participation in a similar way, for example, as social activities which take place with friends or groups, [43] as involvement in voluntary activities or events [44,45] or as involvement in activities with a social element $[46,47]$.

Finally, we found levels of involvement in society as a way authors refer to social participation. Levasseur et al. [23] conducted a systematic review in the literature on aging to capture the meaning and definition of social participation. Based on 43 original definitions, they found that, overall, definitions mostly focussed on the person's (who) involvement (how) in activities that provided interactions (what) with others (with whom) in society or the community (where). Levasseur et al. [23] suggested a definition of social participation and a taxonomy of social activities based on the level of involvement. The proposed definition portrays what was found in most of the definitions that were included in the review: 'Social participation can be defined as a person's involve- 
ment in activities that provide interaction with others in society or the community.' Levasseur et al. [23] stress that involvement can be seen on a continuum from relatively passive to very active, and that social participation can be both an objective and a subjective outcome. The proposed taxonomy of social activities has, along a continuum, six proximal to distal levels of involvement of the individual with others in social activities having different goals (Table 1). The levels distinguish the individual proximity of involvement with others (level 1: alone, level 2: in parallel, levels 3 to 6: in interaction), and the goals of the activity (levels 1 and 2: basic needs oriented, level 3: socially oriented, level 4: task oriented, level 5: oriented toward helping others, and level 6: society oriented). The taxonomy is regarded as an operationalisation of the concepts of participation, social participation and social engagement. In the words of Levasseur et al., [23] the concept of participation encompasses all six levels, while social participation concerns levels 3 through 6 and social engagement includes levels 5 and 6 .

Table 1: A taxonomy for social activities based on the levels of involvement adopted from Levasseur et al. [23] with examples

\begin{tabular}{|c|c|c|}
\hline Levels & $\begin{array}{l}\text { Description of the levels of } \\
\text { involvement }\end{array}$ & $\begin{array}{l}\text { Examples using parental roles in relation to involvement } \\
\text { in society }\end{array}$ \\
\hline First level & $\begin{array}{l}\text { Doing an activity in preparation for } \\
\text { connecting with other people }\end{array}$ & $\begin{array}{l}\text { Reading a policy report to prepare for a meeting with a } \\
\text { rehabilitation team and/or child's teacher }\end{array}$ \\
\hline Second level & Being surrounded with others & Sitting in a metro or train to get to a rehabilitation centre \\
\hline Third level & $\begin{array}{l}\text { Interacting with others without } \\
\text { physical contact }\end{array}$ & $\begin{array}{l}\text { Discussing inclusive education with others through } \\
\text { Facebook, Twitter or Linkedln }\end{array}$ \\
\hline Fourth level & Doing an activity with others & Joining a creative workshop for parents and children \\
\hline Fifth level & Helping others & Helping a child with physical education at primary school \\
\hline Sixth level & Contributing to a community & $\begin{array}{l}\text { Being an active member of a parent organisation or a } \\
\text { political party }\end{array}$ \\
\hline
\end{tabular}

\section{Discussion on the concept of the ICF definition of participation}

Despite the extensive use of the ICF in education, research, and rehabilitation, there is a lot of debate about the definition of participation. A crucial aspect of any conceptual framework is its internal coherence and its ability to differentiate among concepts and categories within the framework [48]. The definition of participation in the ICF as involvement in a life situation' or 'the lived experience of people in the actual context' does not succeed in limiting its scope. The question 'what is not being involved in a life situation?' is not easy to answer. Dijkers [49 p. S6] stated: 'being born and dying, and everything we do in between, involve being in a life situation'. Some authors, like Adolfsson et al. [50] who connect participation to role performance, wonder why the defini- 
tion is restricted to 'a life situation', as performance of a role includes many life situations. Also, the qualifiers capacity (can do) and performance (does do) raise questions about the scope of participation. Capacity emphasises the ability to execute a task in a standardised environment. As current environments are not standardised, this qualifier seems to be more appropriate for activity. Both capacity and performance focus strongly on acting. Involvement in a life situation may be broader then acting or doing. One can be involved in a life situation also when one is not actually doing things himself or herself; [51] a child who is physically completely dependent on others but who is still in control of how and when things are done according to his or her wishes, is participating by fulfilling his societal role and personal goals.

The emphasis in the definition of the ICF on acting further evokes questions about whether participation is merely an objective condition rather than a subjective experience. Several authors [12, 31, 52-55] criticised the definition of the ICF for not including the subjective experience or satisfaction $[12,51,56]$. Is it possible to talk about a child's participation at school without including the child's subjective meaning about the 'lived experience'?

Furthermore, the lack of distinction between the definition of participation and the definition of activity is often criticised. In the ICF, the activity and participation components are presented in a single list that covers the full range of life areas. Several authors $[5,57]$ claim that the differentiation is essential if the ICF is to achieve acceptance by individuals, organisations and associations as an international classification of human functioning and disability.

\section{Discussion on the concept of social participation}

Two concepts are distinct when a person is able to clearly and distinctly differentiate one concept from another [58]. How clear are the suggested descriptions of social participation and how do they relate to the concept of participation as described by the ICF?

A clear definition of social participation as consumer participation or community engagement is lacking $[59,60]$. A complication in defining the scope of social (consumer) participation is its reference to different overlapping groups of people: patients and service users, carers, taxpayers and representatives [60]. Further, the challenge is to make a definition so clear that it distinguishes social (consumer) participation from concepts like empowerment, social inclusion and participation [61, 62]. 
Social participation as consumer participation emphasises both engagement of people in society as well as the societal responsibility to provide the conditions necessary for social engagement. Here lies a major difference with the concept of participation as defined by the ICF. According to Fougeyrollas [25], it is this focus on the responsibility of the environment that distinguishes concepts as social integration and inclusion from participation. Environment is a separate component within the ICF. Although the ICF manual does emphasize the interaction between the environment and functioning, quality indicators of environmental factors determining the quality of participation are not included in the ICF manual. Moreover, social participation as consumer participation seems to be goal oriented. The aim is involvement in decision making to increase the well-being of self and the community. Participation, as defined in the ICF, does not specify any specific goal of involvement in a life situation.

Social participation as social activity is also not yet a well-defined concept. The concept of social participation in this perspective is often used without a specific definition [15]. Some authors $[43,45]$ refer to the concept as an objective state; the amount of social contacts or the number of activities one is engaged in. Others, like Boutot and Bryant, [63] include a subjective experience in the concept (e.g. social preference). Likewise for participation in the ICF, it is important to question whether social participation without the subjective experience is of any relevance in relation to health status and well-being. Social participation as a measurable state of social activities seems to be very close to the concept of activity in the ICF. What is the difference between the activity 'playing' described by Koster et al. [42] and the same activity in the ICF for Children and Youth? For the acknowledgement of social participation as a single concept, it is important to question whether it makes sense to distinguish between social activities and non-social activities.

Social participation is described as levels of involvement in society by Levasseur et al., [23] who do not claim their definition of social participation to be distinct from the ICF definition of participation. Moreover, in their taxonomy they show that both social participation and social engagement fall under the umbrella of participation. Levasseur et al. [23] stated their definition and taxonomy to be a starting point for further discussions on the conceptualisation of social participation. By saying that: 'social engagement necessarily involves a desire for social change or to be heard to affect community choices (...) to contribute to making the community a better place to live', their description of the concept of social engagement is close to the concept of consumer participation. At the same time, it differs from the way the ICF portrays their sub-domains (e.g. community, social and civic life) as possible actions and tasks (e.g. recreation and leisure, religion and spirituality, political life and citizenship) that are required for people to engage 
in organised social life. Furthermore, the ICF sub-domains are presented as single bodies without explanation as to how they link to each other and contribute to engagement in a social life. In contrast, representation of concepts by Levasseur's et al. [23] in their taxonomy has the advantage of highlighting links between the concepts and suggests how they relate to each other.

\section{Implications for rehabilitation}

Previously we showed that a clear definition of social participation is still lacking and proposed definitions have an overlap with participation and activity as defined by the ICF (see Figure 1). Concepts, theories and models guide research and practice. In daily rehabilitation practice, core concepts, like participation, serve as a basis for a deeper understanding of aspects of clients' lives, support analyses and assist in problem solving. These concepts form the base of measurement instruments. Nevertheless, defining concepts is never an easy process. Although quality of life has been an important key concept in research and clinical services, there is still no agreement on what quality of life is and how it should be measured. [64-66] Discussion in the literature about (social) participation might mirror the whole conceptual development of the perceived quality of life concept.

The ongoing critique of participation as defined by the ICF justifies a further debate in rehabilitation on the concept especially concerning issues as the meaning of involvement, the subjective experience of participation and measurement of participation. Recent literature reviews $[67,68]$ into measurement instruments for participation found that most instruments measure capacity related to activity, primarily built on normative standards (frequency and/or duration) and are based on the assumption that 'more is better'. However, a domain for satisfaction or engagement is not included in most of these instruments.

The number of studies and reports using the concept of social participation does urge further debate. Participation as defined by the ICF might inadequately capture the relevance of social activities or societal involvement. The ICF activity and participation domain and its sub-domains currently illustrate types of actions or tasks required for people to engage in organised social life. For example, for paediatric rehabilitation purposes, this might be too broad and too narrow to capture parents' and children's objective state and subjective experience of their involvement with others in society.

Recent developments put even more emphasis on the relevance of societal involvement. Health literacy and self-management, Web 2.0 social media, empowering com- 
munities and 'Nothing About Us Without Us' [69] are developments that will (continue to) have a major impact on health care [33]. Increasingly, people themselves will be held responsible for their health and social participation in society. These developments will change how individuals with chronic diseases and disabilities relate to and engage with society. As a consequence, rehabilitation practitioners should be able to support clients' involvement on all levels of society. For example, in paediatric rehabilitation, family-centred service will be challenged to create opportunities for parents/children to interact, to provide parents/children with tools for self-management, to enable parents/children to help each other and to contribute to society.

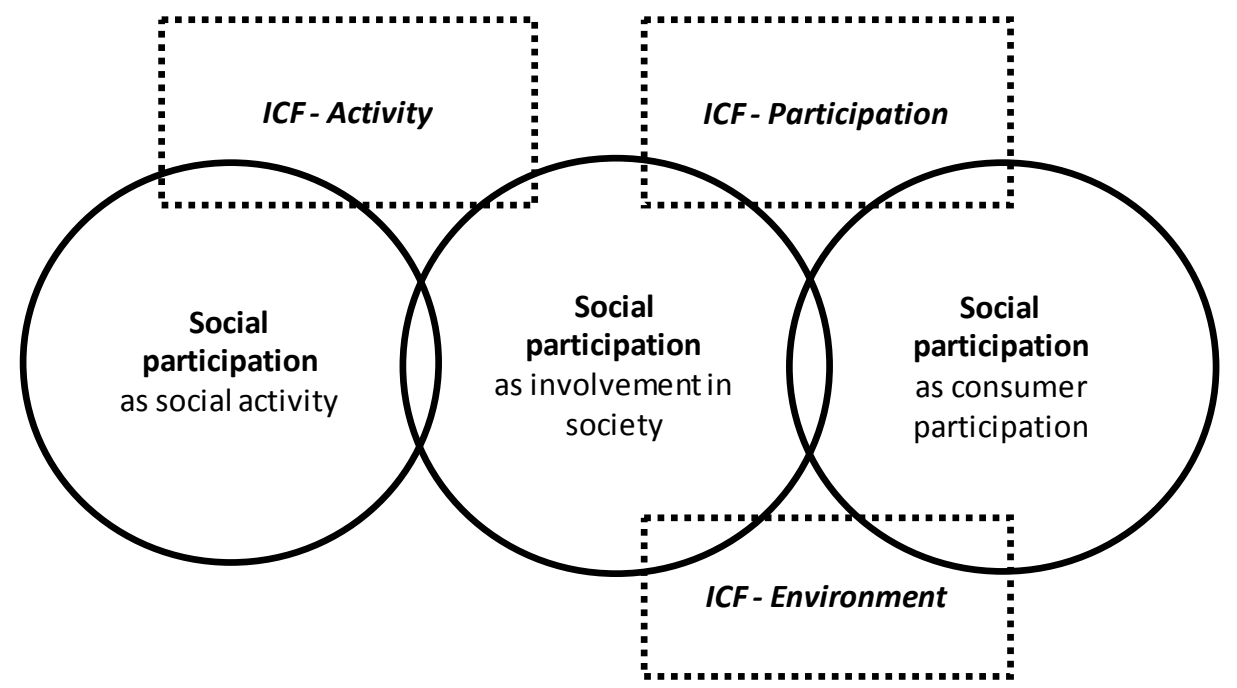

Figure 1: Presentation of the overlap between concepts related to Social participation (social activity, consumer participation, levels of involvement in society) and Participation, activity, environment as defined by the ICF. ICF, International Classification of Functioning, Disability and Health

\section{Possible future directions}

Are participation and social participation distinct concepts? This article shows that, besides a warrant for further deliberation on defining social participation, there is a need for further debate on the definition of participation. In our opinion, the distinction between the two concepts depends on the direction that further discussion on participation, as defined by the ICF, will take. We agree with several authors that a more clear distinction between activity and participation, and an emphasis on subjective experience of participation, can be achieved by putting participation in the perspective of societal involvement defined by an engagement in social roles. Earlier work on disability models showed the importance of social role performance. For Nagi, [70] role perfor- 
mance was the defining concept at the societal level to understand disability. Whiteneck [13] suggests that Nagi's conceptual focus on roles may offer an effective way to differentiate activities and participation in ICF-2. In addition, Badley [71] recommends an emphasis on engagement in roles as one possible alteration of the ICF definition of participation. Participation then does not refer to performing single activities, but to performance of a socially and culturally defined role. Social roles for children are for example daughter, pupil, friend, or teammate. The wider environmental, social and cultural contexts are crucial for setting the scene for societal involvement, as are the personal characteristics of the individual [71]. As these set the opportunities and the nature of role performance, its assessment is largely subjective. Whether or how a social role is carried out depends on personal preferences and on the demands of the role and external factors [71].

Engagement in social roles frequently includes social interaction with others [13]. According to Badley, [71] interaction with other people is usually integral to societal involvement. Consequently, one could argue that social interaction with others would have to be understood in the light of social roles. Being a teacher in a primary school involves a high frequency and variation in social interaction with pupils, co-workers and parents. Barriers in social interaction in this role differ from barriers in social interaction in the role of a fisherman (used to fish alone). The taxonomy of Levasseur et al. [23] can be used to specify the type of social interaction or involvement taking place in a specific social role as highlighted in Table 1.

There would be no ground to separate social participation from participation, once participation is defined as engagement in social roles.

\section{Conclusions}

This article critically discusses the concepts of participation and social participation as described in the literature. To summarise, a clear definition for participation or social participation does not yet exist. Definitions for social participation differ from each other and are not sufficiently distinct from the ICF definition of participation. The ICF definition of participation itself does not adequately capture the objective state and subjective experience of involvement with others in society. Therefore, a redesign of the ICF's definition of participation toward social roles is warranted.

Changing the ICF's definition of participation towards social roles would overcome a number of its shortcomings. Societal involvement would then be understood in the light 
of social roles. Consequently, there would be no need to make a distinction between social participation and participation.

\section{Clinical message}

- Participation and social participation are not sufficiently defined as distinct concepts.

- Every person's societal involvement is an important outcome for rehabilitation.

- Rehabilitation professionals should note that the definition of participation, and measurement instruments based on this definition, do not capture the subjective meaning and societal involvement.

- Societal involvement can be well understood in the light of social roles.

\section{Acknowledgements}

The authors wish to thank Professor Dr DT Wade, Professor of Neurological Rehabilitation, Oxford Centre for Enablement, UK for his valuable contributions to this article.

\section{Funding}

Zuyd University of Applied Sciences financially supported this research project. 


\section{LITERATURE}

1. Segal R, Mandich A, Polatajko H, Valiant Cook J: Stigma and its management: A pilot study of parental perceptions of the experiences of children with developmental coordination disorder. American Journal of Occupational Therapy 2002, 56(4):422-428.

2. McConachie H, Colver AF, Forsyth RJ, Jarvis SN, Parkinson KN: Participation of disabled children: How should it be characterised and measured? Disability and Rehabilitation 2006, 28(18):1157-1164.

3. Law M: Participation in the occupations of everyday life. American Journal of Occupational Therapy 2002, 56(6):640-649.

4. Eriksson L, Granlund M: Conceptions of Participation in Students with Disabilities and Persons in Their Close Environment. Journal of Developmental and Physical Disabilities 2004, 16(3):229-245.

5. Jette AM, Haley SM, Kooyoomjian JT: Are the ICF Activity and Participation dimensions distinct? Journal Of Rehabilitation Medicine: Official Journal Of The UEMS European Board Of Physical And Rehabilitation Medicine 2003, 35(3):145-149.

6. de Róiste A, Kelly C, Molcho M, Gavin A, Gabhainn SN: Is school participation good for children? Associations with health and wellbeing. Health Education 2012, 112(2):88-104.

7. Fredricks JA, Eccles JS: Is Extracurricular Participation Associated with Beneficial Outcomes? Concurrent and Longitudinal Relations. Developmental Psychology 2006, 42(4):698-713.

8. [http://www.un.org/]

9. [http://www.unicef.org/]

10. [www.unesco.org]

11. [http://www.who.int/]

12. Hemmingsson $\mathrm{H}$, Jonsson $\mathrm{H}$ : An occupational perspective on the concept of participation in the International Classification of Functioning, Disability and Health--some critical remarks. American Journal of Occupational Therapy 2005, 59(5):569-576.

13. Whiteneck G: Conceptual models of diabilty: past, present, and future. . In: Workshop on Disability in America, a New Look: Summary and Background Papers. edn. Edited by Marilyn Jane Field AMJ, Linda G. Martin. Washington, DC: National Academies Press; 2006: 50-66.

14. Dalemans RJP, De Witte LP, Wade DT, Van den Heuvel WJA: A description of social participation in working-age persons with aphasia: A review of the literature. Aphasiology 2008, 22(10):1071-1091.

15. Koster M, Nakken H, Pijl SJ, van Houten EJ, Lutje Spelberg HC: Assessing Social Participation of Pupils with Special Needs in Inclusive Education: The Construction of a Teacher Questionnaire. Educational Research and Evaluation 2008, 14(5):395-409.

16. Council of Europe: Council of Europe Action Plan to promote the rights and full participation of people with disabilities in society: Improving the quality of life of people with disabilities in Europe 2006-2015. In.: Council of Europe; 2006.

17. European Commission: Europe 2020: A strategy for smart, sustainable and inclusive growth. In.: European Commission; 2010.

18. Sørensen LV, Waldorff FB, Waldemar G: Social participation in home-living patients with mild Alzheimer's disease. Archives of Gerontology and Geriatrics 2008, 47(3):291-301.

19. Oliver KG, Collin P, Burns J, Nicholas J: Building resilience in young people through meaningful participation. AeJAMH (Australian e-Journal for the Advancement of Mental Health) 2006, 5(1).

20. Hyyppä MT, Mäki J: Social participation and health in a community rich in stock of social capital. Health Education Research 2003, 18(6):770-779.

21. Cattell V: Poor people, poor places, and poor health: the mediating role of social networks and social capital. Social Science \& Medicine (1982) 2001, 52(10):1501-1516. 
22. Bedell GM, Dumas HM: Social participation of children and youth with acquired brain injuries discharged from inpatient rehabilitation: A follow-up study. Brain Injury 2004, 18(1):65-82.

23. Levasseur M, Richard L, Gauvin L, Raymond E: Inventory and analysis of definitions of social participation found in the aging literature: proposed taxonomy of social activities. Social Science and Medicine 2010, 71(12):2141-2149.

24. World Health Organization: International Classification of Functioning, Disability and Health. In. Geneva: World Health Organization; 2001.

25. Fougeyrollas P: Social Participation: Setting the context - From institutional exclusion to social participation. In: International Encyclopedia of Rehabilitation. Buffalo, NY: Center for International Rehabilitation Research Information and Exchange (CIRRIE); 2010.

26. Oliver M: The politics of disablement: Critical texts in social work and the welfare state. London: Macmillan; 1990.

27. Cerniauskaite M, Quintas R, Boldt C, Raggi A, Cieza A, Bickenbach JE, Leonardi M: Systematic literature review on ICF from 2001 to 2009: its use, implementation and operationalisation. Disability and Rehabilitation 2011, 33(4):281-309.

28. World Health Organization: Towards a common language for functioning, disability and health. In. Geneva: World Health Organization; 2002.

29. Rosenbaum P, Stewart D: The World Health Organization International Classification of Functioning, Disability, and Health: a model to guide clinical thinking, practice and research in the field of cerebral palsy. Seminars in Pediatric Neurology 2004, 11(1):5-10.

30. Jette AM: Toward a common language for function, disability, and health. Physical Therapy 2006, 86(5):726-734.

31. Van de Velde D, Bracke P, Van Hove G, Josephsson S, Vanderstraeten G: Perceived participation, experiences from persons with spinal cord injury in their transition period from hospital to home. International Journal of Rehabilitation Research 2010, 33(4):346-355.

32. World Health Organization: International classification of functioning, disability and health. Children and youth version. In. Geneva: World Health Organization; 2007.

33. Piškur B: Social participation: Redesign of education, research, and practice in occupational therapy*. Scandinavian Journal of Occupational Therapy 2013, 20(1):2-8.

34. Cicerone KD, Azulay J: Perceived self-efficacy and life satisfaction after traumatic brain injury. Journal of Head Trauma Rehabilitation 2007, 22(5):257-266.

35. Winkle M, Crowe TK, Hendrix I: Service dogs and people with physical disabilities partnerships: A systematic review. Occupational therapy international 2012, 19(1):54-66.

36. Bowes A, McColgan G: Telecare for older people: Promoting independence, participation and identity. Research on Aging 2013, 35(1):32-49.

37. Bathgate $\mathrm{T}$, Romios $\mathrm{P}$ : Consumer participation in health: Understanding consumers as social participants. In: ISP Seminar Series. La Trobe University: Institute for Social Participation and Health Issues Centre 2011.

38. Social determinates of health: Social participaiton [http://www.who.int/social_determinants/thecommission/countrywork/within/socialparticipation/en/index.html]

39. Wright-Berryman JL, McGuire AB, Salyers MP: A Review of Consumer-Provided Services on Assertive Community Treatment and Intensive Case Management Teams: Implications for Future Research and Practice. Journal of the American Psychiatric Nurses Association 2011, 17(1):37-44.

40. Crawford MJ, Rutter D: Are the views of members of mental health user groups representative of those of 'ordinary' patients? A cross-sectional survey of service users and providers. Journal of Mental Health 2004, 13(6):561-568.

41. Boote J, Baird W, Beecroft C: Public involvement at the design stage of primary health research: a narrative review of case examples. Health Policy 2010, 95(1):10-23. 
42. Koster M, Nakken H, Pijl SJ, van Houten E: Being Part of the Peer Group: A Literature Study Focusing on the Social Dimension of Inclusion in Education. International Journal of Inclusive Education 2009, 13(2):117-140.

43. Shattuck PT, Orsmond GI, Wagner M, Cooper BP: Participation in social activities among adolescents with an autism spectrum disorder. PLoS One 2011, 6(11).

44. Konlaan BB, Bygren LO, Johansson S: Visiting the cinema, concerts, museums or art exhibitions as determinant of survival: a Swedish fourteen-year cohort follow-up. Scandinavian Journal of Public Health 2000, 28(3):174-178.

45. European Commission: Social participation and social isolation. In. Luxembourg: Publications Office of the European Union; 2010.

46. Bygren LO, Konlaan BB, Johansson SE: Attendance at cultural events, reading books or periodicals, and making music or singing in a choir as determinants for survival: Swedish interview survey of living conditions. BMJ (Clinical Research Ed) 1996, 313(7072):1577-1580.

47. Glass TA, Mendes de Leon C, Marottoli RA, Berkman LF: Population based study of social and productive activities as predictors of survival among elderly Americans. BMJ 1999, 319(7208):478-483.

48. Kaplan A: The Conduct of Inquiry: Methodology for Behavioral Science: Transaction Pub; 1964.

49. Dijkers MPJ: Issues in the Conceptualization and Measurement of Participation: An Overview. Archives of Physical Medicine and Rehabilitation 2010, 91(9, Supplement):S5-S16.

50. Adolfsson M, Malmqvist J, Pless M, Granuld M: Identifying child functioning from an ICF-CY perspective: everyday life situations explored in measures of participation. Disability and Rehabilitation 2011, 33(1314):1230-1244.

51. Perenboom RJM, Chorus AMJ: Measuring participation according to the International Classification of Functioning, Disability and Health (ICF). Disability and Rehabilitation 2003, 25(11/12):577-587.

52. Häggström A, Lund ML: The complexity of participation in daily life: A qualitative study of the experiences of persons with acquired brain injury. Journal of Rehabilitation Medicine 2008, 40(2):89-95.

53. Wade DT, Halligan P: New wine in old bottles: the WHO ICF as an explanatory model of human behaviour. Clinical Rehabilitation 2003, 17(4):349-354.

54. Ueda S, Okawa Y: The subjective dimension of functioning and disability: What is it and what is it for? Disability and Rehabilitation: An International, Multidisciplinary Journal 2003, 25(11-12):596-601.

55. Granlund M, Arvidsson P, Niia A, Björck-Åkesson E, Simeonsson R, Maxwell G, Adolfsson M, ErikssonAugustine L, Pless M: Differentiating activity and participation of children and youth with disability in Sweden: a third qualifier in the International Classification of Functioning, Disability, and Health for Children and Youth? American Journal Of Physical Medicine \& Rehabilitation / Association Of Academic Physiatrists 2012, 91(13 Suppl 1):S84-S96.

56. Molin M: Delaktighet inom handikappområdet - en begreppsanalys [Participation within the Disability field - a conceptual analysis]. In: Delaktighetens språk. edn. Edited by Gustavsson A. Lund: Studentlitteratur; 2004.

57. Coster W, Khetani MA: Measuring participation of children with disabilities: Issues and challenges. Disability and Rehabilitation 2008, 30(8):639-648.

58. Rodríguez Pereyra G: Descartes's Substance Dualism and His Independence Conception of Substance. Journal of the History of Philosophy 2008 46(1):69-89.

59. Preston R, Waugh H, Larkins S, Taylor J: Community participation in rural primary health care: intervention or approach? Australian Journal of Primary Health 2010, 16(1):4-16.

60. Menon D, Stafinski T: Role of patient and public participation in health technology assessment and coverage decisions. Expert Review Of Pharmacoeconomics \& Outcomes Research 2011, 11(1):75-89.

61. Evans D, Pilkington P, McEachran M: Rhetoric or reality? A systematic review of the impact of participatory approaches by UK public health units on health and social outcomes. Journal Of Public Health (Oxford, England) 2010, 32(3):418-426. 
62. Goss C, Mosconi P, Renzi C, Deledda G: Participation of patients and citizens in healthcare decisions in Italy. Z Evid Fortbild Qual Gesundhwes 2011, 105(4):277-282.

63. Boutot EA, Bryant DP: Social Integration of Students with Autism in Inclusive Settings. Education and Training in Developmental Disabilities 2005, 40(1):14-23.

64. Dijkers MPJ: Quality of life of individuals with spinal cord injury: a review of conceptualization, measurement, and research findings... 3rd International Congress on the restoration of (wheeled) mobility in $\mathrm{SCl}$ rehabilitation: state of the art III, Amsterdam, April 2004. Journal of Rehabilitation Research and Development 2005, 42(3):87-110.

65. White CL, Lauzon S, Yaffe MJ, Wood-Dauphinee S: Toward a model of quality of life for family caregivers of stroke survivors. Quality Of Life Research: An International Journal Of Quality Of Life Aspects Of Treatment, Care And Rehabilitation 2004, 13(3):625-638.

66. Levasseur M, Desrosiers J, Noreau L: Is social participation associated with quality of life of older adults with physical disabilities? Disability and Rehabilitation: An International, Multidisciplinary Journal 2004, 26(20):1206-1213.

67. Eyssen IC, Steultjens MP, Dekker J, Terwee CB: A systematic review of instruments assessing participation: Challenges in defining participation. Archives of Physical Medicine and Rehabilitation 2011, 92(6):983997.

68. Van de Velde D, Bracke P, Van Hove G, Josephsson S, Vanderstraeten G: Participatie, hoe wordt het gemeten? . Wetenschappelijk Tijdschrift voor Ergotherapie 2012 5(4):5-16.

69. Charlton JI: Nothing about us without us: Disability oppression and empowerment: University of California Press; 1998.

70. Nagi SZ: An epidemiology of disability among adults in the United States. The Milbank Memorial Fund Quarterly 1976, 54:439-467.

71. Badley EM: Enhancing the conceptual clarity of the activity and participation components of the International Classification of Functioning, Disability, and Health. Social Science and Medicine 2008, 66(11):23352345 . 
PART II MIXED METHODS INQUIRY 



\section{CHAPTER 4}

\section{What do parents need to enhance participation of their school-aged child with a physical disability?}

A cross-sectional study in the Netherlands

Published as: Piškur B, Beurskens AJHM, Jongmans MJ, Ketelaar M, Smeets RJEM: What do parents need to enhance participation of their school-aged child with a physical disability? A cross-sectional study in the Netherlands. Child: Care, Health and Development 2015, 41(1):84-92. 


\section{Abstract}

Background The aim was to provide an overview of the number, domains and priority of needs as expressed by parents in supporting participation of their school-aged child with a physical disability. Additionally, this study investigated whether the number of needs within each domain is related to the child's gross motor function level, parent's perceived own general health, family socio-economic status and family type.

Method A cross-sectional study with a total of 146 participants (84.9\% mothers) who completed a survey including the Family Needs Inventory - Paediatric Rehabilitation, the Gross Motor Function Classification System Family Report Questionnaire, the General Health Questionnaire and a demographic questionnaire. A need has been operationalized as 'a family's, parent's or other family member's expressed desire for information, services and supports related to their family'. Descriptive statistics and correlation analysis were applied.

Results Parents ( $n=146$; response rate $27 \%$ ) varied in the number of expressed needs (range 0-124; mean = 35.9; median = 30; SD = 25.6). Highest mean percentage scores were found for the domains 'Laws, regulations and fees' (36\%), 'Leisure time' (35.6\%), and 'Aids, adaptations, facilities and resources' (33.8\%). Seven single needs were expressed by $50 \%$ or more of the parents. All domains of needs showed a positive correlation with perceived parental general health. The domains 'Laws, regulations and fees', 'Day care \& school', 'Emotional and mental support' and 'Raising my child' correlated negatively with family socio-economic status; and child's gross motor function level correlated positively with the domains 'Aids, adaptations, facilities and resources', 'Practical support at home' and 'Leisure time'.

Conclusions As parents have a major influence on participation of children with a physical disability, meeting their individual needs should become an objective for service providers and policy makers. Family-centred service might be more effective by putting a greater emphasis on changing the environment. 


\section{INTRODUCTION}

It is estimated that, worldwide, $5.1 \%$ of children under 14 has some form of disability [1]. Children with a physical disability represent a large category. For example, in the Netherlands it is estimated that $5 \%$ of children between the age of four and 15 have a severe form of physical disability [2]. In western countries, many children with a physical disability and their parents are offered services in different settings, such as paediatric rehabilitation centres. The major goal of paediatric rehabilitation is to promote children's participation in daily life [3]; to enable the fulfilment of children's social roles. Family-centred service (FCS) is such an approach recognizing that each family is unique and a constant in a child's life [4]. The strengths and needs of all family members are considered as crucial in the implementation of FCS [4, 5]. In order to improve FCS in paediatric rehabilitation, an overview and more knowledge about families' needs is warranted [6].

Children's participation in daily life is vital for healthy development, social and physical competencies, social-emotional well-being, sense of meaning, and purpose in life $[7,8]$. Nevertheless, evidence suggesting that children with a physical disability are at risk for lower participation in everyday activities has accumulated [9]. Children with a physical disability participate less frequently in almost all activities compared with children without a physical disability $[10,11]$; they have diminished opportunities for building relationships and often feel socially isolated [12-14].

There is some evidence that factors influence a child's participation, such as lower socio-economic status are related to lower participation diversity [7], and severe gross motor problems were associated with greater participation restrictions [15-17].

It is assumed that the environment has impacts on the participation of a child with a physical disability in diverse activities $[18,19]$. Accessible, socially supportive and nondiscriminatory environmental facilities enable participation of children with a physical disability in daily activities $[17,19,20]$. Parents, in particular, can influence participation at school, at home and in the community [21]. A scoping review [22] revealed that parents of children with a physical disability take several actions, develop a number of strategies and come across numerous challenges when facilitating a child's participation in daily life. The review further revealed that only a limited number of studies have been conducted addressing parents' needs; e.g. needs regarding enabling environments, such as social and system support, and needs for information about meaningful activities, such as leisure for their child [22]. Previous work [23-25] mostly looked at the impact of having a child with a disability on parents' or family life (e.g. family development, parental general health or parent personal stress). Despite the recent increase in interest $[26,27]$, very little is known about what parents' needs are when supporting their 
child's participation in daily life and whether child and family factors associated with participation also have a relation with family needs.

The aim of this study was to give a wide-ranging portrayal of the number, domains and priority of needs of parents to enhance participation of their school-aged child with a physical disability. Additionally, this study investigated whether the number of needs within each domain is related to the child's gross motor function level, parent's perceived own general health (GHQ), family socio-economic status (SES), and family type.

\section{METHODS}

\section{Design}

A cross-sectional, descriptive study was conducted between May 2012 and October 2012.

\section{Study population}

A targeted sample of families of children with a physical disability was selected from the electronic database of the Dutch association of people with a physical disability (i.e., the BOSK). Inclusion criteria were that 1 ) each family had a child with a physical disability that is neurological and non-progressive in nature (e.g. cerebral palsy, spina bifida), 2) the child is living at home, 3) the child is aged between 4 and 12 years, and 4) the child is participating in regular or special education. In total 559 families (17.2\% of all members) were invited to participate in the study.

\section{Recruitment procedure and data gathering}

In May 2012, the targeted members of the BOSK received an information letter inviting them to participate in the study. A stamped return-envelope, an informed consent form and a questionnaire, were included. It should be noted that this study was conducted jointly with a qualitative diary study over a 7-day period. Parents (or primary caregivers) had the choice to refuse cooperation, to complete the diary or the questionnaire, or both. A pilot study including fifteen parents (February 2012) revealed that the questionnaire was feasible and took about 30 minutes to complete.

Parents (or primary caregivers) who did not respond to the first invitation received a reminder from the BOSK after three weeks. Additional promotion for the study was done at the BOSK jubilee congress and on the BOSK website. In August 2012, nonresponders ( $n=499,89.3 \%$ ) again received the information letter, informed consent form and the questionnaire. Participating parents (or primary caregivers) returned the completed questionnaire, as well as the informed consent form in the return envelope 
directly to MEMIC (Centre for Data and Information Management) in Maastricht. The local medical ethics committee (Atrium Medical Centre, Orbis Medical and Healthcare Centre and Zuyd University of Applied Sciences) approved the study protocol (12-N-37).

\section{Measures}

The questionnaire included questions about participants' demographic, child and family characteristics, the Family Needs Inventory - Pediatric Rehabilitation (FNI-PR), the Gross Motor Function Classification System Family Report Questionnaire and the General Health Questionnaire (GHQ).

\section{Family Needs Inventory - Pediatric Rehabilitation (FNI-PR)}

The FNI-PR [6] is a parent self-report inventory that was developed to assess family needs. It consists of 189 items grouped in 13 domains, ranging from 9 to 22 items per domain. Each item starts with a statement: "At the moment I'd like to have help with or information about...", which gives the respondent the option to choose the needs of their family according to their own specific situation. The response options are 'yes' and ' $n o^{\prime}$. The FNI-PR Inventory was developed based on an extensive literature study and discussions with parents and experts $[6,26]$. In the current study, three domains (Diagnosis, development and expectations; Medical treatment; Paramedical treatment) were not included since we regarded these as less relevant for our research question, leaving a total 10 domains (148 items) to be considered by the respondents. Participants were also asked to write down their top-5 priority needs; they could choose item needs from the FNI-PR or name new item needs.

\section{Gross Motor Function Classification System Family Report Questionnaire}

The Gross Motor Function Classification System (GMFCS) $[28,29]$ is a five-level classification system designed for health professionals to classify gross motor function of children and adolescents with cerebral palsy. The newly-developed GMFCS Family and Self Report Questionnaire (a parent self-reported questionnaire) is available for four age groups of children and youth [30-32]. For the purpose of the current study, in a preliminary step, the English versions of the Gross Motor Function Classification System Family Report Questionnaire 4 to 6 years [33] and 6-12 years [34] were translated into Dutch. Translation, back-translation and comparison of the source version with the final version were carried out in agreement with the guidelines for translation proposed by Guillemin et al. [35]. 


\section{General Health Questionnaire (GHQ)}

The General Health Questionnaire (GHQ) [36, 37] is available in four versions. The GHQ12 is the shortest version and commonly used in various cultures as a screening tool to determine whether an individual is at risk of developing a health issue. For the purpose of the current study, the Dutch translation of the GHQ-12 [38] was used and the GHQ Likert scale of 0-1-2-3 applied [37].

\section{Analysis}

Statistical analysis was performed using SPSS for Windows, version 19.0. Descriptive statistics (means, standard deviation, medians and frequency distributions) were generated to describe participants' demographic, child and family characteristics, number of needs in each domain, number of needs per item, range of needs, needs expressed $>50 \%$, overall top 20 needs, five most often expressed needs in each domain and top-5 priority needs. The number of needs in each domain was based on the mean percentage of reported needs, as per domain the number of items in the FNI-PR varies.

Pearson correlation coefficients were calculated to determine the association between the number of needs within each domain on the one hand, and child's gross motor function level, parent perceived own general health, family socio-economic status, and family type on the other hand. All missing data were treated as required by the measures.

\section{RESULTS}

Of the 559 families invited, 154 questionnaires were returned (response rate; 27.6\%). However, two questionnaires were largely uncompleted and six respondents did not fulfil the inclusion criteria (the child was younger than four or older than 12 years) and were excluded leaving a total of 146 participants. In the total questionnaire, there was less than $1 \%$ missing data; with one exception (child education) where $10.3 \%$ of the data were missing.

\section{Demographic characteristics of the sample}

All participants were parents except for one who were grandparents. The majority of the participants in this study were mothers $(84.9 \%, n=124)$. Participants represented all geographical regions in the Netherlands. The mean age of the children was 8.24 years $(S D=2.5)$ and $61 \%(n=89)$ were male. The majority of children had cerebral palsy (65.8\%), followed by spina bifida (22.9\%) and complex disability (e.g. CP and mild mental retardation or CP and epilepsy) (11.3\%). All GMFCS levels (I-V) were represented in 
the sample. Participants' characteristics are shown in Table 1. Participants in this study were highly comparable to those registered in the electronic database of the BOSK considering characteristics such as a child age, child disability and the home location. For example, the mean age of the total group of children by BOSK is 8.5 years ( $S D=2.5)$.

Table 1: Child and family characteristics

\begin{tabular}{|c|c|c|c|}
\hline \multicolumn{2}{|l|}{ Family characteristics } & \multicolumn{2}{|l|}{ Child characteristics } \\
\hline \multirow[t]{2}{*}{ Age participant $(n=146)$ : } & Mean (SD) & Age child $(n=146)$ : & Mean (SD) \\
\hline & $42.4(5.25)$ & & $8.24(2.51)$ \\
\hline Relationship with the child & Number (\%) & Child nationality & Number (\%) \\
\hline Mother & $124(84.9)$ & Dutch & $143(97.9)$ \\
\hline Father & $21(14.4)$ & Other & $3(2.1)$ \\
\hline Other & $1(0.7)$ & Child gender & \\
\hline Nationality of the respondent & & Female & $57(39.0)$ \\
\hline Dutch & $145(99.3)$ & Male & $89(61.0)$ \\
\hline Other & $1(0.7)$ & Child education & \\
\hline Highest level of education participant & & Regular & $63(43.2)$ \\
\hline Less than high school & $15(10.3)$ & Special & $56(38.4)$ \\
\hline High school & $44(30.2)$ & Other & $12(8.2)$ \\
\hline More than high school & $87(59.5)$ & Unknown & $15(10.3)$ \\
\hline Family Type - child lives: & Number (\%) & $\begin{array}{l}\text { GMFCS } 4-6 \text { years }(n=27) \text { and } 6- \\
12 \text { years }(n=119)\end{array}$ & \\
\hline with 2 biol. parents & $132(90.3)$ & I & $18(18.0)$ \\
\hline with 1 biol. parent & $9(6.2)$ & ॥ & $49(75.5)$ \\
\hline with 2 caregivers & $1(0.7)$ & III & $20(28.3)$ \\
\hline Other & $3(2.1)$ & IV & $30(36.7)$ \\
\hline Unknown & $1(0.7)$ & V & $26(41.5)$ \\
\hline \multicolumn{4}{|l|}{ Income per month } \\
\hline Less than $€ 2000$ & $14(9.6)$ & & \\
\hline$€ 2000-€ 4000$ & $92(63.0)$ & & \\
\hline Above $€ 4000$ & $39(26.7)$ & & \\
\hline \multirow[t]{2}{*}{ Unknown } & $1(0.7)$ & & \\
\hline & Mean (SD) & & \\
\hline $\mathrm{GHQ}$ & $12.5(5.1)$ & & \\
\hline Family size & $4.27(0.9)$ & & \\
\hline Number of children & $2.34(0.9)$ & & \\
\hline
\end{tabular}

GMFCS-Gross Motor Function Classification System Family Report Questionnaire GHQ - General Health Questionnaire 


\section{Number of needs}

Participants expressed needs in each of the 10 domains; mean percentage scores are presented in Figure 1. The domain 'Laws, regulations and fees' (36\%) had the highest mean percentage of needs reported, followed by needs in the domains 'Leisure time' (35.6\%) and 'Aids, adaptations, facilities and resources (33.8\%), whereas the domain 'Transportation' was reported least by parents (10.2\%).

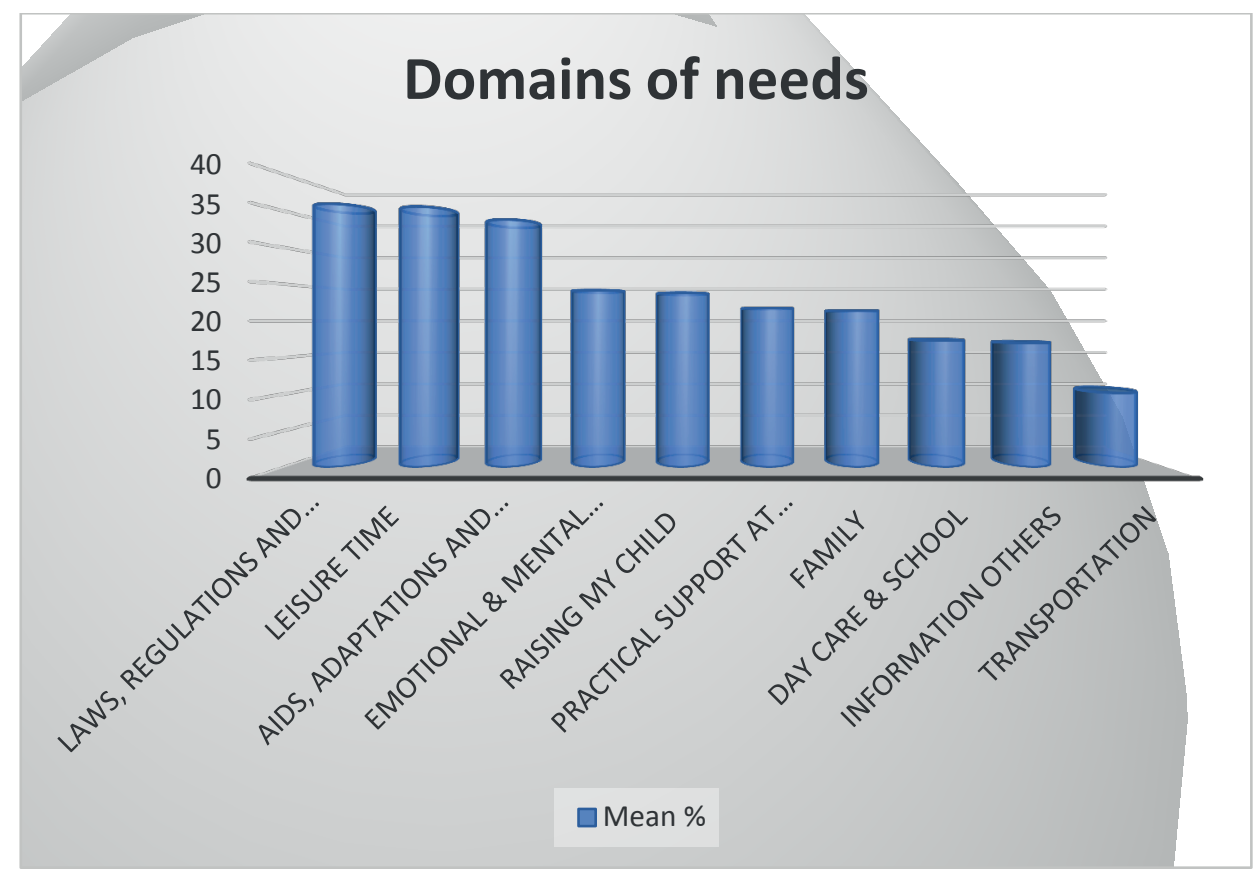

Figure 1: Mean percentage scores in domains of needs

Each item need included in the FNI-PR was reported by one or more participants. The mean number of item needs across all domains expressed by participants was 35.9 (SD $=25.6$; range $=0-124$ ) and the median number of items was 30. One participant expressed 124 needs, while no needs were expressed by six participants. Table 2 provides an overview of the means, standard deviation, medians and range in each domain based on absolute numbers.

The seven single needs which were expressed by $50 \%$ or more of the parents were 'Tax deductions concerning my child's disability' (61.6\%), followed by 'Try out equipment before purchasing it' (58.9\%), 'Information on applying for governmental funding options that apply to us' (58.9\%), 'Possible fees from funds, and foundations' (55.5\%), 
'Finding suitable recreational activities for my child' (54.1\%), 'Access to experiences of other parents having a child with a disability' (52.7\%), 'Resources, equipment and support my child might need in the future' (52.1\%) and 'Finding suitable activities that my child can undertake with children without a disability' (50.7\%). The needs that were expressed the least were 'Placing my child in residential or assisted living' (0.7\%), 'Transportation for my child to and from after school care' (3.4\%), 'Transportation for my child to and from respite care' (4.1\%) and 'Transporting my child together with other children' and 'The possibilities for my child to attend regular day care' (5.5\%).

Appendix 1 provides an overview of all items of the FNI-PR and the number of needs expressed by parents on these items. In addition, it shows the top-20 needs, including needs that were marked by $50 \%$ or more of the parents marked 'bold'. Furthermore, Appendix 1 shows the five most often expressed needs in each domain (marked italic). To illustrate, in the domain 'Leisure time' the five highest needs were: 'Finding suitable recreational activities for my child', 'Finding suitable activities that my child can undertake with non-disabled children', 'Finding suitable activities that my child can undertake with peers with a disability', 'Finding and undertaking recreational activities for our family' and 'Organizing our holidays (e.g. suitable destinations)'.

\section{Priority needs}

Needs in the domains 'Laws, regulations and fees', 'Emotional and mental support' and 'Leisure time' $(14.8 \%, 14.8 \%, 14.2 \%)$ were named most often as top-5 priorities; the 'Laws, regulations and fees' was also expressed by $18 \%$ of participants as their number 1 priority. Needs in the domains 'Inform others about my child', 'The family' and 'Transportation' were seldom named as first priority (3.0\%, 4.7\% and 3.9\%). Parents did not report any new need items beyond those mentioned in the FNI-PR.

\section{Factors related to domain of needs}

Table 2 shows the correlation coefficients for the number of needs within each domain and the child's gross motor function level, parent perceived own general health (GHQ), and family socio-economic status (SES). The results showed that, within all 10 domains, the number of needs was moderately correlated to scores of the GHQ: higher score on $\mathrm{GHQ}$ correlated positively with higher number of needs. Furthermore, the number of needs in the domains 'Laws, regulations and fees', 'Day care \& school', 'Emotional and mental support' and 'Raising my child' negatively correlated with SES; when SES is lower the number of needs is higher. The 'Aids, adaptations, facilities and resources, 'Practical support at home' and 'Leisure time' domains of needs showed a correlation with a child's gross motor function level; higher score on child's gross motor function level 
correlated positively with higher number of needs. Family type was not significantly correlated with reported number of needs.

Table 2: Domains of needs with range, mean, median, standard deviation and correlations with GMFCS, GHQ, SES

\begin{tabular}{lccccccc}
\hline Domain & Range & Mean & Median & SD & GMFCS & GHQ & SES \\
\hline Day care \& school (17 items) & $0-13$ & 2.94 & 2 & 3.02 & -0.042 & $0.267^{* *}-0.216^{* *}$ \\
Aids, adaptations and facilities (17 items) & $0-17$ & 5.75 & 5 & 4.39 & $0.199^{*}$ & $0.296^{* *}$ & -0.077 \\
Practical support at home (16 items) & $0-15$ & 3.48 & 3 & 3.41 & $0.281^{* *}$ & $0.360^{* *}$ & -0.078 \\
The family (16 items) & $0-16$ & 3.42 & 1 & 4.26 & -0.003 & $0.353^{* *}$ & -0.096 \\
Raising my child (17 items) & $0-15$ & 4.05 & 3 & 4.21 & -0.01 & $0.356^{* *}-0.181^{*}$ \\
Emotional and mental support (22 items) & $0-21$ & 5.32 & 4 & 4.88 & -0.053 & $0.461^{* *}-0.215^{* *}$ \\
Inform others about my child (9 items) & $0-9$ & 1.52 & 0 & 2.28 & -0.039 & $0.175^{*}$ & -0.065 \\
Leisure time (9 items) & $0-9$ & 3.21 & 3 & 2.64 & $0.193^{*}$ & $0.293^{* *}$ & -0.045 \\
Transportation (11 items) & $0-8$ & 1.12 & 0 & 1.67 & 0.001 & $0.331^{* *}$ & -0.136 \\
Laws, regulations and fees (14 items) & $0-14$ & 5.04 & 4 & 4.18 & -0.031 & $0.252^{* *}-0.316^{* *}$ \\
Total number of needs (148 items) & $0-124$ & 35.9 & 30 & 25.6 & 0.066 & $0.444^{* *}$ & $-0.206 *$ \\
\hline
\end{tabular}

$* * * p \leq .001, * * p \leq .01, * p \leq .05$

GMFCS-Gross Motor Function Classification System Family Report Questionnaire

GHQ - General Health Questionnaire

SES - Socio-economic status

\section{DISCUSSION}

Despite studies on the impact of having a child with a disability on family life [23] or on relations between family needs and associated factors [27, 39], little is known about the number and domains of single item needs and the priority of the individual item needs of parents of a child with a physical disability.

In this study, the aim was to give a wide-ranging portrayal of the number, domains and priority of needs expressed by parents in supporting participation of their school-aged child with a physical disability. Additionally, this study investigated whether the number of needs within each domain was related to child's gross motor function level, parent perceived own general health, family socio-economic status, and family type.

Most notably, this study showed that there is a large variety in the number, domains and priority of needs among parents. However, the highest mean percentage scores in domains of needs, the top priority needs and single item needs that scored $50 \%$ or higher showed a pattern. Needs belonging to the domains of 'Laws, regulations and fees', 'Leisure time' and 'Aids, adaptations, facilities and resources' were the most- 
frequently expressed. All these needs were related to environmental aspects at home, school and in the community. On a single item level, for instance, 'Finding suitable recreational activities for my child's leisure' was expressed by $54.1 \%$ of participants. All top 20 single item needs, except for one, were about environmental aspects, such as finances, adaptations of environment, resources and social networks. Parents' needs regarding child factors or parents' own skills were rarely expressed.

In this study, the number of needs within each domain showed a positive correlation with parental perceived general health. The number of needs in the domains 'Aids, adaptations, facilities and resources', 'Practical support at home', and 'Leisure time' showed a positive correlation with child's gross motor function level; the number of needs in the domains 'Laws, regulations and fees', 'Day care \& school', 'Emotional and mental support' and 'Raising my child' correlated negatively with family socio-economic status.

Possibilities to compare the outcomes of this study to other studies are limited. Palisano et al. [39] found a similar result for expressed needs on a single item level; a need to locate leisure activities was expressed by $51.5 \%$ of participants. Furthermore, they showed also that family needs were related to the level of child's gross motor function level. Our study showed that parents with lower socio-economic status have more needs in the domain 'Laws, regulations and fees'. Almasri et al. [40] demonstrated that family income is a determinant of parents' needs related to finding community and financial resources. A higher socio-economic status appeared to be a significant protective factor against family needs for services, community, financial, family support and functioning in the study of Almasri et al. [27]. The work of Law et al. [7] demonstrated that lower intensity of participation of children with a physical disability was related to lower family socio-economic status. To our knowledge no other studies have focused on relations between parent perceived general health and family needs. Previous work [24] with parents of children with a physical disability merely looked the impact of living with a child with a disability on parent perceived health.

Some limitations are worth noting in this study. The study population was conducted through the BOSK administration, which could have resulted in selection bias. Parents who are members of the BOSK may not be representative of all parents with a child with a physical disability in the Netherlands. On the other hand, socio-demographic characteristics of the total Dutch population are comparable with the study population (e.g. family with 2 parents: participants 90.3\%, overall Dutch population: 80\%); except the average net income of the BOSK participants was higher than the overall Dutch population ( $€ 36,000$ versus $€ 20,340$ ). Another limitation is that the GMFCS Family and 
Self Report Questionnaire, designed for parents with a child with cerebral palsy, was used in this study for parents of children with different physical disabilities. The completed questionnaires in the pilot and the study, however, did not show any sign of difficulties for parents classifying their child. Furthermore, this is a cross-sectional study in which the main purpose was to provide an overview of the needs of parents. With this design no indications can be made for causal relationships. Yet, to identify causal relationships between child and family characteristics and needs of parents prospective longitudinal study designs are necessary.

In this study parents' furthermost needs were in domains related to environmental aspects at home, school and in the community. The emphasis parents put on the environment is most likely a result of their experiences. This corresponds with King et al. [17] who demonstrated that lower participation of children with a physical disability was related to parental perceptions of environments as unsupportive (i.e., relatively inaccessible in terms of policies, services, attitudes, and assistance). Sleeboom et al. [41] reported a lack of attention in Dutch policy and research on the participation of children with a disability. For example, in the Netherlands there are no specific regulations for leisure and sport clubs concerning children with a disability. Furthermore, very little information is available about the effects of social and care services on the participation of children with a disability [41].

Parents of children with a physical disability greatly influence participation of children, and their furthermost needs concern the environment. Our scoping review [22] revealed that parents do undertake all kind of actions to influence the environment to enhance participation of their child. Not only do they develop strategies to support their children in doing activities, they also become socially involved with others to educate, advocate and network to make participation of their children possible. Levasseur et al, [42] described a taxonomy for social participation. Our study may indicate that, in the terminology of Levasseur et al. [42], parents of children with a physical disability experience challenges and needs on different levels of social participation; the level where individuals help each other, and where individuals contribute more broadly to society by doing an activity that is beneficial to many persons (e.g. educating other children about a disability). How to support parents on those two levels is also of concern to Family-centred service (FCS).

Future research should focus on in-depth understanding of the variety of family needs and personal experiences with environmental aspects at home, school and in the community using a qualitative inquiry. 


\section{CONCLUSIONS}

There is a large variety in the number, domains and priority of needs amongst parents. An interesting pattern of most expressed needs can be seen in relation to the environment. As parents have a major influence on participation of children with a physical disability, and a major goal of FCS in paediatric rehabilitation is to promote children's participation in daily life [3], meeting individual needs of these parents should become an objective for service providers and policy makers. Family-centred service will probably be more effective in supporting engagement of children in social roles by furnishing greater emphasis on changing or enabling environments.

\section{Key Messages}

- A large variety in the number, domains and priority of needs amongst parents with a child with a physical disability exists.

- Most often expressed parents' needs concern environmental aspects.

- Perceived parent general health, family socio-economic status, and child's gross motor function level relate to the number of needs.

- Family-centred service can benefit from emphasis on changing or enabling environments in supporting engagement of children in social roles.

\section{Acknowledgements}

This research study was financially supported by Zuyd University of Applied Sciences, Stichting Belang Gebrekkige Kind Adelante and Maastricht University. The authors wish to thank all the parents (members of BOSK) for their participation in the study; Mrs. Barbara Casparie (client as a partner in research) for contributing to the study design; Mr. Johannes Verheijden (BOSK) for supporting in data-gathering process; Mrs. Vera Mertens (Maastricht University), Mrs. Steffi Schmitz and Mrs. Meghan Norton, Zuyd University of Applied Sciences for supporting in data management. 


\section{LITERATURE}

1. World Health Organization: World Report on Disability. In. Edited by The World Bank. Geneva: World Health Organization; 2011.

2. Kooiker SE: Jeugd met beperkingen: SCP, Sociaal en Cultureel Planbureau; 2006.

3. King G, Tucker MA, Baldwin P, Lowry K, Laporta J, Martens L: A life needs model of pediatric service delivery: services to support community participation and quality of life for children and youth with disabilities. Physical \& Occupational Therapy in Pediatrics 2002, 22(2):53-77.

4. Rosenbaum P, King S, Law M, King G, Evans J: Family-centred service: A conceptual framework and research review. Physical \& Occupational Therapy in Pediatrics 1998, 18(1):1-20.

5. King S, Teplicky R, King G, Rosenbaum P: Family-centered service for children with cerebral palsy and their families: a review of the literature. In: Seminars in pediatric neurology: 2004: Elsevier; 2004: 78-86.

6. Alsem MW, Siebes RC, Gorter JW, Jongmans MJ, Nijhuis BGJ, Ketelaar M: Assessment of family needs in children with physical disabilities: development of a family needs inventory. Child: Care, Health and Development 2013:n/a-n/a.

7. Law M, King G, King S, Kertoy M, Hurley P, Rosenbaum P, Young N, Hanna S: Patterns of participation in recreational and leisure activities among children with complex physical disabilities. Developmental Medicine \& Child Neurology 2006, 48(5):337-342.

8. Kolehmainen N, Francis J, Ramsay C, Owen C, McKee L, Ketelaar M, Rosenbaum P: Participation in physical play and leisure: developing a theory-and evidence-based intervention for children with motor impairments. BMC Pediatr 2011, 11(1):100.

9. King G, Law M, King S, Rosenbaum P, Kertoy MK, Young NL: A conceptual model of the factors affecting the recreation and leisure participation of children with disabilities. Physical \& occupational therapy in pediatrics 2003, 23(1):63-90.

10. Imms C, Reilly S, Carlin J, Dodd K: Diversity of participation in children with cerebral palsy. Developmental Medicine \& Child Neurology 2008, 50(5):363-369.

11. Bult MK, Verschuren O, Gorter J, Jongmans M, Piškur B, Ketelaar M: Cross-cultural validation and psychometric evaluation of the Dutch language version of the Children's Assessment of Participation and Enjoyment (CAPE) in children with and without physical disabilities. Clinical Rehabilitation 2010, 24(9):843853.

12. Frostad P, Pijl SJ: Does being friendly help in making friends? The relation between the social position and social skills of pupils with special needs in mainstream education. European Journal of Special Needs Education 2007, 22(1):15-30.

13. Blum RW, Resnick MD, Nelson R, St Germaine A: Family and peer issues among adolescents with spina bifida and cerebral palsy. Pediatrics 1991, 88(2):280-285.

14. Law M, Dunn W: Perspectives on understanding and changing the environments of children with disabilities. Physical \& Occupational Therapy in Pediatrics 1994, 13(3):1-17.

15. Bult MK, Verschuren O, Jongmans MJ, Lindeman E, Ketelaar M: What influences participation in leisure activities of children and youth with physical disabilities? A systematic review. Research in developmental disabilities 2011, 32(5):1521-1529.

16. Majnemer A, Shevell M, Law M, Birnbaum R, Chilingaryan G, Rosenbaum P, Poulin C: Participation and enjoyment of leisure activities in school-aged children with cerebral palsy. Developmental Medicine \& Child Neurology 2008, 50(10):751-758.

17. King G, Law M, Hanna S, King S, Hurley P, Rosenbaum P, Kertoy M, Petrenchik T: Predictors of the Leisure and Recreation Participation of Children With Physical Disabilities: A Structural Equation Modeling Analysis. Children's Health Care 2006, 35(3):209-234. 
18. Law M, Anaby D, Teplicky R, Khetani MA, Coster W, Bedell G: Participation in the home environment among children and youth with and without disabilities. The British Journal of Occupational Therapy 2013, 76(2):58-66.

19. Welsh B, Jarvis S, Hammal D, Colver A: How might districts identify local barriers to participation for children with cerebral palsy? Public Health 2006, 120(2):167 - 175.

20. Law M, Petrenchik T, King G, Hurley P: Perceived environmental barriers to recreational, community, and school participation for children and youth with physical disabilities. Archives of physical medicine and rehabilitation 2007, 88(12):1636-1642.

21. Turnbull AP, Pereira L, Blue-Banning MJ: Parents' facilitation of friendships between their children with a disability and friends without a disability. Research and Practice for Persons with Severe Disabilities 1999, 24(2):85-99.

22. Piškur B, Beurskens AJ, Jongmans MJ, Ketelaar M, Norton M, Frings CA, Hemmingsson $H$, Smeets RJ: Parents' actions, challenges, and needs while enabling participation of children with a physical disability: a scoping review. BMC Pediatr 2012, 12(1):177.

23. Guyard A, Michelsen SI, Arnaud C, Lyons A, Cans C, Fauconnier J: Measuring the concept of impact of childhood disability on parents: Validation of a multidimensional measurement in a cerebral palsy population. Research in developmental disabilities 2012, 33(5):1594-1604.

24. Hung J-W, Wu Y-H, Chiang Y-C, Wu W-C, Yeh C-H: Mental health of parents having children with physical disabilities. Chang Gung Med J 2010, 33(1):82-91.

25. Yatchmenoff DK, Koren PE, Friesen BJ, Gordon LJ, Kinney RF: Enrichment and stress in families caring for a child with a serious emotional disorder. Journal of Child and Family Studies 1998, 7(2):129-145.

26. Siebes R, Ketelaar M, Gorter JW, Alsem M, Jongmans MJ: Needs of Families with Children Who Have a Physical Disability: A Literature Review. Critical Reviews ${ }^{\text {TM }}$ in Physical and Rehabilitation Medicine 2012, 24(1-2).

27. Almasri NA, O'Neil M, Palisano RJ: Predictors of needs for families of children with cerebral palsy. Disability \& Rehabilitation 2013(0):1-10.

28. Palisano R, Rosenbaum P, Walter S, Russell D, Wood E, Galuppi B: Development and reliability of a system to classify gross motor function in children with cerebral palsy. Developmental Medicine \& Child Neurology 1997, 39(4):214-223.

29. Palisano R, Rosenbaum P, Bartlett D, Livingston MH: Content validity of the expanded and revised Gross Motor Function Classification System. Developmental Medicine \& Child Neurology 2008, 50(10):744-750.

30. Dietrich A, Abercrombie K, Fanning J, Bartlett D: Correspondence of classification of motor function of children with cerebral palsy aged two to four years between families and professionals: a pilot study. Developments, Newsletter of the Pediatric Division of the Canadian Physiotherapy Association 2005(Spring):10-14.

31. Morris C, Galuppi BE, Rosenbaum PL: Reliability of family report for the gross motor function classification system. Developmental Medicine \& Child Neurology 2004, 46(7):455-460.

32. Jewell AT, Stokes AI, Bartlett DJ: Correspondence of classifications between parents of children with cerebral palsy aged 2 to 6 years and therapists using the Gross Motor Function Classification System. Developmental Medicine \& Child Neurology 2011, 53(4):334-337.

33. Kerr C, McDowell B: GMFCS Family Report Questionnaire: Children Aged 4 to 6 Years. In. Edited by http://motorgrowth.canchild.ca/en/GMFCS/resources/GMFCS_Family_4to6.pdf, GMFCS modified with permission from Palisano et al. (1997) Dev Med Child Neurol, 39, 214-223. edn. McMaster Univeristy: CanChild Centre for Childhood Disability Research 2007.

34. Morris C: GMFCS Family Report Questionnaire: Children Aged 6 to 12 Years. In. Edited by http://motorgrowth.canchild.ca/en/GMFCS/resources/GMFCS Family 6to12.pdf, GMFCS modified with permission from Palisano et al. (1997) Dev Med Child Neurol, 39, 214-223. edn. McMaster University CanChild Centre for Childhood Disability Research (www.canchild.ca); 2007 
35. Guillemin F, Bombardier C, Beaton D: Cross-cultural adaptation of health-related quality of life measures: literature review and proposed guidelines. Journal of clinical epidemiology 1993, 46(12):1417-1432.

36. Goldberg DP, Gater R, Sartorius N, Ustun T, Piccinelli M, Gureje O, Rutter C: The validity of two versions of the GHQ in the WHO study of mental illness in general health care. Psychological medicine 1997, 27(01):191-197.

37. Goldberg DP, Williams P: A user's guide to the General Health Questionnaire: Nfer-Nelson; 1988.

38. Buziarsist J, Demarest S, Gisle L, Tafforeau J, Van der Heyden J, Van Oyen H: Health Interview Survey Belgium. In., vol. 2001, March 2003/2 edn. Brussels: Scientific Institute of Public Health; 2003.

39. Palisano R, Almarsi N, Chiarello L, Orlin M, Bagley A, Maggs J: Family needs of parents of children and youth with cerebral palsycch_1030 85.. 92. 2009.

40. Almasri NA, Palisano RJ, Dunst CJ, Chiarello LA, O'Neil ME, Polansky M: Determinants of needs of families of children and youth with cerebral palsy. Children's Health Care 2011, 40(2):130-154.

41. Sleeboom I, Hermanns J, Hermanns V: Meedoen leer je door mee te doen. Een inventarisatie van de wijze waarop in zorg voor kinderen van 0-12 jaar met beperkingen aandacht besteed wordt aan (toekomstige) maatschappelijke participatie. In.: Den Haag: ZonMw/CrossOver; 2010.

42. Levasseur M, Richard L, Gauvin L, Raymond E: Inventory and analysis of definitions of social participation found in the aging literature: proposed taxonomy of social activities. Social Science and Medicine 2010, 71(12):2141-2149. 


\section{CHAPTER 5}

Daily actions, challenges, and needs among Dutch parents while supporting the participation of their child with a physical disability at home, at school, and in the community

A qualitative diary study

Submitted as: Piškur B, Beurskens AJHM, Ketelaar M, Jongmans MJ, Casparie BM, Smeets RJEM, Daily actions, challenges, and needs among Dutch parents while supporting the participation of their child with a physical disability at home, at school, and in the community: a qualitative diary study 


\section{Abstract}

Background Parents have a vital influence on the participation of their child with a physical disability. The aim of this study is to gain insight into parents' own daily actions, challenges, and needs while supporting their child with a physical disability at home, at school, and in the community. An additional objective of this study is to refine the preliminary thematic framework previously identified in a scoping review.

Methods A qualitative research inquiry was performed based on using a diary over a 7-day period to gather data. To systematically organise data into a structured format, content analysis has been applied using both inductive and deductive reasoning guided by the existing preliminary thematic framework.

Results Analysis of the 47 eligible diaries shows that the actions mentioned by the parents describe several efforts to enhance participation of their children with a physical disability by using, enabling, or changing the social and physical environment, or by supporting their child to perform or engage in meaningful activities. Those parents' actions are primarily a result of challenges caused by restrictions in social and physical environments. By parents identified needs underline, above all, a necessity for environments designed for all people. Based on the findings a redefined thematic framework is presented.

Conclusions Parents' actions, challenges, and needs are mainly directed towards the social or/and physical environment. The presented thematic framework can offer practitioners knowledge to support parents. More work is necessary to provide tailored approaches. Paediatric rehabilitation may need to address the importance of the environment on the participation of a child with a physical disability. 


\section{BACKGROUND}

Parents play a significant role in enabling participation of children with a physical disability at home, at school, and in the community. Participation - the involvement in life situations to fulfil social roles - has a positive impact on children's health and wellbeing [1-3]. Children with a physical disability often come across restrictions in their everyday participation [4-6]. The most important factor influencing successful participation of children and adolescents with disabilities is the interplay between the child's environment and activities [7-12]. It is of great significance in this regard that Parents have a considerable knowledge and experiences regarding the environment and the child's preferred or desired activities [13].

Family-Centred Service (FCS) is considered best practice in service for children with a physical disability [14]. Its effectiveness is related to the understanding professionals have about needs and actions of both child and parents, including what parents do to support their child with a physical disability $[15,16]$. A recent scoping review of the literature on this topic [17] revealed 14 studies, which identified several parents' actions, challenges, and needs that were summarised in a preliminary thematic framework. The framework includes two major themes: "parents enable and support performance of meaningful activities of their child at home, at school and in the community" and "parents enable, change and use the environment" [17]. Connected to the major themes, the framework includes three categories (actions, challenges, and needs) and several subcategories with a total of eight actions, eight challenges, and four needs, as presented in Figure 1.

However, the scoping review [17] also underlines how little information is available on what parents actually do every day to enhance their child's participation. Time-use diaries are particularly relevant and suitable instruments for studying the daily lives of families, including families with a child with a physical disability, as they give insight into what they as a family actually do in context [18]. Participants who fill out the diaries are both observers and informants, providing the researcher a "view from within" [19, 20].

The aim of this study is to gain insight into parents' own daily actions, challenges, and needs while supporting their child with a physical disability at home, at school, and in the community. Additionally, the study results will be used to refine the preliminary thematic framework. 


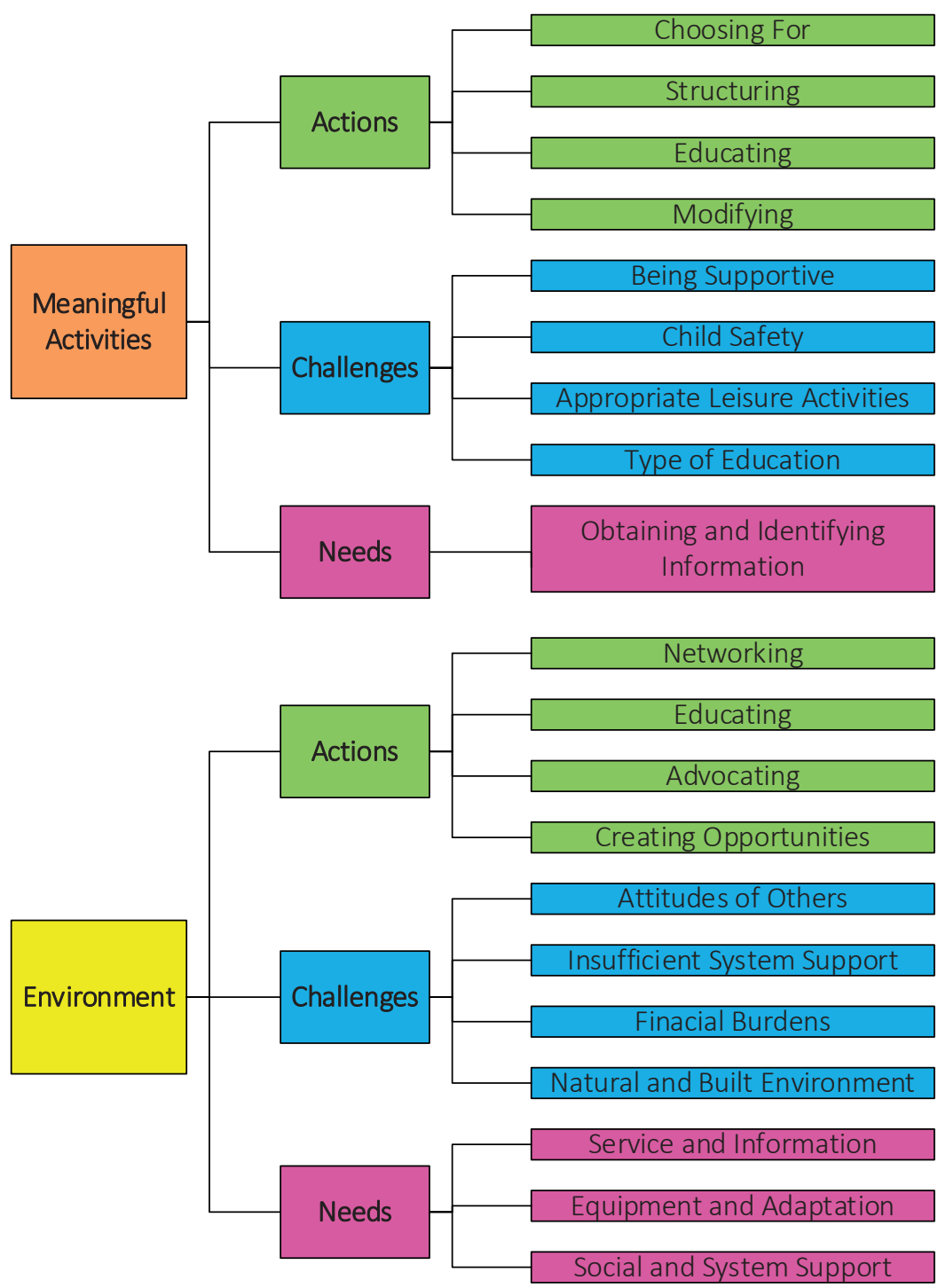

Figure 1: A preliminary thematic framework (Piškur et al., 2012)

\section{METHODS}

Between May 2012 and July 2012, a qualitative research inquiry was performed based on using a diary over a 7-day period. Direct content analysis was used as theoretical framework to systematically organise data into a structured format [21-23]. 


\section{Study population}

Potential participant families of children with a physical disability were selected from the electronic database of the Dutch Association of People with Disabilities and their Parents (BOSK). All potential families had a child aged between 4 and 12 years with a physical disability that is neurological and non-progressive in nature (e.g. cerebral palsy, spina bifida) and who was living at home. Persons identified in the database of the BOSK as the contact person for each family (parent or primary caregiver) were considered eligible for this study.

\section{Recruitment procedure}

In May 2012, 559 (17.2\% from all the BOSK members) eligible parents (or primary caregivers) of children who fulfilled the criteria received an information letter from the BOSK inviting them to participate in the study. A stamped return-envelope, an informed consent form, information about the study, and a diary covering a 7-day period, were included. This study was conducted jointly with a quantitative study aimed to give a wide-ranging portrayal of the number, domains, and priority of needs expressed by parents using the Family Needs Inventory - Pediatric Rehabilitation [24, 25]. Parents (or primary caregivers) had the choice to refuse cooperation, to fill in the diary or the questionnaire, or both.

Parents (or primary caregivers) who did not respond to the first invitation received a reminder from the BOSK after three weeks. The local medical ethics committee (Atrium Medical Centre, Orbis Medical and Healthcare Centre and Zuyd University of Applied Sciences) approved the study protocol (12-N-37).

\section{Data gathering}

Participating parents (or primary caregivers) returned the completed diary and/or questionnaire as well as the informed consent form in the return envelope directly to the Centre for Data and Information Management (MEMIC) in Maastricht.

Solicited diaries, with optimum length between 1 and 2 weeks, provide a rich source of data and are often utilised to elicit specific information [18, 26, 27]. Participants were asked to complete the diary each day over a 7-day period, reflecting on issues that are of interest to the study - actions, challenges, and needs while supporting their child with a physical disability at home, at school, or in the community. A pilot study including fifteen parents (February 2012) revealed that the 7-day period solicited diary was feasible and took about 15 minutes per day to complete. 
Participants used a printed diary (A4 booklet template) with worksheets for each day of the week, and an example of the worksheet with participant instructions. On each sheet columns were created for Time of start of the activity, Activity the child was engaged in, Actions parents performed, Challenges parents came across, Needs parents experienced, and the possibility for additional remarks (for an example of a spreadsheet see Figure 2). Participants were asked to write down all activities their child did over 24 hours, name the actions they did to facilitate those activities, and mention challenges and unmet needs they experienced. Next, an option was given for possible additional information.

\section{Data analysis}

For the data-analysis of the diaries both deductive and inductive reasoning was used $[28,29]$. Directed content analysis $[23,27]$, using deductive reasoning, was conducted to validate or conceptually extend the existing preliminary thematic framework as described above [17]. In this deductive analysis, the existing framework guided development of an initial coding and categorising scheme, and operational definitions for the codes were used [30].

Inductive reasoning was also used. In this way, potentially new major themes, categories and/or sub-categories could be identified from the data through the researcher's careful examination and constant comparison [31].

After transcription of all diaries into a word-processing package, a coding scheme was developed and subsequently applied by means of manual coding. The first author (BP) prepared the coding scheme and the second author (AJHMB) inspected it to ensure congruence with the elements of the preliminary thematic framework. Then, the first author (BP) applied the identical coding and categorising scheme to all data using techniques of memoing, constant comparison, and questions. NVivo software (v.9, QSR International, Cambridge, MA) was used to organise the data during analysis. Two debriefing sessions took place between the user as co-research (BC) and the first author (BP) to discuss the findings leading to small changes in the wording of the codes of actions, challenges, and needs.

In this study Lincoln and Guba's [32-34] four criteria (credibility, transferability, dependability, and confirmability) for evaluating interpretive research work were applied in accordance with Elo's et al. [35] aspects of trustworthiness in relation to qualitative content analysis. 


\begin{tabular}{|c|c|c|c|c|c|}
\hline & $A$ & $B$ & C & $D$ & $E$ \\
\hline Time & $\begin{array}{l}\text { Activity the } \\
\text { child engages } \\
\text { in }\end{array}$ & $\begin{array}{l}\text { Do you support your child } \\
\text { (sometimes) during the } \\
\text { activity? If yes, how? }\end{array}$ & $\begin{array}{l}\text { Do you face } \\
\text { challenges/problems with } \\
\text { this? If yes, which one? }\end{array}$ & $\begin{array}{l}\text { What kind of } \\
\text { support do you } \\
\text { need? }\end{array}$ & $\begin{array}{l}\text { Additional } \\
\text { remarks }\end{array}$ \\
\hline \begin{tabular}{|l|}
$6.00-$ \\
9.00
\end{tabular} & & & & & \\
\hline \begin{tabular}{|l|}
$9.00-$ \\
12.00
\end{tabular} & & & & & \\
\hline \begin{tabular}{|l|}
$12.00-$ \\
15.00
\end{tabular} & & & & & \\
\hline \begin{tabular}{|l|}
$15.00-$ \\
18.00
\end{tabular} & & & & & \\
\hline \begin{tabular}{|l|}
$18.00-$ \\
21.00
\end{tabular} & & & & & \\
\hline \begin{tabular}{|l|}
$21.00-$ \\
24.00
\end{tabular} & & & & & \\
\hline \begin{tabular}{|l|}
$24.00-$ \\
6.00 \\
\end{tabular} & & & & & \\
\hline
\end{tabular}

Figure 2: An example of the worksheet for one day of the week

Credibility was ensured with organising debriefing sessions between the first researcher (BP) and a client research assistant (BC) and by using random sampling. Transferability was guaranteed by passing information to the reader about the boundaries of the study and providing characteristics of the study population. Dependability is assured by reporting in detail the processes within this study, thereby enabling a future researcher to repeat the work, as is confirmability by reporting findings that are solely the result of the experiences and ideas of the participants.

\section{RESULTS}

In total, 51 diaries were returned. Three diaries were largely unfilled and one completely empty, and so these were excluded, leaving 47 eligible for the analysis. Participants were all biological parents - mainly mothers (92 \%) - who have a child with a disability who is between 4 and 12 years of age (for more characteristics see Table 1 ).

In comparison with the original framework, two previously identified major themes, "parents enable and support performance of meaningful activities at home, at school and in the community" and "parents enable, change and use the environment", remained the same. 
Major theme 1: Parents enable and support performance of meaningful activities at home, at school, and in the community

This theme concerns actions, challenges, and needs of parents while supporting their child with a physical disability to engage in meaningful activities at home, at school, or in the community. Additionally, the categories "actions", "challenges", and "needs" did not change. However, in all three categories new sub-categories were identified: two in the category actions, two in the category challenges, and three in the category needs. On the contrary, the previously named challenge regarding financial burden, and the need for service and information were not identified in the current analysis.

Table 1: Demographic characteristics of study participants

\begin{tabular}{|c|c|}
\hline Family characteristics & \\
\hline & Number (\%) \\
\hline Mean/SD age participant $(n=47)$ : & $43(5.4)$ \\
\hline Relationship with the child & \\
\hline Mother & $43(92 \%)$ \\
\hline Father & $4(8 \%)$ \\
\hline Other & $0(0 \%)$ \\
\hline Nationality of the respondent & \\
\hline Dutch & $47(100 \%)$ \\
\hline Other & $0(0 \%)$ \\
\hline Highest level of education of participan & \\
\hline Less than high school & $1(2 \%)$ \\
\hline High school & $4(8 \%)$ \\
\hline More than high school & $42(90 \%)$ \\
\hline (total Dutch female population =36\%) & \\
\hline Family Type - child lives: & \\
\hline with 2 biol. Parents & $43(92 \%)$ \\
\hline with 1 biol. Parent & $4(8 \%)$ \\
\hline Child characteristics & \\
\hline Mean/SD age child $(n=47)$ : & $7.9(2.6)$ \\
\hline Child nationality & \\
\hline Dutch & $45(96 \%)$ \\
\hline Unknown & $2(4 \%)$ \\
\hline Child gender & \\
\hline Female & $22(47 \%)$ \\
\hline Male & $25(53 \%)$ \\
\hline Child education & \\
\hline Regular & $23(50 \%)$ \\
\hline Special & $14(30 \%)$ \\
\hline Unknown & $10(20 \%)$ \\
\hline
\end{tabular}


Figure 3 portrays the presentation of all the major themes, categories, and subcategories that were identified in both studies. Previously identified major themes with categories and sub-categories of the preliminary framework [17] that remained the same are marked "italic"; new sub-categories that emerged from the inductive analyses are marked "bold". Two sub-categories that were not identified in this study are "underlined".

\section{Category: Actions to support meaningful activities}

One new action was identified (role taking) and four previously identified actions (choosing for, structuring, educating, and modifying) emerged in this study.

The new action "role taking" implies how parents are taking up a new role that allows supporting meaningful activities of their child. Parents in this study act as a volunteer in scouting to help their child to complete tasks like cooking or assisting a swimming teacher. Parents also gave assistance to teachers at school during physical education.

The action "choosing for" refers to parents making choices regarding the kind of activities in which their child will be socially engaged. A number of examples were described in the diaries: deciding on joining a birthday party with peers without a disability, playing at a friend's home, or playing outside the house with neighbours. Parents mentioned that they chose a team sport, such as judo or grass-hockey, as a leisure activity for their child to enable contact with peers without a disability. Parents also described their choice for doing 'normal' family activities outside their house, such as visiting an open-air museum by bus or going to a playground.

"Structuring" describes the parents' action to organise daily routines at home in such a way that their child can engage in meaningful activities. One parent explained the change of a daily routine of eating a warm evening meal at 6 p.m. to be in time for horse riding.

The action "educating" applies to teaching the child a new strategy to be able to participate in activities. Parents described this action with different examples, such as showing their child an easier way to use the computer; showing their child how to perform a domestic task such as preparing cutlery for seven people using a strategy to count aloud one, two, three...; and by using modelling while practicing with a flute.

Examples related to school were also described, such as teaching their child how to reach his classroom independently and showing an alternative way of doing mathematics.

The action "modifying" stands for adaptations of activities to support the child's independence and social interaction. One example in this study was about a family walk in a forest. A mother described that she walks next to her bicycle while her child with a physical disability sits on it. Another example is buying clothes with Velcro tape that enables a child to dress himself at school. 


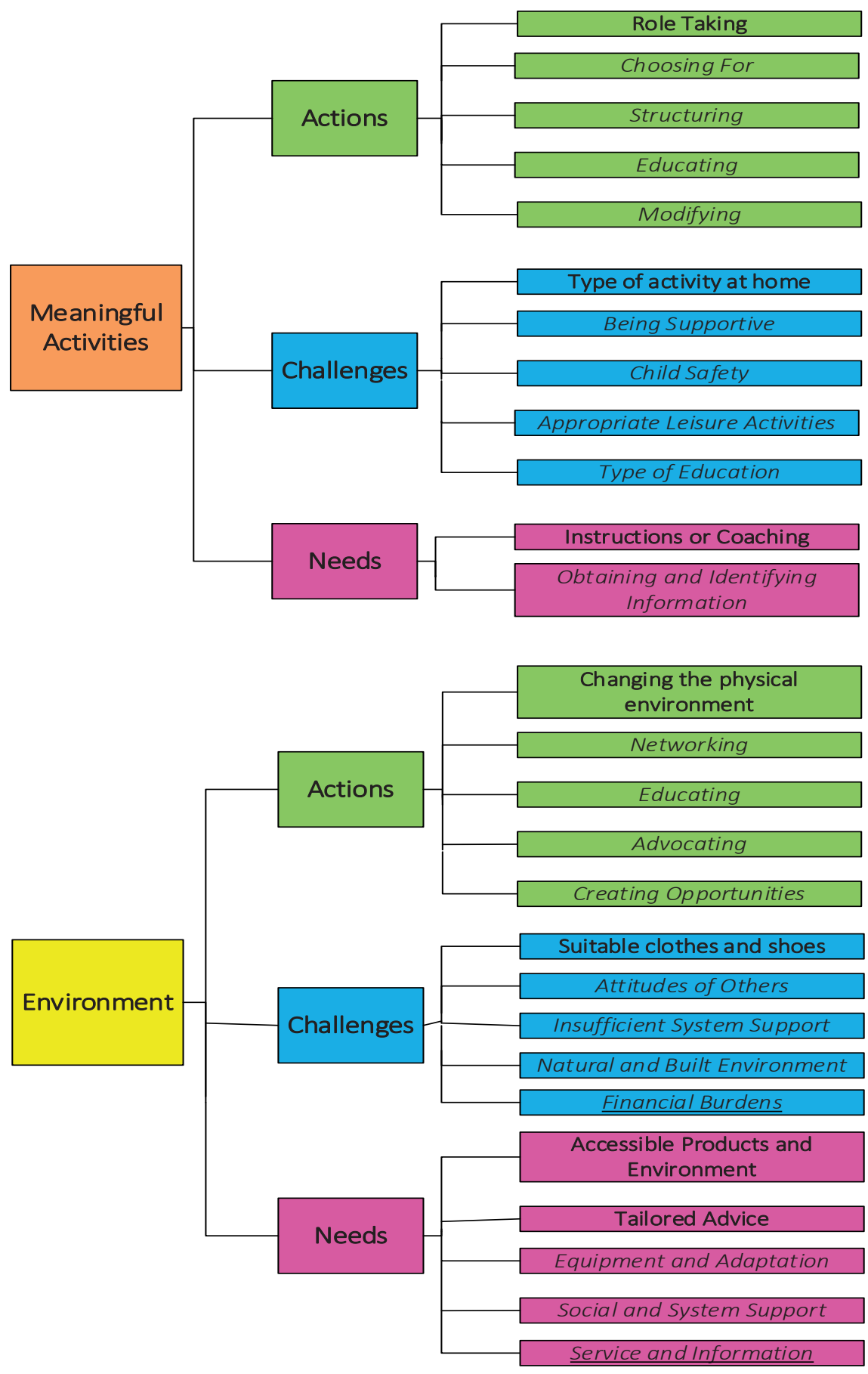

Figure 3: Preliminary framework of parent's actions, challenges and needs based on the results of the diary study 


\section{Category: Challenges while supporting meaningful activities}

Parents reported several challenges that emerged while supporting their child's meaningful activities. One new challenge (choosing the right type of activity at home) and four formerly identified challenges (being supportive in a correct manner, coping with child safety, choosing the most appropriate leisure activities, and selecting the best type of education) have been identified.

The challenge "choosing the right type of activity at home" refers to the struggle over how to decide what kind of activities their child can engage in with other children at home. An example is that parents go through great effort to find an appropriate activity suitable for their child to play together with a brother or sister without a disability.

The challenge "being supportive in a correct manner" is about deliberating whether the child is capable of doing an activity (at home or outside) alone and estimating what would be appropriate support. Several examples were given in this study. Parents explained that it is a dilemma during breakfast whether or not to cut bread; the child had the ability to do it alone but it might slow down the morning routine, resulting in being too late for school or the school-taxi. Other examples were parents struggling with whether they should tie their child's shoes or to explain how to do it, and how much support should be given during bathing, showering, dressing, or cycling.

"Coping with child safety" is about parents having difficulties coping with situations

with no parental control. Activities provoking these challenges were: learning how to make a fire at scouting, playing at a friend's home, and going with another family to a playground.

The challenge "choosing the most appropriate leisure activities" indicates problems finding a leisure activity that fits the child's abilities and brings a sense of accomplishment. Parents reported challenges finding suitable team sports and appropriate swimming lessons for their child.

"Selecting the best type of education" is a challenge parents also faced in this study. For example, one parent explained that it was difficult to make the choice for the type of education for their child, as they got dissimilar advice from different professionals.

\section{Category: Needs while supporting meaningful activities}

Parents provided information about unmet needs while supporting meaningful activities of their child. In this study one new need (instructions or coaching) emerged and one existing need (identifying and obtaining information) was confirmed.

The need "instructions or coaching" is about receiving written or verbal support. One parent wrote in the diary that having instructions or coaching in how to put their 
child into the car and how to put her in the seat would be helpful. Other parents expressed a need for instructions to support independence during meals. One parent showed a need for coaching on how they can support their child while playing in a play garden. In addition, parents expressed a need for coaching in understanding laws and regulations (e.g. the 'Social Support Act' - WMO) or in choosing a new type of education.

"Identifying and obtaining information" is a need for more information about meaningful activities. For example, one parent expressed the need for an overview of suitable leisure activities for children with a physical disability.

\section{Major theme 2: Parents enable, change, and use the environment}

This theme relates to actions, challenges, and needs of parents while using, enabling, and changing the social and physical environment at home, at school, and in the community to make participation of their child with a physical disability possible.

\section{Category: Actions to enable, change, and use the environment}

One new action (changing the physical environment) was identified and four previously discovered actions (networking, educating, advocating, and creating opportunities) were confirmed.

The new action "changing the physical environment" demonstrates how parents take the initiative to change the physical environment into a more suitable one to support their child's participation. One example of such action is an adaptation of a bathroom at home to aid the child in becoming independent. Another example of this kind of action is that some parents made a school entrance accessible to their child.

"Networking" refers to the establishing of connections with people with similar experiences. Parents in this study explained their attempts to find people through their social network to connect and share experiences, and their attempts to connect with people through social media, like forums.

The action "educating" is defined as the giving of instructions to others on how to support the participation of their child. Examples in this study are parents educating employees of the day care centre or educating a judo trainer to optimise assistance of their children.

"Advocating" refers to the competing of resources, supports, and services within the system. One parent reported in the diary about a rival with a taxi service to make sure their child would get extra support and be taken on board as a passenger.

"Creating opportunities" means the creation of events by parents in order to shape opportunities for their child to get acquainted with other children. One example in this 
study concerns parents organising a "get together" meeting where their child could connect to other children. Additionally, this action is also about making and keeping connections at school. One parent described in the diary that she organised extra afterschool lessons to make sure her child will be able to stay in the same group of children next year.

\section{Category: Challenges to enable, change, and use the environment}

One new challenge (customised products) and three previously recognised challenges (attitudes of others, insufficient system support, and barriers in the natural and physical environment) emerged during the analysis.

"Customised products" pertains to a new challenge faced by many parents in this study. Several examples were described about difficulties in trying to find appropriate clothes that support independence and the challenge of finding fitting shoes, mainly for children that need to wear a splint. Parents also noted that it is difficult to find shoes with Velcro tape, particularly in bigger sizes.

The "attitudes of others" refers to the experience of parents facing negative attitudes from other children or adults towards their child with a physical disability. Examples in this study are negative attitudes of friends during play activities and negative remarks about disability from friends' parents. Similar attitudes were experienced with professional services, like taxi service employees (drivers) reacting negatively towards a child with a disability and not being willing to help a child to get in and out of the taxi.

The challenge "insufficient system support" concerns unsupportive social structures. Parents in this study described that teachers and sports instructors lack knowledge of how to support children with a physical disability at school and during swimming lessons. Parents mentioned that support assistants (paid from personal budget funded by the Dutch Exceptional Medical Expenses Act - AWBZ) are not always capable of supporting their child, such as while eating a meal or engaging in play activities with their child at home. Others wrote that it is difficult to get a support assistant between 6 a.m. and 8 a.m. One parent described the complication of getting assistance for an empty wheelchair tire when visiting a museum.

A "barrier in the natural and built environment" refers to the physical accessibility of buildings and public places. Parents' examples of these challenges concern the built environment: non-user-friendly public toilets, as at the Zoo; inaccessible walking paths in an open-air museum; and family cars that are unable to fit in a special swing-auto chair or a wheelchair. Similar challenges were described for the natural environment, like the impossibility to use walking paths in the forest with a wheelchair. 
Category: Needs to enable, change, and use the environment

Two new needs (accessible products and environments and tailored advice about equipment, devices, and adaptations) and two previously identified needs (equipment and adaptations, social and system support) emerged.

"Accessible products and environments" shows a new need for products and environments designed to be usable by all people. Parents gave examples of this need in relation to the built environment (e.g. shops and other public places, houses, playgrounds) but also to shoes and clothes.

"Tailored advice about equipment, devices, and adaptations" illustrates a need for personalised advice about equipment, devices, and adaptations. Examples from this study describe a need for advice about adaptations in the house or in the day care centre. Furthermore, parents expressed a need for advice about the availability and appropriateness of devices for their child and about suitable clothes, shoes, and convert cutlery.

"Equipment and adaptations" refers to the need for equipment that is designed to support independence and participation in activities. Examples from this study demonstrate a need for equipment to support and facilitate independence while eating. Furthermore, parents expressed a need for equipment that can be used in a normal car, a need for easy-to-modify adaptations for a toilet or a shower, and a safe bicycle seat for bigger children.

"Social and system support" refers to the needs of parents for more expansive social networks to enable their child's participation. In this study parents' examples referred to extra support from grandparents and support assistants to bring their child to leisure activities, assistance during physical education at school or during church services, engagement in play activities at home or in the play garden, and to do educational activities on a computer.

\section{DISCUSSION}

The purpose of this study is to gain insight into parents' own daily actions, challenges, and needs while supporting their child with a physical disability at home, at school, and in the community. In one week, on every single day, all participating parents described several efforts to enhance the participation of their children with a physical disability by using, enabling, or changing the social and physical environment, or by supporting their child to perform or engage in meaningful activities. Fascinatingly, those actions were primarily a result of challenges caused by restrictions in social and physical environments. Needs described by parents notably spotlight environmental aspects, like a need for environments designed for all people. 
Additionally, this study intended to refine the existing preliminary thematic framework arising from a scoping review [17]. Two major themes, all categories and sub-categories, except two, of the preliminary thematic framework [17] were consistent with the actions, challenges, and needs mentioned by the parents in this study. One challenge regarding financial burden, and one need for service and information were not identified in the analysis.

However, the analysis reveals two new actions (role taking, changing the physical environment), two new challenges (choosing the right type of activity at home, customised products), and three new needs (instructions and coaching; accessible products and environments; tailored advice about equipment, devices, and adaptations).

The previous scoping review [17] showed that parallels exist between the parents actions, challenges, and needs described in the preliminary framework for children with a physical disability and studies done with parents of children with Down syndrome, young people with epilepsy, and young adults with a physical disability [36-38]. Studies and policy reports from the Netherlands support the newly found actions, challenges, and needs related to environment. For example, free access to public buildings and places for all citizens in the Netherlands was not taken into the Equal Opportunities Act; there is no obligation to guarantee access for persons with a disability [39]. Consequently, only $29 \%$ of people with a severe physical disability in the Netherlands can enter shops [40]. Parents in this study expressed a new need for "accessible products and environments", like playgrounds, and showed their own initiatives to change the physical environment into a more suitable one to support their child's participation (action: "changing the physical environment"). In the Netherlands there are no specific regulations for leisure and sports clubs concerning children with a disability [41]. The inclusion of children with disabilities in mainstream primary education has been arranged by law in August 2014 [42].

Some possible limitations in this study are noteworthy to discuss. Selection bias may have occurred as we used the database of the Dutch Association of People with Disabilities and their Parents (BOSK) to draw our participants from, and only $9 \%$ of eligible parents decided to participate. The participating parents, $92 \%$ mothers, had a higher educational level than average in the Netherlands, and, considering their membership in BOSK, may have been parents who are very involved and motivated in enhancing the participation of their child with a physical disability. However, the data set is rich in nature and there is a large variety among data; some parents reported more actions, challenges, and needs at home, and others at school or in the community. Further, mothers are usually the respondents in other similar studies, like Almasri et al. [43]. They are known as caretakers of children with a disability, and are therefore most involved in enhancing the participation of their child. In a study about parents of children with intellectual disabilities, Rowbotham et al. [44] found that mothers undertake more 
daily care-giving tasks than fathers, but the range of tasks is similar. However, it is unclear how such differences influence actions, challenges, and needs of fathers and mothers. Additionally, it can be argued whether data collection of just one week is sufficient. As the optimal length for this type of study is one to two weeks [27] and the data received were rich in nature, the period of time probably has not been a limitation.

The 47 included diaries indicate that parents of children with a physical disability carry out many actions, face numerous challenges, and have several unmet needs while supporting their child's participation at home, at school, and in the community. It is interesting that parents' actions, challenges, and needs are mainly directed towards the social or/and physical environment. Therefore, paediatric rehabilitation using FCS may need to address the importance and the impact of the environment on the participation of a child with a physical disability, rather than only focus on the child's abilities.

In order to effectively support parents while enabling the participation of their children in daily life, tailored approaches are compulsory. These approaches may also contribute to stress reduction and better health and well-being of parents. Raina et al. [45] found that health and well-being of parents of children with cerebral palsy seem strongly influenced by child disability; Parkes et al. [46] showed that a quarter of parents of children with cerebral palsy experience very high stress. However, any approach needs to be based on parents' wishes for support. Future research into the meaning parents ascribe to their experiences regarding actions, challenges, and needs while supporting participation of their child is warranted.

\section{CONCLUSIONS}

Actions, challenges, and needs of Dutch parents' of children with a physical disability are mainly directed towards the social or/and physical environment. The presented thematic framework can offer practitioners knowledge of how to support parents and promotes relevance for future research investigation. With the intention of supporting parents, further work is necessary to supply tailored approaches.

\section{Acknowledgements}

The authors wish to thank all the parents (members of BOSK) for their participation in the study; Mr. Johannes Verheijden (BOSK) for supporting in data-gathering process; Mr. Ramon Daniëls, PhD; Mrs. Sarah Meuser, MSc.; and Mrs. Wencke W.G.P. Emonts, Zuyd University of Applied Sciences for their valuable contributions to this study. 


\section{LITERATURE}

1. Law M: Participation in the occupations of everyday life. American Journal of Occupational Therapy 2002, 56(6):640-649.

2. World Health Organization: International classification of functioning, disability and health. Children and youth version. In. Geneva: World Health Organization; 2007.

3. Piškur B, Daniëls R, Jongmans MJ, Ketelaar M, Smeets RJEM, Norton M, Beurskens AJHM: Participation and social participation: are they distinct concepts? Clinical Rehabilitation 2014, 28(3):211-220.

4. Hilton CL, Crouch MC, Israel H: Out-of-School Participation Patterns in Children With High-Functioning Autism Spectrum Disorders. The American Journal of Occupational Therapy 2008, 62(5):554-563.

5. King GA, Law M, King S, Hurley P, Hanna S, Kertoy M, Rosenbaum P: Measuring children's participation in recreation and leisure activities: Construct validation of the CAPE and PAC. Child: Care, Health and Development 2007, 33(1):28-39.

6. Bult MK, Verschuren O, Gorter JW, Jongmans MJ, Piskur B, Ketelaar M: Cross-cultural validation and psychometric evaluation of the Dutch language version of the Children's Assessment of Participation and Enjoyment (CAPE) in children with and without physical disabilities. Clinical Rehabilitation 2010, 24(9):843-853.

7. Law M, Haight M, Milroy B, Willms D, Stewart D, Rosenbaum P: Environmental factors affecting the occupations of children with physical disabilities. Journal of Occupational Science 1999, 6(3):102-110.

8. King G, Lawm M, King S, Rosenbaum P, Kertoy MK, Young NL: A Conceptual Model of the Factors Affecting the Recreation and Leisure Participation of Children with Disabilities. Physical \& Occupational Therapy In Pediatrics 2003, 23(1):63-90.

9. Lawlor K, Mihaylov S, Welsh B, Jarvis S, Colver A: A qualitative study of the physical, social and attitudinal environments influencing the participation of children with cerebral palsy in northeast England. Pediatr Rehabil 2006, 9(3):219-228.

10. Shikako-Thomas K, Majnemer A, Law M, Lach L: Determinants of Participation in Leisure Activities in Children and Youth with Cerebral Palsy: Systematic Review. Physical \& Occupational Therapy In Pediatrics 2008, 28(2):155-169.

11. Colver AF, Dickinson HO, Parkinson K, Arnaud C, Beckung E, Fauconnier J, Marcelli M, Mcmanus V, Michelsen SI, Parkes J et al: Access of children with cerebral palsy to the physical, social and attitudinal environment they need: a cross-sectional European study. Disability and Rehabilitation 2011, 33(1):28-35.

12. Law M, Anaby D, Teplicky R, Khetani MA, Coster W, Bedell G: Participation in the home environment among children and youth with and without disabilities. The British Journal of Occupational Therapy 2013, 76(2):58-66

13. Turnbull AP, Pereira L, Blue-Banning MJ: Parents' Facilitation of Friendships between Their Children with a Disability and Friends without a Disability. Journal of the Association for Persons with Severe Handicaps 1999, 24(2):85-99.

14. Rosenbaum P, King S, Law M, King G, Evans J: Family-centred service. Phys Occup Ther Pediatr 1998, 18(1):1 - 20.

15. Bailey DB, Raspa M, Fox LC: What Is the Future of Family Outcomes and Family-Centered Services? Topics in Early Childhood Special Education 2012, 31(4):216-223.

16. Seligman M, Darling RB: Ordinary Families, Special Children, Third Edition: A Systems Approach to Childhood Disability 3rd ed. edn. New York: Guilford Publications; 2007.

17. Piškur B, Beurskens AJ, Jongmans $M$, Ketelaar M, Norton M, Frings C, Hemmingsson H, Smeets RJ: Parents' actions, challenges, and needs while enabling participation of children with a physical disability: a scoping review. BMC Pediatrics 2012, 12(1):177. 
18. Thomas M, Hunt A, Hurley M, Robertson S, Carter B: Time-use diaries are acceptable to parents with a disabled preschool child and are helpful in understanding families' daily lives. Child: Care, Health And Development 2011, 37(2):168-174.

19. Zimmerman DH, Wieder L: The Diary: Diary-Interview Method. Urban Life 1977, 5(4):479-489.

20. Meth P: Entries and omissions: using solicited diaries in geographical research. Area 2003, 35(2):195-205.

21. Tong A, Sainsbury P, Craig J: Consolidated criteria for reporting qualitative research (COREQ): a 32-item checklist for interviews and focus groups. International Journal for Quality in Health Care 2007, 19(6):349357.

22. Liamputtong P: Qualitative research methods. Australia \& New Zealand: Oxford University Press 2009.

23. Hsieh H-F, Shannon SE: Three Approaches to Qualitative Content Analysis. Qualitative Health Research 2005, 15(9):1277-1288.

24. Alsem MW, Siebes RC, Gorter JW, Jongmans MJ, Nijhuis BGJ, Ketelaar M: Assessment of family needs in children with physical disabilities: development of a family needs inventory. Child: Care, Health And Development 2013:n/a-n/a.

25. Piškur B, Beurskens AJHM, Jongmans MJ, Ketelaar M, Smeets RJEM: What do parents need to enhance participation of their school-aged child with a physical disability? A cross-sectional study in the Netherlands. Child: Care, Health And Development 2014:n/a-n/a.

26. Elliott $\mathrm{H}$ : The use of diary methods in sociological research on health experience. Sociological Research Online 1997, 2(2).

27. Jacelon CS, Imperio K: Participant Diaries as a Source of Data in Research With Older Adults. Qualitative Health Research 2005, 15(7):991-997.

28. Bendassolli PF: Theory Building in Qualitative Research: Reconsidering the Problem of Induction, vol. 14; 2013.

29. Creswell JW: Research design: Qualitative, quantitative, and mixed methods approaches: Thousand Oaks: Sage; 2009.

30. Potter WJ, Levine-Donnerstein D: Rethinking validity and reliability in content analysis. Journal of Applied Communication Research 1999, 27(3):258-284.

31. Wildemuth BM: Applications of Social Research Methods to Questions in Information and Library Science. Westport, USA: Libraries Unlimited; 2009.

32. Guba E: Criteria for assessing the trustworthiness of naturalistic inquiries. ECTJ 1981, 29(2):75-91.

33. Shenton AK: Strategies for ensuring trustworthiness in qualitative research projects. Education for Information 2004(22):63-75.

34. Reynolds J, Kizito J, Ezumah N, Mangesho P, Allen E, Chandler C: Quality assurance of qualitative research: a review of the discourse. Health Res Policy Sys 2011, 9(1):1-10.

35. Elo S, Kääriäinen M, Kanste O, Pölkki T, Utriainen K, Kyngäs H: Qualitative Content Analysis. SAGE Open 2014, 4(1).

36. Reid A, Imrie H, Brouwer E, Clutton S, Evans J, Russell D, Bartlett D: "If I knew then what I know now": parents' reflections on raising a child with cerebral palsy. Phys Occup TherPediatr 2011, 31(2):169 - 183.

37. Lewis S, Noyes J, Mackereth S: Knowledge and information needs of young people with epilepsy and their parents: Mixed-method systematic review. BMC Pediatr 2010, 10:103.

38. Bedell G, Khetani M, Cousins M, Coster W, Law M: Parent perspectives to inform development of measures of children's participation and environment. Arch Phys Med Rehabil 2011, 92(5):765 - 773.

39. Waal dC, Meurens N: Landenrapport Nederland voor de studie over het beleid van lidstaten inzake kinderen met een handicap In. Brussel: Europese Unie; 2013.

40. Jong dMJ, Exter dAP, Hulst EH: Economische gevolgen van ratificatie van het verdrag handicap In. Rotterdam, The Netherlands: Erasmus School of Economics \& Rasmus Universiteit Rotterdam; 2013.

41. Sleeboom I, Hermanns J, Hermanns V: Meedoen leer je door mee te doen. Een inventarisatie van de wijze waarop in zorg voor kinderen van 0-12 jaar met beperkingen aandacht besteed wordt aan (toekomstige) maatschappelijke participatie. In.: Den Haag: ZonMw/CrossOver; 2010. 
42. Wetenschap MvOCe: Rijksbegroting 2014 VIII Onderwijs, Cultuur en Wetenschap. In., vol. 1. Tweede Kamer der Staten-Generaal; 2014.

43. Almasri NA, Palisano RJ, Dunst CJ, Chiarello LA, O'Neil ME, Polansky M: Determinants of Needs of Families of Children and Youth With Cerebral Palsy. Children's Health Care 2011, 40(2):130-154.

44. Rowbotham M, Carroll A, Cuskelly M: Mothers' and Fathers' Roles in Caring for an Adult Child with an Intellectual Disability. International Journal of Disability, Development and Education 2011, 58(3):223-240.

45. Raina P, O'Donnell M, Rosenbaum P, Brehaut J, Walter SD, Russell D, Swinton M, Zhu B, Wood E: The health and well-being of caregivers of children with cerebral palsy. Pediatrics 2005, 115(6):626-636.

46. Parkes J, Caravale B, Marcelli M, Franco F, Colver A: Parenting stress and children with cerebral palsy: a European cross-sectional survey. Developmental Medicine \& Child Neurology 2011, 53(9):815-821. 



\section{CHAPTER 6}

The lived experience of parents enabling participation of their child with a physical disability at home, at school and in the community

An Interpretative Phenomenological Analysis

Submitted as: Piškur B, Meuser S, Jongmans MJ, Ketelaar M, Smeets RJEM, Casparie BM, Haarsma FA, Beurskens AJHM, The lived experience of parents while enabling participation of their child with a physical disability at home, at school and in the community: An Interpretative Phenomenological Analysis 


\begin{abstract}
Background: Parents of children with a physical disability play a crucial role in supporting their child's participation. To date, some knowledge exists about the kind of actions parents undertake to support their child. However, a deep understanding of what parents do, encounter and what their needs are to enhance participation of their child is scarce. The aim of this study was to provide an in-depth exploration and understanding of parents' thoughts, feelings and concerns they experience while reflecting on their actions, challenges and needs in enabling their child's participation at home, at school and in the community.
\end{abstract}

Methods: A naturalistic inquiry with Interpretative Phenomenological Analysis (IPA) was applied. Thirteen Dutch parents were interviewed using a semi-structured interview guide.

Results: The IPA revealed three super-ordinate themes: "Parents' experiences and concerns about systems, laws, and regulations," "Parents' experiences and thoughts about physical and/or social environment" and "Parents' experiences and feelings of finding and/or enabling an activity." Parents often expressed disappointment regarding the situations in which they were misunderstood, namely about the complexity of systems, about their child's participation being hindered by the social and the physical environment and about the lack of leisure activities for their child. It is primarily restrictions in the physical and social environments that urge them to take actions, to experience challenges and think of needs.

Conclusions: In-depth exploration and understanding of parents' articulated matters must be shared and taken seriously by policymakers and service providers. Parents' knowledge and experiences should be of major relevance to efforts to improve services to provide support to parents to enable their child to participate. 


\section{INTRODUCTION}

Parents are the one constant in their child's life [1], and for most parents caring for a child is an experience full of triumphs and joy as well as challenges and stress [2]. Similar to parents of non-disabled children, parents of a child with a disability play a crucial role in the development of their child. However, providing care and supporting a child with a disability furnish more intensive care that requires a significantly larger amount of time, greater financial stress, more frequent disruption of family routine and reduced social activities outside the family [3-5]. Despite the increased demands of parenting a child with a disability, many families are able to manage life effectively [6].

Participation, defined as being involved in life situations to fulfil social roles [7, 8], has a positive impact on children's health and well-being $[9,10]$. Research shows that children with a physical disability experience restrictions in participation at school, home and in the community [11, 12], feel more socially isolated [13], have fewer friends and decreased opportunities to build relationships compared to children without a physical disability [14].

Varied environmental features, such as accessible or accommodating facilities [15] as well as the support of the social environment, in particular parents, have a major influence on participation of children with a physical disability [16]. Previous studies [4, 17-19] have primarily investigated the impact of having a child with a disability on parents' life (e.g., parental mental health or parent personal stress). Moreover, Lalvani and Polvere [20] point out that research concerning children with a physical disability often takes a more medical perspective and tends to look for negative outcomes or patterns of dysfunction and might therefore not sufficiently represent perspectives of families of children with disabilities $[20,21]$. As parents of children with a physical disability are regarded as vital for their child's participation, understanding the parent's personal experiences and perspectives is fundamental to take further steps in designing better strategies to improve participation.

Steps towards understanding of parents' actions, challenges and needs while enabling their child's participation have been made. A scoping review of the literature on this topic [22] revealed 14 studies that identified several parents' actions, challenges and needs, and underlined how little information is available on what parents actually do every day to enhance their child's participation. A diary study with 47 Dutch parents (Piškur et al., submitted) described parents' efforts to enhance the participation of their child with a physical disability by using, enabling, or changing the social and physical environment, or by supporting their child to perform or engage in meaningful activities. A cross-sectional quantitative study among 146 Dutch parents showed that there is a large variety in the number, domains and priority of needs among parents in supporting participation of their school-aged child with a physical disability; needs are mainly relat- 
ed to environmental aspects at home, school and in the community [23]. These studies, as do others [24-26], illustrate that parents take all kind of actions and experience challenges and needs while enabling participation of their child in all sorts of life situations.

In order to grasp the complexity and get a deeper understanding of parents' daily experiences regarding enhancing their child's participation, exploration of this phenomenon is warranted. As familial matters are embedded in cultural beliefs and values [21], describing, understanding, and interpreting the meaning of parents' daily life experiences can only be reached through naturalistic inquiry. The aim of this study is to provide an in-depth exploration and understanding of parents' thoughts, feelings and concerns they experienced while reflecting on their actions, challenges, and needs in enabling their child's participation at home, at school and in the community.

\section{METHOD}

A naturalistic inquiry with phenomenological design was utilized for this study. More specifically, Interpretative Phenomenological Analysis (IPA) was used [27], considering in-depth exploration of parents' individual experiences as they reflected on their actions, challenges and needs while enabling participation of their child at home, at school and in the community. IPA is theoretically rooted in critical realism $[28,29]$ and the social cognition paradigm $[29,30]$. The method offers insight into a particular perspective on a phenomenon by employing a double hermeneutic, as the researcher attempts to make sense of the ways in which participants make sense of their experiences, whilst acknowledging the impact of his/her own perspective on the analysis [27].

\section{Sample and sampling procedure}

Thirteen participants (see Table 1) were interviewed, all mothers, aged between 32 and 43 years. Potential participants were all members of the Dutch Association of People with Disabilities and their Parents (BOSK), had a child aged between 4 and 12 years with a physical disability that is neurological and non-progressive in nature (e.g., Cerebral palsy, Spina bifida), and who was living at home. For this study, out of 52 families that took part in a cross-sectional study [31] and had shown their interest to participate in future research studies, 15 were contacted by e-mail. The intention was to cover the different geographical regions in the Netherlands; therefore three families in five main Dutch regions (North, West, East, Central, and South) were approached. Those parents received detailed information about the study with the possibility of contacting the researcher in case of remaining questions. A research assistant contacted the first two parents from each region who expressed interest in participating in this study, via tele- 
phone. Additionally, three more parents were approached to attain purposed heterogeneity in the children's age and type of education in the sample.

\section{Data gathering}

The local medical ethics committee (Atrium Medical Centre, Orbis Medical and Healthcare Centre and Zuyd University of Applied Sciences) approved the study protocol (13-N-51). Following receipt of written and verbal information, participants provided written consent for their involvement in the study; they were able to decide freely to withdraw in any stage of the research process. An independent experienced moderator (FAH) conducted the interviews in 2013 in the parents' home environment while at the same time the first author (BP) took field notes and made observations. In order to respect the privacy and give voice to parents, they were asked how they and their child wish to be named in the findings.

Table 1: Participant information

\begin{tabular}{lllllll}
\hline Participant & Role & Age & Region & Child & Age & Type of education \\
\hline 1 & mother & 45 & South & girl & 8 & Mainstream \\
2 & mother & 36 & South & girl & 9 & Special \\
3 & mother & 41 & West & boy & 8.5 & Mainstream \\
4 & mother & 46 & East & girl & 7 & Mainstream \\
5 & mother & 32 & South-East & boy & 5 & Mainstream \\
6 & mother & 44 & Central & boy & 11 & Special \\
7 & mother & 45 & East & boy & 7 & Mainstream \\
8 & mother & 43 & Central & girl & 9 & Mainstream \\
9 & mother & 39 & North-West & boy & 8 & Mainstream \\
10 & mother & 35 & North & girl & 7 & Special \\
11 & mother & 47 & North & boy & 10 & Mainstream \\
12 & mother & 45 & Central & girl & 12 & Mainstream \\
13 & mother & 38 & North & boy & 5 & Mainstream \& Special \\
\hline
\end{tabular}

A semi-structured interview guide, developed according to guidelines provided by Smith et al. [27], included a set of guiding questions served to direct the interview. The guiding questions to provide insight into meanings, thoughts, feelings and concerns were, for example: If you think of a normal day, could you tell me what kind of activities your child is doing? What are you doing yourself when necessary to support the just mentioned activities of your child? Could you tell me about any challenges you might experience while supporting your child at home or at school or in the community? If you think of a possible support, could you tell me something about the kind of support you wish to 
receive while experiencing those challenges as just described? The involvement of a client as a co-researcher $(\mathrm{BC})$ in designing the interview guide was to ensure the appropriateness of the questions. Producing a guide beforehand forces the researchers to explicitly think about what the interview might cover [27]. The interview process was still collaborative, emphasising that the participants were the primary experts [32].

First, a pilot (with two parents of a child with a physical disability) was conducted in order to test for flaws, limitations, or other weaknesses of the interview design. A pilot test should always be conducted with participants who have similar interests to those who will participate in the implemented study [33]. Based on the reflections obtained during the pilot, necessary revisions prior to the implementation of the study were made. In this study, the introductory ice-breaking question was changed.

The interviews lasted between 89 and 127 minutes; they were recorded and transcribed verbatim.

\section{Data analysis}

IPA recommendations guided data analysis [27]. Each transcript line was annotated with a line number and each participant's transcript was colour-coded to aid the analysis process, allowing for easy reference. An idiographic approach used by the first author (BP) followed, focusing on one interview transcript in detail at a time and developing emergent themes before moving on to the next transcript. Each interview transcript was analysed individually, read and re-read until the researcher was immersed in, and familiar with, the content of the data. Initial observations were recorded in the margin and a tracking system was used to code relevant quotations. This process was repeated for all participants. Four interviews were identically analysed by the second author (SM). Debriefing sessions took place to discuss the results of the analysis and to reach consensus. Examples of data from the study, as well as suggested themes, were presented and discussed with all authors. Peer debriefing sessions were organised with two coauthors (SM, BC) to discuss the super-ordinate themes, sub-ordinate themes and their sub-categories.

In this study, Lincoln and Guba's [34-37] four criteria (credibility, transferability, dependability, and confirmability) for evaluating interpretive research work were applied. The first author took the preliminary results back to one of the participants to receive feedback indicating that experiences in the descriptions given were recognized. The 12 other participants in the study did a member check of the summaries of their interviews and provided written feedback. Confirmability has been applied by reporting findings that are solely the result of the experiences and ideas of the participants. Dependability was assured by reporting, in detail, the processes within this study thus, enabling a future researcher to repeat the work. 


\section{RESULTS}

The analysis of the interviews revealed three super-ordinate, and seven sub-ordinate themes with sub-categories portraying parents' experiences described by the meaning of their thoughts, feelings and concerns, illustrated with some examples of actions, challenges or needs. A summary is presented in Table 2.

Super-ordinate theme 1: Parents' experiences and concerns about systems, laws, and regulations

The first super-ordinate theme comprised three sub-ordinate themes: "clashes with the educational system" (Sub-ordinate theme 1.1), "conflicts with administrative procedures and local authorities" (Sub-ordinate theme 1.2) and "struggles with health care professionals" (Sub-ordinate theme 1.3). Within each sub-ordinate theme several subcategories are present.

\section{Sub-ordinate theme 1.1 Clashes with the educational system}

Parents described their experiences as clashes with representatives of the educational system due to (1) differences in perception about the child's abilities, (2) structure, (3) flexibility of the system and (4) professional know-how. In their efforts to enable their child's participation parents reported facing a number of challenges.

All parents explained the intensiveness of the process and their own struggles with making decisions about the right type of education for their child. According to parents, choosing a mainstream school is not an easy decision. Participant 12 gave the following example:

"And then from various people we heard comments like, well, if she can attend a regular school it would be really good because it lays a solid basis for the future. And the special education program (Mytylschool) is, well, it's like a warm cocoon, but afterwards you still have to be able to survive in normal society" (Participant 12).

Parents saw many pitfalls in mainstream education, like peer pressure and the possibility that their child would be bullied. Furthermore, several parents shared that the acceptance of a child with a physical disability in mainstream education is not evident. 
Table 2: Summary of the super-ordinate, sub-ordinate themes and sub-categories

\begin{tabular}{|c|c|c|}
\hline \multirow{3}{*}{$\begin{array}{l}\text { Super-ordinate theme } 1 \text { : } \\
\text { Parents' experiences and concerns } \\
\text { about systems, laws, and regulations }\end{array}$} & \multirow{3}{*}{$\begin{array}{l}\text { Sub-ordinate theme } 1.1 \\
\text { Clashes with the educational } \\
\text { system }\end{array}$} & \multirow{3}{*}{$\begin{array}{l}\text { Differences in perception about the } \\
\text { child's abilities } \\
\text { Structure } \\
\text { Flexibility of the system } \\
\text { Lack of professional "know-how" }\end{array}$} \\
\hline & & \\
\hline & & \\
\hline & Sub-ordinate theme 1.2 & Complexity \\
\hline & Conflicts with administrative & Duration \\
\hline & procedures and local authorities & $\begin{array}{l}\text { Not taking the child's needs into } \\
\text { account }\end{array}$ \\
\hline & & Lack of professional "know-how" \\
\hline & $\begin{array}{l}\text { Sub-ordinate theme } 1.3 \\
\text { Struggles with health care } \\
\text { professionals }\end{array}$ & $\begin{array}{l}\text { No understanding what supports } \\
\text { child's social participation } \\
\text { Deficient in information, } \\
\text { Lack of inter-professional } \\
\text { communication }\end{array}$ \\
\hline Super-ordinate theme 2 : & $\begin{array}{l}\text { Sub-ordinate theme } 2.1 \\
\text { Problems of the physical }\end{array}$ & $\begin{array}{l}\text { Restrictions caused by the physical } \\
\text { environmental }\end{array}$ \\
\hline $\begin{array}{l}\text { Parents' experiences and thoughts } \\
\text { about physical and/or social }\end{array}$ & $\begin{array}{l}\text { environment, available } \\
\text { equipment, aids and clothing }\end{array}$ & $\begin{array}{l}\text { Lack of available equipment, aids } \\
\text { and clothing }\end{array}$ \\
\hline environment & $\begin{array}{l}\text { Sub-ordinate theme } 2.2 \\
\text { Paradox in attitudes of other } \\
\text { people }\end{array}$ & $\begin{array}{l}\text { Discriminatory and negative } \\
\text { attitudes of others }\end{array}$ \\
\hline \multirow[t]{2}{*}{ Super-ordinate theme 3 : } & Sub-ordinate theme 3.1 & Limited choices \\
\hline & Efforts to find a suitable leisure & Lack of adequate information \\
\hline \multirow{5}{*}{$\begin{array}{l}\text { Parents' experiences and feelings of } \\
\text { finding or/and enabling an activity }\end{array}$} & activity & Lack of experiences \\
\hline & & Lack of professional "know-how" \\
\hline & Sub-ordinate theme 3.2 & Educating a child how to apply new \\
\hline & Strategies to promote & strategies \\
\hline & independence and participation & $\begin{array}{l}\text { Providing prompts to support } \\
\text { independence and participation }\end{array}$ \\
\hline
\end{tabular}

Parents mentioned that they went through several complex negotiation processes with school boards to achieve their child's acceptance in mainstream education. Discussions, centred on child abilities, resulted in parents advocating for their child's rights. To convince others, parents sometimes even suggested having their child's IQ tested.

For these parents, requests beyond the usual structure of the system lead to many challenges. Participant 13 spoke very positively about an agreement with the director of a mainstream school and the director of a school for special education about combined education in both schools, considered by all stakeholders to be an optimal solution.

"Because his cognitive skills are just the same as any other child...umm... when he turned four we tried to see if we could set up a combination of both special 
schooling and normal education, and it worked. Yes, we are just so unbelievably happy with this. But this would seem to be ...umm... I would say, something of a unique situation" (Participant 13).

Unfortunately, this part of the conversation ended with less positive news; Participant 13 explained that just a few days before the interview was conducted she heard, according to the law, combined education is not allowed.

Children with a physical disability make use of services, like occupational therapy and physiotherapy. In the eyes of several parents, linking the world of education and these services is hindered by the flexibility of the Dutch system; mainstream education does not allow a child to miss school classes several times a week. Different actions to find solutions were mentioned. One parent explained that they replaced service in a rehabilitation centre with an adequate private service, while another parent chose to include their child in a special education program where all services are available. Several parents expressed a need for flexibility in education, accommodating health care services or a possibility of having a therapist available in mainstream education.

Parents perceived the lack of "know-how" of teachers and teacher assistants in mainstream education as challenging. In their opinion, there is too little anticipation of the needs of their child in the classroom and outside. To illustrate this, Participant 8 said that the teacher lacks the right strategies to support their child, who is excluded and neglected by other children while playing outside during the school-breaks. This family decided to empower their child by doing role-plays at home.

Parents often felt they had a better understanding of the causes of problems than educational staff and consequently were able to propose solutions that worked. Examples parents provided were related to enabling their child during educational activities in the classroom, physical education or activities during a school trip.

"She repeatedly failed the tests. I came to pick her up from school one day and quite by chance she was sitting in the hallway doing a test on the computer. It was then that I saw what was actually happening, because with only one hand, she only has one hand which functions properly, you can't do everything. ...So I wrote another email, like, couldn't it be because of the method used to test her, I think this might be the problem. Well, luckily the next day the teacher teamed her up with a buddy who was allowed to type for her, she only had to say what needed to be typed and she passed straight away!" (Participant 1).

According to parents, teachers' insufficient understanding of what disability means and lack of experiences with children with physical disabilities leads to incorrect interpretations of problems, as for example one parent said: 
"After four years we swapped schools, this was because he got completely stuck...umm...they underestimated him...umm...approached him in the wrong manner. For instance, the material offered was very, very visually orientated, even though he suffers from low vision. This was never fully acknowledged by the school. In the end we sort of investigated and made recordings in the classroom. This revealed more than enough!" (Participant 6).

Parents expressed their wish to have more adequately prepared teachers and teachersassistants during regular classes, during outside play and during school trips. Furthermore, parents talked about having more children with a disability in mainstream education to let other children get used to it and accept differences more easily.

\section{Sub-ordinate theme 1.2 Conflicts with administrative procedures and local authorities}

With the intention of enabling their child's participation, parents experienced conflicts with bureaucratic procedures due to (1) complexity and (2) duration. Parents also struggled with employees of local authorities because of (3) not taking the child's needs into account and (4) lack of professional "know-how."

Parents expressed their belief that procedures for financial support regarding additional equipment, adaptations or resources are deliberately multifaceted. Parents' right for financial support for reimbursement of an assistant at school, for leisure activities or support at home and a so-called personal budget funded by the Exceptional Medical Expenses Act - AWBZ, is perceived by parents as a battle with bureaucratic procedures. These procedures often take a significant amount of time and the complexity requires good investigation skills.

"Yes, in the beginning I, I was sent back and forth and nobody actually wanted to tell me in detail, how and what to do to get the personal budget. Hmmm, ... finally it took more than half a year before I ... could start the application procedure and then still, the whole process was waiting ahead of me, huh, before you get it ... it's like a complex research project (smile)" (Participant 1).

Another parent said it is strategic to invest in personal connections with staff from the local community to be able to understand how bureaucratic procedures work in order to succeed. Participants stressed the need for changing these procedures. Some parents wonder, in view of the fact that even they do not understand how the system works, how this must feel for parents with a foreign background. The need for a coach or clear signposts was expressed. 
According to parents, the bureaucratic system does not take the child's needs well enough into account. Participant 3 noted that the allowed frequency of getting, for example, a new foot-splint is fixed no matter how fast a child develops. This participant expressed a need for having flexible rules and regulations that better fit the child's needs.

With astonishment, parents spoke about the amount of time procedures take in the Netherlands from application to receiving a new piece of equipment. For example, it takes roughly a year to get a new wheelchair or half a year to get a three-wheeler. Parents described undertaking several actions, like negotiating with different authorities by phone or face-to-face, to accelerate the procedure. Procedures actually can take so long that, as children grow, the equipment does not fit anymore by the time it arrives.

Parents talked about their conflicts with people working for local authorities and being responsible for decisions about adaptations and aids due to lack of "know-how." Participant 10 became very emotional about her experience:

"He said to us... we can't do much with a house that's hard to manoeuvre in...and...well...I don't know if there is even any point in doing anything at all because...umm...in a few years your child will only be capable of lying down..." (Participant 10).

Parents felt actions to improve these situations were needed. Participant 10 wrote a complaint to the local authorities about the lack of professional attitude of one of their employees. Another participant (3) even suggested that having a non-cooperative attitude might be part of their education and training.

Participants stressed that professionals working at local authorities responsible for the bureaucratic procedures often lack necessary "know-how" and understanding of what a disability is. Participant 11 explained the reason for not getting a disabled parking permit was a note in the child's record saying he is able to walk:

"My son can walk, so of course he won't be getting a disabled parking permit .../laughs/...well, so we explained,... we really would like to have the disabled parking permit, because he could walk, but for short distances only, and to ensure that he keeps walking, not having to rely on the wheelchair everywhere" (Participant 11).

Parents mentioned initiating different actions to get the support they requested. For example, parents educated the employees of the local authority about the meaning of having a disability for their child's participation or they appeal decisions. 


\section{Sub-ordinate theme 1.3 Struggles with health care professionals}

All participating parents had experienced struggles with health care professionals who do (1) not have an understanding what supports their child's social participation, (2) are deficient in providing information, or (3) demonstrate lack of inter-professional communication.

Participant 10 experienced a lack of understanding and insight by health care professionals about her child's functioning in a real context:

"I wish they could see what it's like to drive with my daughter in the car or to play at the playground...and then give me an advice" (Participant 10).

Currently, most children receive physiotherapy, speech therapy or occupational therapy in the rehabilitation centre or primary care clinic. The majority of the participants were wondering how practicing in the simulated environment of the institution is beneficial for their child's participation at home or elsewhere. Parents also mentioned that their child does not like practicing without any meaning; in parents' opinion those exercises are difficult to transfer to daily life situations:

"But at home I'm not going to say, like,...hmm...from now on you've got to train for one hour every day, that doesn't get you anywhere. She's not a machine you can program, that's not how it works, so..." (Participant 4).

The above-mentioned struggles generated different types of actions, as described by several parents. Some parents adapted the exercises into a meaningful activity for the child, while others did not exercise at all. In order to support their child in daily life, parents wish therapy would take place at home, at school and in leisure situations.

The quality of information received from health care professionals about supporting their child at home or elsewhere is seen as insufficient; information either was not specific enough to their child's situation or had little relation to enabling the child's daily activities. Furthermore, parents missed tips on where to find additional information.

"Yes, from my point of view, for instance, a doctor could easily have referred us to the Dutch Association of People with Disabilities and their Parents (BOSK) and that through BOSK, as I found out later; there is lots of information to be found. Hmm, that there is more of...umm...yes, a sort of, some sort of a central point you can go to with your questions. That's what I would like to see" (Participant 5). 
As a result of those challenges, parents described various actions undertaken to find information. Most often, information was derived from other parents in similar situations or through the internet. Participant 11 explained that she collected information on the internet before meeting her physiotherapist. She then informed him about a dynamic arm brace resulting in better arm use during several activities, like playing hockey.

Furthermore, participants explained that health care professionals do not sufficiently communicate with each other. Participant 5 gave an example that each time she meets another member of the team she needs to clarify the same things about her child over and over again. Parents expressed a need for improved communication and documentation between professionals.

"Well, you know, in general I'm not really happy with the rehabilitation doctors we have...Now, for example, take these splints, well then yeah, if he (the specialist) takes a look he always says, 'ohh those splints are no good for your son,' but what about the other rehabilitation doctors, they have never said anything about them" (Participant 11).

The same participant continued saying that their child, while wearing a splint, was not able to engage in several activities, like playing hockey.

Parents expressed, based on those challenges, their wish that therapy would take place in a real context. According to them, this could overcome misunderstandings between professionals and families. Further, they need professionals to keep in mind the participation of their child in daily life whilst engaging in deliberations.

\section{Super-ordinate theme 2: Parents' experiences and thoughts about physical and/or social environments}

The second super-ordinate theme comprised two sub-ordinate themes: "Problems of the physical environment, available equipment, aids and clothing" (Sub-ordinate theme 2.1) and "Paradox in attitudes of other people" (Sub-ordinate theme 2.2). Within each sub-ordinate theme several sub-categories were exposed.

\section{Sub-ordinate theme 2.1 Problems of the physical environment, available equipment, aids and clothing}

Parents described experiencing (1) restrictions caused by the physical environment, and (2) lack of available equipment, aids and clothing due to differences in parent's perceptions about their child's abilities, needs and wishes and what the environment has to offer. 
Several parents, some very worried, described a mismatch between what is needed for their child to participate in mainstream education and the actual school environment. Inaccessible entrances, stairs or suitable furniture and shoes were the most often named challenges. For instance, some children with a physical disability are provided with an electric wheelchair to sustain their mobility at home or elsewhere. However, electric wheelchairs can be a major challenge at school due to entrances, space in the classroom and stairs. As such, it creates many dangerous situations for everybody. Participant 12 with the feeling of being powerless in changing the school environment, explained that they - she and her husband - decided to replace an expensive electric wheelchair with an ordinary office chair at school.

Parents also explained that they take actions themselves to overcome these kinds of environmental barriers. For example, parents made an adaptation to the school entrance for wheelchair users, adapted the table height, or made an arm support that enabled their child to sit adequately in the classroom. All parents expressed an urgent need to change the school environment into an accessible place for everyone. Similar challenges have been described for public places such as entering a dressing room in a shop or a public toilet with a wheelchair.

Finding adequate equipment and aids like bicycles, beds, shoes or splints is perceived as challenging. Even specialised stores only offer limited choices. For example:

"He attends a regular school, and all of the children have a certain style of bike, because at the moment this is fancy and trendy; my son also wants such a bicycle... There was no deal in a special shop; I had to search for it on the internet myself and you know what?; this bicycle also exists as a three-wheeler. Nobody in this special store said so" (Participant 3).

This participant pointed out that the design of equipment and aids should not be stigmatising to a child with a disability.

Several participants illustrated that they were forced to find solutions themselves, like to design an aid for moving-around (Participant 6) or a special bed (Participant 10). Lack of choices was also experienced while looking for appropriate clothes and shoes. Participant 9 gives an example:

"At first he had orthopaedic shoes, but there is absolutely no choice, just one model....umm...so now I buy two pairs of shoes in two different sizes and occasionally a shoe store will give a $10 \%$ discount on the second pair."

Searching for information on the internet is a common action described by parents seeking equipment and aids. Participant 3 found a store in the United States of America 
on the internet selling exactly the same arm-splint as offered in the Dutch special store, however, with many more choices of colours and designs. Gathering information from their private social network and collecting ideas from other parents with similar experiences are other often-mentioned actions taken by parents:

"Right, and then you've got, we have, you could say, umm, other people's experiences...you can build on these, but if you don't have that you have no idea that it exists. For instance, we have now ordered one of those toilets with a posterior wash and blow dryer. Well yes, we first saw this at somebody else's place" (Participant 2).

Several parents expressed the need for tailored, easy accessible quality information and more choices in specialised stores with attention to the child's personal wishes and needs.

\section{Sub-ordinate theme 2.2 Paradox in attitudes of other people}

All participants described situations in which they experienced (1) discriminatory and negative attitudes of others that influenced their child's participation in daily life situations. All parents expressed feelings of frustration and pain. Sometimes awkward situations occurred as other people judge without understanding, as an example of Participant 8 demonstrates:

"Yes well, take the "Hema" [a Dutch retail shop] for instance, they have a wide staircase and normally speaking you would walk up the stairs on the right and down on the right. But her right side is her difficult side so she climbs the stairs on the left. An older person, who also walks with difficulty, could, for instance, come down the stairs on the right. The look that follows clearly says "move over why don't you," like, "why are you going against the flow." Then I think, well she also has difficulty walking. These are just the really awkward things, the times that you think; if I were an elderly, widowed woman I would also think "well, come on." Yes, these are the things you have to face in, yes especially in, the outside world."

Participant 2 expressed that they often get negative remarks while using a special parking place for people with disabilities; it seems others do not recognize their child as having a disability. Different examples were given regarding professionals having negative attitudes towards their child with a disability. This is illustrated by the following quote: 
"They had a letter, one which I was not supposed to receive as it was meant for internal use only, all sorts of things were written in it, umm Jens is umm, it was written, a little bit of a strange lad, that's how it was written in the letter...very painful" (Participant 3).

Many parents had thoughts and wishes about a less discriminatory and less negative society, and wished for more sensitive professionals.

\section{Super-ordinate theme 3: Parents' experiences and feelings of finding and/or enabling an activity}

The third super-ordinate theme comprised two sub-ordinate themes: "Efforts to find a suitable leisure activity" (Sub-ordinate theme 3.1) and "Strategies to promote independence and participation" (Sub-ordinate theme 3.2). Within each sub-ordinate theme several sub-categories were revealed.

\section{Sub-ordinate theme 3.1 Efforts to find a suitable leisure activity}

Parents described their efforts to find suitable leisure activities for their child as intensive; a consequence of (1) limited choices, (2) lack of adequate information, (3) lack of experiences and (4) lack of professional "know-how."

With a hint of frustration, all participants mentioned a restriction in opportunities to join leisure activities for a child with a physical disability. Participant 7 experienced finding appropriate swimming lessons to be a big challenge; swimming lessons with specialised trainers are very expensive and mostly scheduled late in the evening.

According to the parents, health care professionals hardly provide information about suitable leisure activities. Moreover, parents stressed that often professionals perceive a leisure activity as an additional therapy instead of something a child wants to do to have fun with other children. As Participant 6 explained:

"Well now, horse riding is actually a suggestion made by the physiotherapist at the time, he said it would be good for him, for his sense of balance as well as a being a form of relaxation,...umm...for his muscles.... And the scouts, they do all sorts of things, everything to do with being a scout... And my son enjoys being outside and partaking in all of sorts of wild and dangerous games etc., yeah, he really enjoys it, and it; it is a part of who he is. And we enjoyed it too, because at the scouts he is part of a group and with his horse riding he is doing something as an individual. We, well, considered this important in respect to his social development." 
Situations as described above stimulated parents taking actions, like asking parents with similar experiences for advice through social media. Furthermore, parents also advocated for their child in sport clubs or looked for a person with experience in working with children with a disability. Participant 7 notes:

"And then we decided to take a further look into judo. I googled a few clubs and turns out that the guy giving the judo lessens is also a movement therapist at our rehabilitation centre, never knew that; yep, you've got to have a bit of luck and know how to meet the right people."

A lack of experiences and professional "know-how" in sport centres is also perceived as a challenge. Parents experienced sport educators' lack of knowledge on how to explain an activity to children and in how to support a child with a physical disability in connecting with other children.

"This has been a pretty traumatic, long journey. All of this didn't fit or it was more like yeah, no, no, we can't do that, this is too difficult for us, huh. Of course, all too often they think like, 'oh, not a person with a disability' " (Participant 1).

With the intention of including their child in a leisure activity different actions were described; parents joined an activity to support their child, they provided the instructor with additional information or they became an instructor themselves.

\section{Sub-ordinate theme 3.2 Strategies to promote independence and participation}

Throughout the interviews parents reflected on the strategies they use to support or improve their child's participation at home or at school. This included (1) educating a child about how to apply new strategies during an activity or (2) providing prompts to support independence and participation.

Participant 2 proudly described that she found pictograms on the internet to enable her child at school; she taught her child to communicate more effectively using pictograms. Participant 2 further described that she taught her child to use pictograms in combination with written language. Another parent (Participant 1) shared her positive experiences with pictograms to enable independence while taking a shower at home; pictograms on the wall in the bathroom showed the sequence of showering. Pictograms were also used to understand the structure of the day as described by Participant 9: 
"Here we have, a shopping list I call it, on the door in the /coughs/ sorry. At a certain point I hung up pictograms for all three of my children (no differentiation there ha-ha) showing the tasks they each had to perform every day. These included putting on their shoes, packing a bag, brushing teeth, combing hair. It's all on there and it works, otherwise I would be forever on the go."

In order to increase their child's participation at home, parents described that using verbal strategies helped their child to become independent, like asking a child before going to take a shower to prepare everything needed. Furthermore, alternative strategies to support communication were mentioned. One parent (Participant 10) used different smells to give prompts for starting a new activity, like lemongrass means that they are going out by car. Participant 9 showed a prototype of their new house made of wood; in this way they were able to explain what the new house will look like and to enable their child to think with them about how his room should look.

\section{DISCUSSION}

The aim of this study was to provide an in-depth exploration and understanding of parents' thoughts, feelings and concerns they experienced while reflecting on their actions, challenges, and needs in enabling their child's participation at home, at school and in the community.

The analysis revealed 3 super-ordinate, and 7 sub-ordinate themes with subcategories. Findings mainly illustrated parents' disappointments related to their interactions on different societal levels while reflecting on their actions, challenges and needs. Their feelings and thoughts of being misunderstood, about dealing with complex systems, and about participation of their child being hindered by the social and the physical environment motivated them to take actions, and express needs and wishes. In the eyes of parents, especially situations in which professionals and authorities lack understanding of the life of a child with a disability, lack of understanding of needs of children to participate, and misunderstanding the experience and expertise of the parents, pushes them to take action. Moreover, parents showed their worries and efforts to find appropriate leisure activities and described their strategies to enable independence in activities at home or at school.

The findings of this study seem to be comparable to results from studies in other cultural contexts; barriers in physical and social environments, negative attitudes of other people, fear of bullying and lack of knowledge by professionals are examples of parents' challenges [25, 38-42]. Slade et al., [43] reported that across the United Kingdom, parents of children with a physical disability experience lack of information, lack of knowledge, and lack of involvement in decision making when dealing with professionals 
(treatment, care and support) prompting them to adopt a pro-active approach. Salminen and Karhula [44], in their review study, concluded that environmental interventions may be even more crucial to support participation, than interventions directed to child abilities.

Findings in our previous work ([31], Piškur et al., submitted), other Dutch studies and policy reports support the findings of this study. The Netherlands has laws and regulations to support children with a disability to participate in society. However, Sleeboom et al., [45] conclude that the difficulty to fully understand these laws and regulations often leads to the question of whether or not they optimally support participation of children with a disability. Parents in this study experienced similar obstacles within the systems, laws, and regulations.

At the moment, the Dutch school system is in reform; in August 2014 the new Law of Inclusive Education and Opportunities for all children to be included in mainstream education was launched [46]. De Boer [47] demonstrated that Dutch parents of children with a disability feel positively about these changes although they also expressed worries about the attitudes of peers towards their child. Parents in this study were concerned about the lack of knowledge teachers have in mainstream education to support their child's educational activities. An enquiry by the Dutch national public advocate [48] revealed that teachers lack information about the disabilities of their students and ways to support them.

Furthermore, in the Netherlands, free accessibility to public buildings and places for all citizens was not included in the Equal Opportunities Act. This means there is no obligation to guarantee access for persons with a disability [49]. De Jong et al., [50] found that only $29 \%$ of people with a severe physical disability in the Netherlands can enter shops. In this study, parents expressed that accessibility of schools and public buildings cause participation restrictions. The Netherlands also has no specific regulations for leisure and sports clubs concerning children with a disability [45]. Parents in this study stressed that finding an appropriate leisure activity is a "pretty traumatic, long journey" due to limited choices, lack of adequate information and sport educators' lack of experience and professional "know-how" concerning their children.

Thirteen parents participated in the current study. This number can be seen as a possible limitation; however, the general aim of the IPA approach is to gather rich information and to explore in-depth individual experiences with a small sample [51]. A second limitation might be the researchers' prior knowledge having an influence on data analysis. Two authors involved in data analysis have prior experiences and knowledge in this field (as described under 'Authors' information') and one co-author is a parent of a child with a physical disability. However, all the methodological recommendations have been followed and the data analysis has been done according to the IPA protocol as described by Smith \& Osborn [27] to ensure the credibility of the analyt- 
ic process. Finally, there is a possibility, taking the many negative experiences into account, that the data sampling procedure attracted only the most disillusioned parents. However, triangulation with literature from the Netherlands and other international studies showed that these findings do not stand alone.

The parents in this study seemed to be very aware of the influence of the environment on participation of their child with a physical disability. Social-ecological perspectives $[52,53]$, like Bronfenbrenner's theory, underlined the importance of interaction among and within systems at different levels and its influence on child development $[54,55]$. Most studies on environment and child development conducted so far are, however, with respect to family and parenting processes rather than any other environmental components [56]. Investigating parents' reflection on their actions, challenges, and needs in enabling their child's participation did not aim to evaluate systems and services, but rather to more deeply understand what makes parents take actions in enabling their child's participation. Among their examples are many negative experiences with environmental support. From a sociological perspective [57], this might point to a conflict between the 'life-world' and the 'system world'. The life-world is the informal world of the street and the community; the system-world is the world of rules and protocols, often driven by economic interests and power. Shifting processes and decision making from the system world to the life world is a current issue in the implementation of the Dutch Social Support Act with the municipal authorities having the responsibility to promote participation in society for those who need it [58], including children with a physical disability. Dutch policy puts much emphasis on a civil society, pointing out the importance of local tailor-made solutions, empowerment and involvement of citizens and a facilitating municipality [59]. Parents in this study expressed that their actions are not something additional, but very vital for their child to be able to be part of society. Enhancing participation for children with a physical disability could benefit from acknowledging and learning from these parents' thoughts, feelings and concerns, gathered through their experiences and expertise, and could provide a starting point for finding ways for cooperation on an equal level.

Therefore, future studies ought to focus on ways to involve parents in policymaking, quality improvement of services and learning from their experiences. Furthermore, there is a need for studies focusing on the influence of different environments, other than parents, on enabling children's participation. Last, it is recommended that similar studies on exploring parents' actions, challenges and needs in other cultural contexts be conducted. 


\section{CONCLUSIONS}

In-depth exploration and understanding of parents' articulated matters regarding different environmental features and their impact on their child's participation are reported in this study. Parents' thoughts, while reflecting on their actions, challenges and needs to enhance participation for their child with a physical disability, are primarily focused on their interactions on different societal levels. Feelings of disappointment deriving from being misunderstood, from dealing with the complexity of systems, and from hindrance of participation of their children by the social and the physical environment urged them to take actions, and think of their needs and wishes. Their unique perspective on those matters must be shared and taken seriously by policymakers and service providers. Parents' knowledge and experiences should be of major relevance to help improve services to support parents seeking to enable their child's participation at home, at school and in the community.

\section{Funding}

Zuyd University of Applied Sciences and Maastricht University financially supported this research study.

\section{Acknowledgements}

The authors wish to thank all the parents (members of BOSK) for their participation in the study; Mr. Johannes Verheijden (BOSK), Mrs. Helen HJ Korpel and Dr. Ramon Daniëls, Zuyd University of Applied Sciences, for their valuable contribution to this study. 


\section{LITERATURE}

1. Austin JF: The Role of Parents as Advocates for the Transition Rights of Their Disabled Youth. Disability Studies Quarterly 2000, 20(4).

2. Resch JA, Mireles G, Benz MR, Grenwelge C, Peterson R, Zhang D: Giving parents a voice: A qualitative study of the challenges experienced by parents of children with disabilities. Rehabilitation Psychology 2010, 55(2):139-150.

3. LaPlante MP: Families with Disabilities in the United States. Disability Statistics Report 8. In. California Univ, San Francisco Inst for Health Aging, 1996.

4. Parkes J, Caravale B, Marcelli M, Franco F, Colver A: Parenting stress and children with cerebral palsy: a European cross-sectional survey. Developmental Medicine \& Child Neurology 2011, 53(9):815-821.

5. Hatzmann J, Maurice-Stam H, Heymans H, Grootenhuis M: A predictive model of Health Related Quality of life of parents of chronically ill children: the importance of care-dependency of their child and their support system. Health and Quality of Life Outcomes 2009, 7(1):72.

6. Scorgie K, Wilgosh L, Sobsey D: The Experience of Transformation in Parents of Children with Disabilities: Theoretical Considerations. Developmental Disabilities Bulletin 2004, 32(1):84-110.

7. Piškur B, Daniëls R, Jongmans MJ, Ketelaar M, Smeets RJEM, Norton M, Beurskens AJHM: Participation and social participation: are they distinct concepts? Clinical Rehabilitation 2014, 28(3):211-220.

8. World Health Organization: Geneva: World Health Organization; 2007.

9. Law M: Participation in the occupations of everyday life. Am J Occup Ther 2002, 56(6):640 - 649.

10. Dahan-Oliel N, Shikako-Thomas K, Majnemer A: Quality of life and leisure participation in children with neurodevelopmental disabilities: a thematic analysis of the literature. Quality of Life Research 2012, 21(3):427-439.

11. Imms C, Reilly S, Carlin J, Dodd K: Diversity of participation in children with cerebral palsy. Dev Med Child Neurol 2008, 50(5):363 - 369.

12. Bult M, Verschuren O, Gorter J, Jongmans M, Piskur B, Ketelaar M: Cross-cultural validation and psychometric evaluation of the Dutch language version of the Children's Assessment of Participation and Enjoyment (CAPE) in children with and without physical disabilities. Clin Rehabil 2010, 24(9):843 - 853.

13. Shikako-Thomas K, Majnemer A, Law M, Lach L: Determinants of Participation in Leisure Activities in Children and Youth with Cerebral Palsy: Systematic Review. Physical \& Occupational Therapy In Pediatrics 2008, 28(2):155-169.

14. Frostad P, Pijl S: Does being friendly help in making friends? The relation between the social position and social skills of pupils with special needs in mainstream education. Eur J Spec Needs Educ 2007, 22(1):15 30.

15. Welsh B, Jarvis S, Hammal D, Colver A: How might districts identify local barriers to participation for children with cerebral palsy? Public Health 2006, 120(2):167 - 175.

16. Turnbull A, Pereira L, Blue-Banning M: Parents' facilitation of friendships between their children with a disability and friends without a disability. J Assoc Persons Severe Handicaps 1999, 24(2):85 - 99.

17. Hung J, Wu Y, Chiang Y, Wu W, Yeh C: Mental health of parents having children with physical disabilities. Chang Gung Med J 2010, 33(1):82-91.

18. Ketelaar M, Volman MJM, Gorter JW, Vermeer A: Stress in parents of children with cerebral palsy: what sources of stress are we talking about? Child: Care, Health and Development 2008, 34(6):825-829.

19. Skok A, Harvey D, Reddihough D: Perceived stress, perceived social support, and wellbeing among mothers of school-aged children with cerebral palsy. Journal of Intellectual and Developmental Disability 2006, 31(1):53-57.

20. Lalvani P, Polvere L: Historical perspectives on studying families of children with disabilities: A case for critical research Disability Studies Quarterly 2013, 33(3). 
21. Ferguson PM: A Place in the Family: An Historical Interpretation of Research on Parental Reactions to Having a Child with a Disability, Journal of Special Education 2002, 36 (3).

22. Piškur B, Beurskens AJ, Jongmans $M$, Ketelaar $M$, Norton M, Frings $C$, Hemmingsson $H$, Smeets RJ: Parents' actions, challenges, and needs while enabling participation of children with a physical disability: a scoping review. BMC Pediatrics 2012, 12(1):177.

23. Piškur B, Beurskens AJHM, Jongmans MJ, Ketelaar M, Smeets RJEM: What do parents need to enhance participation of their school-aged child with a physical disability? A cross-sectional study in the Netherlands. Child: Care, Health and Development 2015, 41(1):84-92.

24. Lawlor K, Mihaylov S, Welsh B, Jarvis S, Colver A: A qualitative study of the physical, social and attitudinal environments influencing the participation of children with cerebral palsy in northeast England. Pediatr Rehabil 2006, 9(3):219-228.

25. Missiuna C, Moll S, Law M, King S, King G: Mysteries and mazes: Parents' experiences of children with developmental coordination disorder. Canadian J Occup Ther 2006, 73(1):7 - 17.

26. Vogts N, Mackey A, Ameratunga S, Stott N: Parent-perceived barriers to participation in children and adolescents with cerebral palsy. J Paediatr Child Health 2010, 46(11):680 - 685.

27. Smith JA, Flowers $P$, Larkin M: Interpretative Phenomenological Analysis: Theory, Method and Research. London: SAGE; 2009.

28. Bhaskar R: A Realist Theory of Science. Oxon: Routledge; 2008.

29. Fade S: Using interpretative phenomenological analysis for public health nutrition and dietetic research: a practical guide. Proceedings of the Nutrition Society 2004, 63(04):647-653.

30. Fiske ST, Taylor SE: Social Cognition, 2 edn. New York: McGraw-Hill; 1991.

31. Piškur B, Beurskens AJHM, Jongmans MJ, Ketelaar M, Smeets RJEM: What do parents need to enhance participation of their school-aged child with a physical disability? A cross-sectional study in the Netherlands. Child: Care, Health And Development 2014:n/a-n/a.

32. Brocki JM, Wearden AJ: A critical evaluation of the use of interpretative phenomenological analysis (IPA) in health psychology. Psychology \& Health 2006, 21(1):87-108.

33. Kvale S: InterViews: An Introduction to Qualitative Research Interviewing London, UK: SAGE; 1996.

34. Guba E: Criteria for assessing the trustworthiness of naturalistic inquiries. ECTJ 1981, 29(2):75-91.

35. Shenton AK: Strategies for ensuring trustworthiness in qualitative research projects. Education for Information 2004(22):63-75.

36. Reynolds J, Kizito J, Ezumah N, Mangesho P, Allen E, Chandler C: Quality assurance of qualitative research: a review of the discourse. Health Res Policy Sys 2011, 9(1):1-10.

37. Rodham K, Fox F, Doran N: Exploring analytical trustworthiness and the process of reaching consensus in interpretative phenomenological analysis: lost in transcription. International Journal of Social Research Methodology 2013:1-13.

38. Bedell G, Dumas H: Social participation of children and youth with acquired brain injuries discharged from inpatient rehabilitation: A follow-up study. Brain Inj 2004, 18(1):65 - 82.

39. Segal R, Mandich A, Polatajko H, Valiant Cook J: Stigma and its management: A pilot study of parental perceptions of the experiences of children with developmental coordination disorder. Am J Occup Ther 2002, 56(4):422 - 428 .

40. Colver A: Study protocol: SPARCLE--a multi-centre European study of the relationship of environment to participation and quality of life in children with cerebral palsy. BMC Public Health 2006, 6:105.

41. Mandich AD, Polatajko HJ, Rodger S: Rites of passage: Understanding participation of children with developmental coordination disorder. Human Movement Science 2003, 22(4-5):583-595.

42. Majnemer A, Shevell M, Law M, Birnbaum R, Chilingaryan G, Rosenbaum P, Poulin C: Participation and enjoyment of leisure activities in school-aged children with cerebral palsy. Developmental Medicine \& Child Neurology 2008, 50(10):751-758.

43. Slade Z, Coulter A, Joyce L: Parental Experience of Services for Disabled Children: Research Report DCSFRR147. In.: Department for children, schools and families; 2009. 
44. Salminen A-L, Karhula ME: Young persons with visual impairment: Challenges of participation. Scandinavian Journal of Occupational Therapy 2014, 21(4):267-276.

45. Sleeboom I, Hermanns J, Hermanns V: Meedoen leer je door mee te doen. Een inventarisatie van de wijze waarop in zorg voor kinderen van 0-12 jaar met beperkingen aandacht besteed wordt aan (toekomstige) maatschappelijke participatie. In.: Den Haag: ZonMw/CrossOver; 2010.

46. Rijksoverheid: Passend onderwijs: Derde voortgangsrapportage december 2013. In. Edited by Ministerie van Onderwijs CeW. Den Haag; 2013.

47. Boer de AA: Inclusie: een kwestie van attitudes? Onderzoek naar de acceptatie van leerlingen met leerlinggebonden financiering in het reguliere basisonderwijs. In. Groningen: Stichting Kinderstudies; 2012.

48. Ombudsman D: In Gesprek: Onderzoek naar de positie van ouders van kinderen met extra ondersteuningsbehoefte op school. In. Hilversum: Stichting De Ombudsman; 2012.

49. Waal dC, Meurens N: Landenrapport Nederland voor de studie over het beleid van lidstaten inzake kinderen met een handicap In. Brussel: Europese Unie; 2013.

50. Jong de JM, Exter den AP, Hulst EH: Economische gevolgen van ratificatie van het verdrag handicap In. Rotterdam: SEOR, Erasmus Universiteit Rotterdam; 2013.

51. Hale ED, Treharne GJ, Kitas GD: Qualitative methodologies II: a brief guide to applying interpretative phenomenological analysis in musculoskeletal care. Musculoskeletal Care 2008, 6(2):86-96.

52. Bronfenbrenner U, Morris PA: The Bioecological Model of Human Development. In: Handbook of child psychology (6th ed): Vol 1, Theoretical models of human development. edn. Edited by Lerner RM, Damon W. Hoboken, NJ US: John Wiley \& Sons Inc; 2006: 793-828.

53. Ungar M, Ghazinour M, Richter J: Annual research review: What is resilience within the social ecology of human development? Journal of Child Psychology and Psychiatry 2013, 54(4):348-366.

54. Derksen T: The Influence of Ecological Theory in Child and Youth Care: A Review of the Literature. International Journal of Child, Youth and Family Studies 2010, 1(3/4).

55. Faust V, Jasper CR, Kaufman A, Nellis MJ: Cooperative Inquiry in Human Ecology: Historical Roots and Future Applications. Family \& Consumer Sciences Research Journal 2014, 42(3):267-277.

56. Bornstein MH: Handbook of Parenting, vol. 5, 2 edn. Mahwah, New Jersey: Lawrence Erlbaum Associates; 2002.

57. Habermas J: Actions, speech acts, linguistically mediated interactions and the lifeworld. In: Philosophical Problems Today / Problèmes Philosophiques d'Aujourd'hui. Volume 1, edn. Edited by Fløistad G: Springer Netherlands; 1994: 45-74.

58. Stam M, Jansen D, Jong de C, Räkers M: Outreachend besturen in tijden van transitie. In.: MOVISIE; 2012.

59. Metz J: Anatomisch model van de civil society voor de WMO. Journal of Social Intervention: Theory and Practice 2008, 17(3). 


\section{CHAPTER 7}

\section{Summary and general discussion}

In this chapter, the summary and the main findings of this thesis are presented, followed by a general discussion of the thesis. 



\section{SUMMARY AND MAIN FINDINGS OF THE THESIS}

Parental involvement is a crucial force in children's development, learning and success at school and in life [1]. Participation, defined by the World Health Organization as ' $a$ person's involvement in life situations' [2] for children means involvement in everyday activities, such as recreational, leisure, school and household activities [3]. Several authors use the term social participation emphasising the importance of engagement in social situations $[4,5]$.

Children's participation in daily life is vital for healthy development, social and physical competencies, social-emotional well-being, sense of meaning and purpose in life [6]. Through participation in different social contexts, children gather the knowledge and skills needed to interact, play, work, and live with other people $[4,7,8]$. Unfortunately, research shows that children with a physical disability are at risk of lower participation in everyday activities [9]; they participate less frequently in almost all activities compared with children without physical disabilities [10, 11], have fewer friends and often feel socially isolated [12-14].

Parents, in particular, positively influence the participation of their children with a physical disability at school, at home and in the community [15]. They undertake many actions to improve their child's participation in daily life $[15,16]$. However, little information is available about what parents of children with a physical disability do to enable their child's participation, what they come across and what kind of needs they have.

The overall aim of this thesis was to investigate parents' actions, challenges, and needs while enhancing the participation of their school-aged child with a physical disability.

In order to achieve this aim, two steps have been made. In the first step, the literature has been examined to explore the topic of this thesis (actions, challenges and needs) and to clarify definitions for the concepts of participation and social participation. Second, for the purposes of giving breadth and depth of understanding of the topic of this thesis a mixed methods approach using three different empirical research methods [17-19], was applied to gather information from parents regarding their actions, challenges and needs.

This thesis consists of the following studies and research questions:

\section{Part I - literature inquiry}

\section{Scoping review}

What is known from the scientific literature about parents' actions, challenges, and needs while enabling participation of their children with a physical disability? 
Discussion paper

Are participation and social participation distinct concepts?

\section{Part II - mixed methods inquiry}

\section{Survey study}

What are the number, domains and priority of needs as expressed by parents in supporting the participation of their children with a physical disability?

Does the number of needs within each domain relate to the child's gross motor function level, parent's perceived own general health, family socio-economic status and family type?

\section{Diary study}

How do parents of children with a physical disability describe their daily actions, challenges, and needs while supporting their child with a physical disability at home, at school, and in the community?

\section{Phenomenological study}

How do parents of children with a physical disability express their thoughts, feelings and concerns as they reflect on their actions, challenges and needs while enabling their children's participation at home, at school and in the community?

The main findings of this thesis in Part I give an overview of the literature inquiry on parents' actions challenges and needs and a critical exploration of the concepts of participation and social participation.

The scoping review into parents' actions, challenges and needs is presented in Chapter 2. This review shows that parents apply a broad range of strategies to support the participation of their child. They experience many challenges, especially as a result of constraints in social and physical environments. Results are presented in a preliminary thematic framework including two major themes: (1) parents enable and support performance of meaningful activities; and (2) parents enable, change and use the environment. The most cited actions are 'choosing for' meaningful activities for their child, 'advocating' for the child, 'educating' the social environment, and 'networking' with other people. Further, in supporting participation, parents often face challenges in the environment such as 'attitudes of other people', 'insufficient system support', and 'barriers in both natural and built environments'. However, this review also displayed that little is known about the needs of parents in facilitating participation.

The International Classification of Functioning, Disability and Health (ICF) definition of participation has been much quoted, but has also been criticised in the literature [20- 
23]. Authors have frequently been using the concept of social participation interchangeably with participation $[24,25]$. As participation is one of the central concepts of this thesis, a thorough discussion about the concepts of participation and social participation is presented in Chapter 3. The central question in this discussion paper was whether participation, as defined by the ICF, and social participation are distinct concepts. As a result, we concluded that a clear definition for both participation and social participation does not yet exist. The ICF definition of participation hampers differentiation between the concept of activity and participation, and does not adequately capture the objective state and subjective experience of involvement with others in society. Definitions for social participation differ from each other and are not sufficiently distinct from the ICF definition of participation. In conclusion our suggestion is to change the ICF's definition of participation towards social roles to overcome a number of its shortcomings. Societal involvement would then be understood in the light of social roles. Consequently, there would be no need to make a distinction between social participation and participation.

Part II presents a mixed methods inquiry with three empirical studies conducted with Dutch parents of school-aged children with a physical disability that is neurological and non-progressive in nature (e.g. cerebral palsy, spina bifida). The child, who is living at home, is between 4 and 12 years old and participates in regular or special education.

The first empirical study, presented in Chapter 4, aims to provide an overview of the number, domains and priority of needs as expressed by parents in supporting participation of their child with a physical disability. Additionally, this study also investigated whether the number of needs within each domain is associated to the child's gross motor function level, parent's perceived own general health, family socio-economic status and family type. One hundred and forty-six participants took part in this crosssectional study showing that there is a large variety in the number, domains and priority of needs among parents in supporting participation of their child with a physical disability. The highest mean percentage scores in domains of needs, the top priority needs and single item needs that scored $50 \%$ or higher revealed a pattern of needs related to environmental aspects. Parents' needs that were the most frequently expressed are needs belonging to the domains of 'laws, regulations and fees', 'leisure time' and 'aids, adaptations, facilities and resources'. All domains of needs showed a positive correlation with perceived parental general health. The domains 'laws, regulations and fees', 'day care and school', 'emotional and mental support' and 'raising my child' correlated negatively with family socio-economic status; the child's gross motor function level correlated positively with the domains 'aids, adaptations, facilities and resources', 'practical support at home' and 'leisure time'.

Chapter 5 focuses on gaining insights into parents' own daily actions, challenges, and needs while supporting their children with a physical disability at home, at school 
and in the community. An additional objective of this study was to refine the preliminary thematic framework previously identified in the scoping review. Analysis of the 47 eligible diaries showed that the actions mentioned by the parents describe several efforts to enhance participation of their child with a physical disability by using, enabling, or changing the social and physical environment or by supporting their child to perform or engage in meaningful activities. These parents' actions are primarily a result of challenges caused by restrictions in social and physical environments. Based on the findings a redefined thematic framework was presented revealing two new actions (role taking, changing the physical environment), two new challenges (choosing the right type of activity at home, customised products), and three new needs (instructions and coaching, accessible products and environments, tailored advice about equipment, devices, and adaptations).

The aim of the third empirical study was to provide an in-depth exploration and understanding of parents' thoughts, feelings and concerns as they reflect on their actions, challenges and needs while enabling their child's participation at home, at school and in the community, as presented in Chapter 6 . Findings of this study are summarised in three super-ordinate, and seven sub-ordinate themes with sub-categories. Findings mainly illustrated parents' disappointment related to their interactions at different societal levels while reflecting on their actions, challenges and needs. Their feelings and thoughts about being misunderstood, about dealing with complex systems and about the participation of their child being hindered by the social and the physical environment motivated them to take action and think of needs and wishes. In the eyes of the parents, they are pushed to take action when faced with situations where professionals and authorities lack understanding of a child's life with a disability, of the needs of children to participate, and fail to recognise or acknowledge the experience and expertise of the parents. Moreover, parents disclosed their worries and efforts to find appropriate leisure activities and described their strategies to enable independence in activities at home and at school.

The overall aim of this thesis was to generate new knowledge and insights into parents' actions, challenges, and needs while enhancing the participation of their child with a physical disability. Our studies showed that there is much to be learned from parents' experiences as they take many different actions to support their child, come across numerous challenges and have a wide variety of needs. Together though, the findings show a pattern: parents' actions, challenges and needs are mainly directed towards barriers in physical and/or social environments. This requires further elaboration in the general discussion of this thesis. 


\section{GENERAL DISCUSSION}

In this section, some theoretical and methodological issues are presented and discussed. Based on the conclusions that can be drawn from this thesis, future directions and implications are presented.

\section{Theoretical considerations}

This thesis demonstrated the complexity of the role of parents in enabling participation of their child with a physical disability. Moreover, the findings of the studies are consistent in showing that parents' actions, challenges and needs are mainly directed towards social and physical environments. To enhance further reflection and understanding of the outcomes of the studies four theoretical perspectives are used: (1) Social inclusion; (2) Bio-Ecological Systems Theory; (3) Theory of communicative action; and (4) Community participation and empowerment.

The concept of social inclusion is extensively discussed in scientific literature and has become an important issue in European policymaking. Social inclusion is all about equal rights, of having the same opportunities to participate in society and to perform the right of citizenship in everyday life [26]. Efforts to promote social inclusion include policies and actions that promote equal access to (public) services to create a 'society for all' [27], as well as enable citizens' participation in the decision-making processes that affect their lives [26]. Many Europeans, especially people with disabilities, are facing social exclusion. They are unable to take part in important activities and aspects of society in an equal manner, simply because policies, societies and environments are not designed to meet their requirements [28]. Whether one is welcomed, represented or provided for by the mainstream, or whether one is disliked or ignored, such social practices result from various degrees of interactions between friends, strangers, families, colleagues, groups, communities, cultures, and even whole societies [29, 30].

Barriers in social or physical environments cause social exclusion of children with a physical disability [31]. Findings of this thesis illustrate parents' efforts to affect the social environment to achieve equal opportunities for their child to play with peers or to participate in educational or recreational activities. Challenges have been described in relation to physical environments such as, for example, non-user-friendly shops, cinemas, playgrounds, public toilets and inaccessible walking paths. Parents expressed a need for products and environments designed to be usable by all people. Other studies [32-35] also showed that children with cerebral palsy specifically are victims of social exclusion due to barriers in social or physical environments. They face bullying within 
the school context, negative attitudes from adults and children, as well as barriers within the physical environment (e.g. playgrounds).

The concepts of participation and social inclusion are closely related to each other [26]. Strategies to improve social inclusion will enhance participation of children with a physical disability. A study that explored disabled children's suggestions for improving social inclusion described several strategies directed at the social environment: disclosure of conditions and creating awareness of disability, awareness of bullying, developing a peer support network and building self-confidence, and suggestions on what teachers could do [36].

Universal Design is a strategy for making physical environments, products, communication- information technology and services accessible to and usable by everyone - particularly people with disabilities - to the greatest extent possible [37]. Inclusion barriers can be avoided when universal design principles are applied to mainstream policies. For instance, schools that are built based on universal design principles are more effective in enabling children to learn, develop and participate in the school context [38]. Several examples of projects using strategies affecting social or physical environments are available in the Netherlands. The Dutch Foundation for Disabled Children supports several projects focusing on accessible environments for all children, such as playgrounds. Recently, with their support, the first outdoor park based on universal design was opened [39]. Further, the Foundation supports support projects to increase awareness and understanding of disability, for example by developing educational material for primary schools.

Bronfenbrenner's $[40,41]$ bio-ecological system's theory (EST) recognises that development is embedded in multiple structures from those that are most proximal to the child's experience, such as the family, to those that are more distal, such as policies in place at federal and state level, that all indirectly influence developmental processes. Later scholars have presented ecological systems as being networked, where each system is defined in terms of the social relationships surrounding the individual, and where systems at different levels relate to one another in an overlapping but non-nested way [42]. Defining ecological systems in network terms not only provides greater theoretical clarity but also yields a form of EST that more closely matches Bronfenbrenner's early recognition of the role of social networks in shaping development. An ecological system being networked includes five social systems (the microsystem, the mesosystem, the exosystem, the macrosystem and the chronosystem), which all attempt to emphasise relationships between and within systems; the dynamics of these relationships influence a child's activities, his/her social interaction and development [40,42]. 
Findings in this thesis give insights into parents' relationships with different environments while enabling their child's participation at home or elsewhere. Actions they undertake to support their child's participation are mostly directed at the microsystem (e.g. action 'educating' is about teaching and coaching a child on how to solve problems while performing new or difficult activities), the mesosystem (e.g. action 'advocating' for additional services at school) or at the exosystem (e.g. action 'creating opportunities', means the creation of events by parents in the neighbourhood). Challenges they face are concerned with the microsystem (e.g. 'choosing the right type of activity at home' refers to the struggle over how to decide what kind of activities their child can engage in with other children at home), the mesosystem (e.g. challenge negative 'attitude of other people'), the exosystem (e.g. challenge 'Insufficient system support' pertains to the challenges stemming from unsupportive social structures) and the macrosystem (e.g. challenge 'conflicts with administrative procedures and local authorities'). Parents' needs relate to the microsystem (e.g. 'Tailored advice about equipment, devices, and adaptations' illustrates a need for personalised advice about adaptations in the house), mesosystem (e.g. 'Finding suitable recreational activities for my child, like sports, horse riding, music, scouting'), the exosystem (e.g. need 'Try out equipment before purchasing $i t^{\prime}$ ) and the macrosystem (e.g. need 'Information an applying on governmental funding options that apply to us').

Other studies found similar outcomes in terms of the relation that parents see between participation of their child with a physical disability and the role of the environment. Bedell et al. [43] found that parents spontaneously related participation to environmental factors: their descriptions consistently included information about features of the environment that influenced their child's participation. Whiting $[44,45]$ reported that the sense parents of children with disabilities make of their situation in relation to ecological systems plays a pivotal role in determining how they experience the need for help and support from these different systems.

Reflecting on parents' experiences of their actions, challenges and needs, one could assume that supporting child participation is a highly complex task. The core of Bronfenbrenner's theory [40] is that child development is dependent on the quality and context of the relationships within and between ecological systems. Likewise, participation of children with a physical disability depends on the quality of relationships with and within different ecological systems [46]. Following Bronfenbrenner's theory [40], several authors suggested an ecological approach to enhance participation of children with a physical disability. Examples of ecological approaches can be found for example in policy reports from New Zealand [47] and Australia [48], and in papers from researchers from Canada [49]. The core of the ecological approach is that the several 
environments involved acknowledge how their actions are intertwined and that they develop a common vision on how to support child participation. Partnerships between service providers and families could be established to overcome existing barriers within various ecological systems, as encountered by parents of children with disabilities [5052].

The theory of communicative action is presented by Habermas in two volumes $[53,54]$; in the second volume [54] Habermas creates a two-level concept of modern society. He distinguishes the 'life world', inherently familiar and knowable, in which man leads his everyday life by establishing more or less direct relationships with others from the 'system world' (economic, political, legal-normative) that has a formal position, a hierarchical power and is focused on making strategic decisions. Habermas states that as a result of new caring tasks for the government, sub-systems in society were developed, leading over time to complex bureaucratic and economical systems that created their own realities without taking the daily lives of people, their motivation and their way of communication into account. Habermas [54] provides a theoretical basis for a view on planning services that emphasises widespread public participation, sharing of information with the public, reaching consensus through public dialogue rather than exercising power, avoiding the privileging of experts and bureaucrats. This should all lead to communicative action regarded by Habermas as cooperative action undertaken by individuals based upon mutual deliberation and argumentation [53]. In communicative action, people from the system world should step out of their strategic, and ego-centric rationality, their formal role and identity [55].

Parents' actions, challenges and needs described in this thesis, from Habermas' perspective [56], show a conflict between the life world and the system world. Parents often felt misunderstood and described interactions with the system world for example as 'clashes with the educational system', 'conflicts with administrative procedures and local authorities' and 'struggles with health care professionals', often as a result of differences in understanding of the child's abilities, and a lack of communication or lack of professional know-how. Other examples about the resistance between the life world and the system world are available in health care literature. Baur [55] showed the differences between the life world of residents of a residential care home and the system world of the managers. Communicative action proved to be an important prerequisite for older people and their representatives in residential care homes to be able to participate in decision making. De Wit [57] stressed that communicative action between the medical system world and the life world of clients often becomes problematic, as the system world is not automatically addressing the concerns and desires of the clients. 
Habermas has been criticised for stigmatisation of the system world [58]. Not everybody in the system world is non-cooperative; not everybody in the life world is cooperative. Nevertheless, applying Habermas' theory of communicative action to the life world of parents with a child with a physical disability presumes that a dialogue needs to be established between parents and service providers. Service providers need to open up to others, listen to parents and view them as people with a name and a face, with the intention of engaging in processes towards reaching mutual understanding and shared decision making [55].

Community participation is the organisation of activities by groups of persons who have disabilities (or their family members/friends), in conjunction with others who do not have disabilities, to increase their ability to influence social conditions, and in doing so to improve their disability situations [59]. Community participation can be conceptualised as both a means and as an end. When understood as a means, (instrumental participation) the process of involvement achieves some predetermined common social goal or objective (e.g. establishment of a technical aids centre). This form of community participation tends to be short term and does not necessarily lead to an increased capacity of individual persons to participate. In contrast, when understood as an end (transformational participation) a longer-term process develops and strengthens the self-capabilities of people to be involved in social developments (e.g. development of a disability policy paper). Community participation in this sense promotes goals such as social justice, equity and democracy. In a broader sense, community participation is a process to give communities an opportunity to determine their own destination in terms of their needs and resources [60] in order to take part in (1) planning and policymaking; (2) allocation and distribution of resources; and (3) the management of services. Holcombe [61] identified that community participation and empowerment are inseparably linked, they are different but they depend on each other to give meaning and purpose. Community participation represents action, or being part of an action such as a decision-making process [61]. Empowerment represents sharing control, the entitlement and the ability to participate and to influence decisions, such as on the allocation of resources [61].

The findings of this thesis show many different examples of parents' involvement in the community through the nature of their actions (e.g. networking, educating, advocating or creating opportunities) while enabling participation of their child with a physical disability. However, findings also show their struggle to participate in the decisionmaking process within the educational system, with local authorities or with health care professionals. Often the level of parental involvement is low: their experience is that of 
beneficiaries and users of services, rather than potential long-term partners that make mutual decisions for their child's participation.

The core of community participation and empowerment is maximum involvement, participative partnerships and shared decision-making. In most Western societies, policymaking is focused on enhancing community participation [26]. In the Netherlands, a major reform is taking place. An important social aim of the new Social Support Act [62] is to promote participation of people with disabilities and impairments. Under the Act, local authorities are required to give support to those who need it to help them take part in society. However, the reform is also based on the assumption that citizens need to take more responsibility to tackle their own problems and also have a responsibility for the well-being of others [63]. Citizens will receive more space to develop their own initiatives, while the government will become a facilitator. Further, the intention is to create collaboration between several stakeholders including citizens and the local community (schools, sports organisations, local authorities, health care centres) to develop integral solutions for supporting participation. How to arrange client and citizen participation in policy decision making is a key theme in this new reform.

Actions of parents as described in this thesis are in line with being responsible for taking care of their children, solving problems and being active in the community. However, it can be questioned whether these actions at this point are regarded by service providers in the face of active citizenship. Achieving effective community participation of these parents may be a necessary step in improving participation of children with a physical disability.

Based on these previous four perspectives, it is plausible to state that most actions, challenges and needs of parents to enhance participation of their child with a physical disability are a result of how Dutch society is constructed. Equal participation of children with a physical disability can only be reached when societies and their systems are taking social inclusion as a guiding principle, when ecological systems on a macro-, exo-, meso- and micro-level collaborate from a shared vision, and when children and parents themselves are involved as equal partners in decision making on each societal level.

\section{Methodological considerations}

\section{Literature studies}

Scoping reviews are a relatively new but increasingly common approach for mapping broad topics. According to Pham et al. [64] there is a need for their methodological 
standardisation. Still, the framework of Arksey and O'Malley [65] is the most used; among 344 scoping reviews, Pham et al. [64] found that $62 \%$ used their framework. Our study strictly followed the steps described in Arksey and O'Malley's framework. Challenges we encountered were related to selection bias. As reported in Chapter 2 there is a possibility that relevant studies were not identified in the scoping review. The first challenge we faced in the selection phase of the scoping review was the variety of concepts used to describe disability. Although a number of free-text and MeSH terms were used for addressing physical disabilities, there is a possibility that studies were missed due to the use of other terms. A similar challenge we faced was how to operationalise the concept of participation for the purpose of selecting articles, as the concept is used in many different ways. In addition, the most frequently used definition, the ICF definition of participation itself, does not differentiate sufficiently between domains activity and participation, as described in Chapter 3. To overcome this obstacle we decided not to exclude articles based on one definition of participation. We included studies if they focused on parents supporting their child with a physical disability in daily activities, regardless of whether the child actually performed or was engaged in the activity.

Relevant in the discussion of the standardisation of scoping review methodology is the debate about assessment of the methodological quality of studies. Scoping reviews should include all relevant literature regardless of research type or methodological quality, given that their intent is to present an overview of the existing literature in a field of interest [65]. However, Pham et al. [64] recognise that some form of quality assessment of all included studies would enable the identification of gaps in the evidence base. In our study, we aimed to map the research regarding actions, challenges and needs of parents while enabling their child's participation, which justifies inclusion of all articles regardless of study type or methodological quality. Any conclusions towards the findings of the studies have been drawn with caution, as methodological quality of the selected articles was not assessed.

\section{Mixed methods inquiry}

In Part II we presented a mixed methods research inquiry with three different independently applied research methods [61]. Using the positivist and the constructivist paradigm [62] in research helps to provide structure, substance and strength to the findings [17, 63]. Four rationales of mixed methods inquiry [64] have been used: (a) triangulation (i.e. parents' actions, challenges and needs have been studied with three different methods), (b) complementarity (i.e. the preliminary thematic framework from the scoping review study has been elaborated in the diary study), (c) development (i.e. using the results of the scoping review that showed that little is known about parents' 
needs helped to inform the survey method design), and (d) expansion (i.e. each study has been an expansion of a previous one by using different methods. The diary study showed many different actions, challenges and needs of parents while enabling participation of their child at home at school and in the community. To get in-depth understanding of their experiences while reflecting on their actions, challenges and needs a phenomenological study was conducted).

As with any other approach, the mixed methods approach also has its weaknesses. According to literature [64], the challenge for a researcher is to carry out different research methods, to learn how to apply multiple methods and understand how to appropriately sequence them. Our PhD research team covered different areas of expertise, however, to overcome this critical issue, additional experts were consulted to support parts of the thesis process.

A few questions remain regarding our approach. All three studies were conducted with more or less the same sample, recruited through the BOSK administration. Would the findings of this thesis hold a different view if the sample had included participants who were not members of BOSK? Do parents who are members of BOSK have different characteristics to non-members that influence their actions, challenges and needs in enhancing participation of their children? As we cannot answer these questions, clarity about the sample while disseminating our work is warranted as described in Chapters 4-6. Readers should take into account the fact that generalisation of findings to other populations or contexts is limited, for example due to methodologies used in this thesis or context-specific characteristics (e.g. laws or regulations).

Furthermore, this thesis does explore the perspectives of parents. Corker et al. [65] stated that research projects also need to involve young children with a disability themselves into debates about their lives. When given the right support, children can express themselves in a manner meaningful to their lives. This research project might have benefitted from the perspectives of children on their parents' action, challenges and needs. Dedding et al. [66] illustrated that children's own perspectives, based on their unique experiences, result in questions and themes other than those of adults. The knowledge of children about the world surrounding them is different, but not inferior to the knowledge of adults.

\section{Service-user involvement}

Involving users in research has received a lot a attention in the last 20 years [72]. In 2008, the UK Clinical Research Collaboration 'Patient and Public Involvement Project 
Group' presented an extensive systematic review on patient and public involvement [73]. The review provided emerging, but important evidence of the impact of patient and public involvement on health and social care research in relation to three key areas: making research more relevant and appropriate for users, improving the quality of the research, and in developing better relationships between researchers and communities. A recently published study by Ennis et al. [74] made the potential contribution of service-user involvement to research projects concrete by showing that studies that involved users to a greater extent were more likely to have achieved their recruitment target. However, implementing user involvement in research needs a strategy. For seven years Teunissen et al. [75] followed the implementation of service-user involvement within the research cycle of the Lung Foundation Netherlands and found that patients' involvement in health research is practicable, both in applied research and in fundamental research, however in their opinion service-user involvement in research remains dependent on individuals and 'believers'. The Netherlands Organisation for Health Research and Development (ZonMw) launched a grant research programme in the period between 2009-2013 on user involvement in research [75, 76]. This programme provided more insights about service-user involvement for the research field; what works and what does not, and how user involvement might differ in different contexts [76]. Furthermore, instruments and tools to support service-user involvement were developed, e.g. 'the participation compass' [77]. Moreover, the network of experts in the field of service-user involvement increased, and many patients and researchers experienced collaboration in research. Still, much is unclear how to implement service user involvement in research and how to use tools to support it.

Our entire research project took the tenet 'Nothing about us without us' as a guiding principle. Four years ago, very little information in the Netherlands was available on how to support the process of user involvement in research or how to support researchers in this process. Service users participated in the project in several meaningful ways: (a) Mrs B. Casparie, mother of a child with a physical disability, as a co-researcher - partner or in control; (b) BOSK as an advocate or consultant (study recruitment, study design, dissemination, implementation); (c) a parents' panel for consultation (study approval); and (d) study participants in three empirical studies as informants.

Table 1 shows a matrix describing vertically the five possible roles of service-user involvement in research, as described in the participation ladder [78], and horizontally the different stages of the research cycle. Based on previous work [79], this matrix has been recently developed at Zuyd University of Applied Sciences by researchers and service users. 
Table 1: Matrix for user involvement in research based on $[73,74]$ with examples of service-user involvement in this thesis

\begin{tabular}{|c|c|c|c|c|c|c|c|c|}
\hline & \multicolumn{2}{|c|}{ Preparation phase } & \multicolumn{3}{|c|}{ Execution phase } & \multicolumn{3}{|c|}{ Translation phase } \\
\hline & $\begin{array}{l}\text { Agenda } \\
\text { setting }\end{array}$ & $\begin{array}{l}\text { Study design } \\
\& \text { procedures }\end{array}$ & $\begin{array}{l}\text { Study } \\
\text { recruitment }\end{array}$ & $\begin{array}{l}\text { Data } \\
\text { collection }\end{array}$ & $\begin{array}{l}\text { Data } \\
\text { analysis }\end{array}$ & Dissemination & Implementation & Evaluation \\
\hline $\begin{array}{l}\text { User } \\
\text { in control - }\end{array}$ & & & & & & & & \\
\hline empower & & $A^{*} B^{*} C^{*}$ & & & $B^{*} C^{*}$ & $A^{*} B^{*} C^{*}$ & $A^{*} B^{*} C^{*}$ & \\
\hline User & & & $A^{*} B^{*}$ & $A^{*} B^{*} C^{*}$ & $A^{*}$ & & & $A^{*} B^{*} C^{*}$ \\
\hline $\begin{array}{l}\text { as partner - } \\
\text { collaborate }\end{array}$ & $A^{*} B^{*} C^{*}$ & & $C^{*}$ & & & & & \\
\hline User & & & $A^{\wedge} B^{\wedge} C^{\wedge}$ & & & & & \\
\hline $\begin{array}{l}\text { as an } \\
\text { advocate - } \\
\text { involve }\end{array}$ & & & & & & $A^{\wedge} B^{\wedge} C^{\wedge}$ & $A^{\wedge} B^{\wedge} C^{\wedge}$ & \\
\hline User as & & & & & & & & \\
\hline $\begin{array}{l}\text { Consultant - } \\
\text { consult }\end{array}$ & & $A^{\wedge} B^{\wedge} A^{\prime \prime} B^{\prime \prime}$ & & & & & & \\
\hline $\begin{array}{l}\text { User } \\
\text { as informant } \\
\text { - } \\
\text { inform }\end{array}$ & & & & A\# B\# C\# & $\mathrm{CH}$ & & & \\
\hline
\end{tabular}

A - survey study, B - diary study, C - phenomenological study, * - Mrs. B. Casparie, ^ - BOSK, " - parents' panel, \#-study participants

The matrix can be used as a tool to support research teams in identifying the possible roles and tasks of service users throughout the entire research process. The presentation of service-user involvement in our project in Table 1 was done afterwards. Such a tool, however, would have been helpful for our team from the beginning of the process to discuss, reflect and document service-user involvement through the entire project.

Working with a co-researcher was the most intense experience of service-user involvement. To learn how to be a co-researcher, Mrs B. Casparie followed the educational programme organised by TOOLS2use, initiated by De Wit and colleagues [80]. Mrs B. Casparie joined our team in the beginning of the thesis process. Two examples will be used to illustrate her contribution: 
- Mrs B. Casparie's role in the survey study design represents a level of service-user involvement, positioned between empower and collaborate. She still remembers the first discussions about instruments that could be included in the parent questionnaire very well: 'I know you suggested to use a particular valid instrument, as a part of the parent questionnaire, but some questions in this instrument were very negative, almost aggressive...this is not very nice for parents...for me personally something like this makes me decide to throw it in the trash.' Based on her advice, the team included a different instrument in the questionnaire.

- Mrs B. Casparie was involved in the analysis of the phenomenological study (level service-user in control). During the process of describing the findings, she challenged the team about the naming of the themes. In her opinion the names of the themes did not fully capture the experiences of the parents; they were understated. Based on her remarks and suggestions, the names of the themes were changed.

The four-year journey with the co-researcher in this thesis project has been meaningful in many ways: the research team learned:

- about the importance of focusing research on what matters to parents (e.g. the design of the folder for parents, or the sequence of the questions in the parent questionnaire);

- $\quad$ to be able to work together as a team and able to make mutual decisions (needing open dialogue, equal positions and critical reflection);

- $\quad$ how to involve the user as co-researcher in all the stages of the research process to improve its quality (e.g. by realising that not every valid assessment instrument is user friendly);

- to understand each other's language and to appreciate each unique contribution to the research process (research language is not always easy to follow for a service user);

- $\quad$ about the amount of effort and organisation user involvement may take (e.g. some meetings were held in Eindhoven and due to practical reasons Mrs. Casparie was not able to join all those meetings).

To our knowledge, at the start of our project in the Netherlands no education for researchers about collaboration with service users was available. In 2013, in cooperation with Dr. Maarten de Wit (expert in service-user involvement) Zuyd University started a new initiative called 'Enabling researchers for user involvement'. 


\section{Overall conclusions and implications}

The findings of this thesis indicate that parents of children with a physical disability perform various actions to enable their child's participation at home, at school and in the community. These actions are mainly focused on enabling, changing and using the social and physical environment. Challenges faced by parents are related to situations where they experience the social and physical environments as hindering the participation of their child in society. These challenges seem most evident when parents interact with service providers aiming to solve participation restrictions. Among parents of a child with a physical disability, there is a large variety in the number of expressed needs as described in Chapter 4. Despite the variety in the number of needs, there is a pattern in the kind of needs. Also needs of parents are primarily focused on the social and physical environment. When reflecting on their actions, challenges and needs, as portrayed mainly in Chapter 6, there is disappointment among parents about interactions at different societal levels, especially in cases where parents experience professionals and authorities to lack understanding of a child's life with a disability, of needs of children to participate in society, and a lack of interest in the experience and expertise of the parents.

The findings of this thesis indicate the complexity of the role of parents in enabling the participation of their child with a physical disability, as also portrayed in Figure 1. From a societal perspective, one could argue that their actions, challenges and needs are a result of confrontation with a society that is not fully constructed according to the principle of social inclusion, and as a result restricts the possibilities of children with a physical disability to participate in daily life. In striving for equal rights for their child to participate, parents need to go through difficult discussions with representatives from different societal systems. The unmet needs of parents in enabling their child's participation could be met by society truly embracing the principle of social inclusion, by collaboration between social environments from a shared vision, and by enabling the children and parents themselves to participate in decision making. 


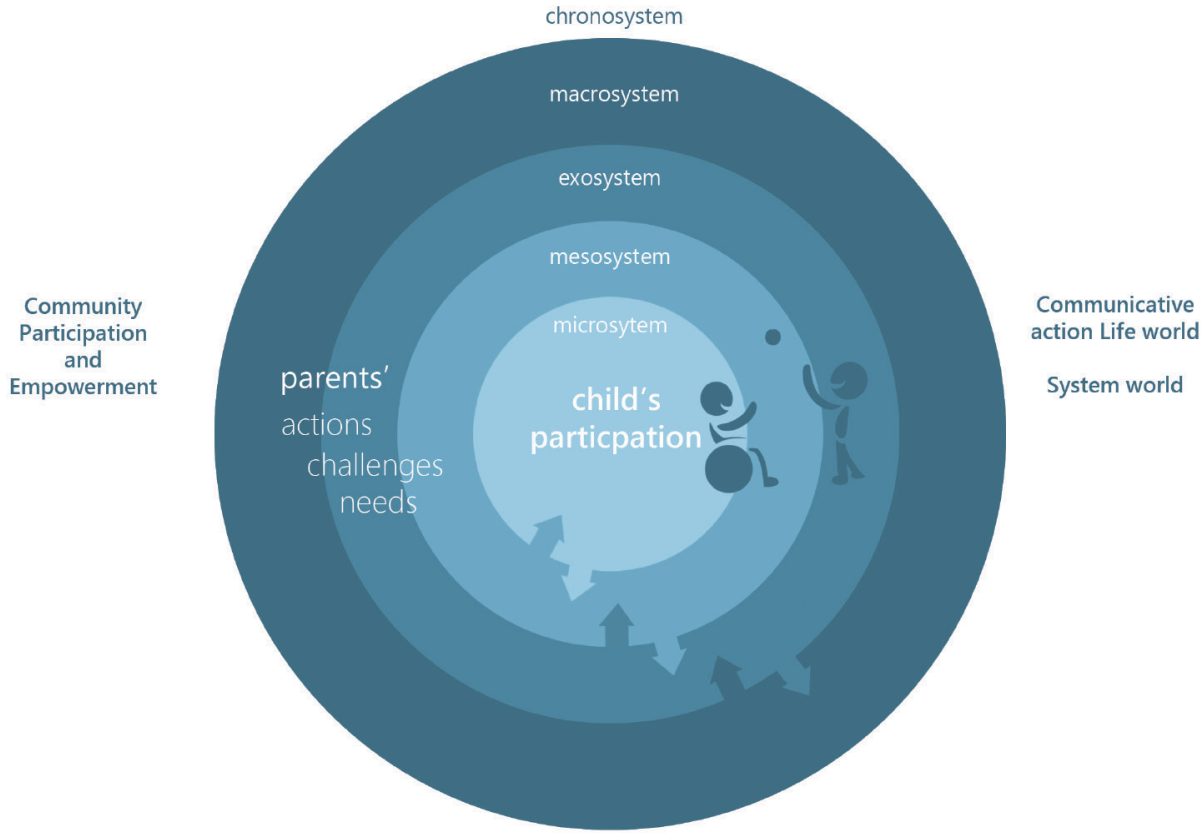

"Nothing about us without us"

Figure 1: Parents' role in enabling the participation of their child with a physical disability from different perspectives

\section{Implications for service providers}

This thesis explored parents' actions, challenges and needs while enabling their child's participation. In all studies, one pattern dominates: actions, challenges and needs are mainly the result of restrictions in social and/or physical environments. To clarify, this thesis is not an evaluation of service providers', employees or services. The findings merely indicate that when parents of a child with a physical disability take actions to enhance participation it is related to restrictions in social and physical environments, including services provided by schools, sport centres, health care institutes and local governments. Almost all parents in the cross-sectional study (Chapter 4) had needs; most expressed needs were related to the environment. This finding could be a signal for service providers to reflect on their understanding and recognition of the parents' needs, as well as on their communication and relationships with parents. The theoreti- 
cal perspectives as presented in the general discussion of this thesis point to a number of questions for consideration by service providers:

- Do we take enough effort to truly understand the life world of children with a physical disability and their parents?

- Are our services in line with requirements to support social inclusion of children with a physical disability?

- Are we taking needs of parents of child with a physical disability seriously enough in trying to provide tailor-made solutions?

- Are we giving voice to parents when initiating new tools, strategies, laws and regulations that are of influence on child's participation?

- Do we collaborate sufficiently with parents of children with a physical disability from a shared vision on different levels of decision making?

- Do we support parents enough in community participation?

A pitfall at this point of the thesis could be to be tempted to give recommendations about what practise should look like. However, that would not be in line with the 'Nothing about us without us' tenet of this thesis. The one recommendation that is correct is to advice service providers to consider a user-led approach and connect with parents of children with a physical disability. The above-mentioned questions might serve as a starting point for discussions.

\section{Implications for research}

This thesis contributes to the field of research on parents of children with a physical disability in seeking to understand their experiences and needs in enhancing participation at home, at school and in the community. Nevertheless, more research in this area is warranted. Fundamental research to generate knowledge how physical and social environments are of influence on the participation of children with a physical disability, in the Netherlands or elsewhere; perspectives of children with a disability ought to be included in these studies. In order to look for possible causal relationships a larger group of parents needs to be followed longitudinally. Applied research to provide and evaluate solutions for the unmet needs of parents and to tackle the barriers that impact on participation of children with a physical disability or any other disability. More specifically, future studies could focus on how parents perceive support to deal with their actions, challenges and needs. Further, applied research could aim to support service providers and parents to achieve shared decision making regarding enabling participation of children with a physical disability. Finally, research could be directed to the development of vehicles to support the sharing of experiences and knowledge of parents. 
However, the research agenda should be set in collaboration with parents. Taking 'Nothing about us, without us' seriously as tenet, means that this thesis can only end by saying that any other study in this area has to be considered by parents and children with a physical disability as meaningful to their lives. 


\section{LITERATURE}

1. Patrikakou EN: The Power of Parent Involvement: Evidence, Ideas, and Tools for Student Success. In. Lincoln, IL: Center on Innovation \& Improvement, DePaul University; 2008.

2. World Health Organization: International classification of functioning disability and health. In. Geneva: ICF; 2001.

3. World Health Organization: Geneva: World Health Organization; 2007.

4. Koster M, Pijl S, Nakken H, Van Houten E: Social participation of students with special needs in regular primary education in the Netherlands. Int J Disabil Dev Educ 2010, 57(1):59 - 75.

5. Hjelle K, Vik K: The ups and downs of social participation: experiences of wheelchair users in Norway. Disabil Rehabil 2011, 33(25/26):2479 - 2489.

6. Law M, King G, King S, Kertoy M, Hurley P, Rosenbaum P, Young N, Hanna S: Patterns of participation in recreational and leisure activities among children with complex physical disabilities. Dev Med Child Neurol 2006, 48(5):337-342.

7. Law M: Participation in the occupations of everyday life. Am J Occup Ther 2002, 56(6):640 - 649.

8. Bedell G, Dumas H: Social participation of children and youth with acquired brain injuries discharged from inpatient rehabilitation: A follow-up study. Brain Inj 2004, 18(1):65 - 82.

9. King G, Law M, Hanna S, King S, Hurley P, Rosenbaum P, Kertoy M, Petrenchik T: Predictors of the Leisure and Recreation Participation of Children With Physical Disabilities: A Structural Equation Modeling Analysis. Children's Health Care 2006, 35(3):209-234.

10. Imms C, Reilly S, Carlin J, Dodd K: Diversity of participation in children with cerebral palsy. Dev Med Child Neurol 2008, 50(5):363 - 369.

11. Bult M, Verschuren O, Gorter J, Jongmans M, Piskur B, Ketelaar M: Cross-cultural validation and psychometric evaluation of the Dutch language version of the Children's Assessment of Participation and Enjoyment (CAPE) in children with and without physical disabilities. Clin Rehabil 2010, 24(9):843 - 853.

12. Frostad P, Pijl S: Does being friendly help in making friends? The relation between the social position and social skills of pupils with special needs in mainstream education. Eur J Spec Needs Educ 2007, 22(1):15 30.

13. Blum R, Resnick M, Nelson R, St Germaine A: Family and peer issues among adolescents with spina bifida and cerebral palsy. Pediatrics 1991, 88(2):280 - 285.

14. Law M, Dunn W: Perspectives on understanding and changing the environments of children with disabilities. Phys Occup Ther Pediatr 1993, 13(3):1 - 17.

15. Turnbull A, Pereira L, Blue-Banning M: Parents' facilitation of friendships between their children with a disability and friends without a disability. J Assoc Persons Severe Handicaps 1999, 24(2):85 - 99.

16. Rodger S, Ziviani J: Occupational Therapy with Children: Understanding Children's Occupations and Enabling Participation: Malden: Blackwell Publishing; 2006.

17. Creswell JW: Research design: Qualitative, quantitative, and mixed methods approaches: Thousand Oaks: Sage; 2009.

18. Betzner AE: Pragmatic and Dialectic Mixed Method Approaches: An Empirical Comparison. In. Minnesota, University of Minnesota; 2008.

19. Cronholm S, Hjalmarsson A: Experiences from sequential use of mixed methods. Electronic Journal of Business Research Methods 2011, 9(2):87-95.

20. Granlund M, Arvidsson P, Niia A, Björck-Åkesson E, Simeonsson R, Maxwell G, Adolfsson M, ErikssonAugustine L, Pless M: Differentiating Activity and Participation of Children and Youth with Disability in Sweden: A Third Qualifier in the International Classification of Functioning, Disability, and Health for Children and Youth? American Journal of Physical Medicine \& Rehabilitation 2012, 91(13):S84-S96.

21. Ueda S, Okawa Y: The subjective dimension of functioning and disability: what is it and what is it for? Disability and Rehabilitation 2003, 25(11-12):596-601. 
22. Wade D, Halligan P: New wine in old bottles: the WHO ICF as an explanatory model of human behaviour. Clin Rehabil 2003, 17(4):349 - 354.

23. Hemmingsson $\mathrm{H}$, Jonsson $\mathrm{H}$ : An occupational perspective on the concept of participation in the international classification of functioning, disability and health-some critical remarks. Am J Occup Ther 2005, 59(5):569 - 576.

24. Bowes A, McColgan G: Telecare for Older People: Promoting Independence, Participation, and Identity. Research on Aging 2012.

25. Cicerone KD, Azulay J: Perceived Self-efficacy and Quality of Life in Traumatic Brain Injury. The Journal of Head Trauma Rehabilitation 2006, 21(5):408-409.

26. Whiteford GE, Hocking C: Occupational Science: Society, Inclusion, Participation. West Sussex: WileyBlackwell; 2012.

27. Nations U: Analysing and Measuring Social Inclusion in a Global Context. In. New York: United Nations: Department of Economic and Social Affairs; 2010.

28. Europe Co: Achieving full participation through Universal Design. In. Strasbourg: Council of Europe Publishing; 2009.

29. Allman D: The Sociology of Social Inclusion, vol. 3; 2013.

30. UNDESA, UNESCO, UN-HABITAT: Creating an Inclusive Society: Practical Strategies to Promote Social Integration. In. Paris: Division for Social Policy and Development: United Nations Department of Economic and Social Affairs; 2007.

31. Unit S: Improving the life chances of disabled people. In.; 2005.

32. Lindsay S, McPherson AC: Experiences of social exclusion and bullying at school among children and youth with cerebral palsy. Disability and Rehabilitation 2012, 34(2):101-109.

33. Clarke H: Preventing Social Exclusion of Disabled Children and Their Families: Literature review. In. Birmingham: Institute of Applied Social Studies: The University of Birmingham; 2006.

34. Prellwitz M: Playground Accessibility and Usability for Children with Disabilities: Experiences of children, parents and professionals, Luleå: Luleå University of Technology, 2007.

35. Anaby D, Hand C, Bradley L, DiRezze B, Forhan M, DiGiacomo A, Law M: The effect of the environment on participation of children and youth with disabilities: a scoping review. Disability and Rehabilitation 2013, 35(19):1589-1598.

36. Lindsay S, McPherson AC: Strategies for improving disability awareness and social inclusion of children and young people with cerebral palsy. Child: Care, Health and Development 2012, 38(6):809-816.

37. Ginnerup S: Achieving full participation through Universal Design. In. Strasbourg Cedex: Council of Europe Publishing; 2009.

38. Bremer CD, Clapper AT, Hitchcock C, Hall T, Kachgal M: Universal Design: A Strategy to Support Students' Access to the General Education Curriculum. In., vol. 1: NCSET: The National Center on Secondary Education and Transition; 2002.

39. De Nederlandse Stichting voor het Gehandicapte Kind [http://www.nsgk.nl/]

40. Bronfenbrenner U: Making Human Beings Human: Bioecological Perspectives on Human Development: SAGE Publications, Inc 2005.

41. Bronfenbrenner U: The ecology of human development: Harvard University Press; 1979.

42. Neal JW, Neal ZP: Nested or Networked? Future Directions for Ecological Systems Theory. Social Development 2013, 22(4):722-737.

43. Bedell G, Khetani M, Cousins M, Coster W, Law M: Parent perspectives to inform development of measures of children's participation and environment. Arch Phys Med Rehabil 2011, 92(5):765 - 773.

44. Whiting M: What it means to be the parent of a child with a disability or complex health need. Nursing Children \& Young People 2014, 26(5):26-29.

45. Whiting M: Support requirements of parents caring for a child with disability and complex health needs. Nursing Children \& Young People 2014, 26(4):24-27. 
46. Rosenberg L, Bart O, Ratzon N, Jarus T: Personal and Environmental Factors Predict Participation of Children With and Without Mild Developmental Disabilities. Journal of Child \& Family Studies 2013, 22(5):658-671.

47. Mitchell D: Joined-up: A comprehensive, ecological model for working with children with complex needs and their families. A review of the literature carried out for the New Zealand Ministry of Education. In. Canterbury: University of Canterbury; 2012.

48. Welfare AloHa: Social and emotional wellbeing: Development of a Children's Headline Indicator. In. Canberra: The Australian Institute of Health and Welfare; 2012.

49. King G, Curran CJ, McPherson A: A four-part ecological model of community-focused therapeutic recreation and life skills services for children and youth with disabilities. Child: Care, Health \& Development 2013, 39(3):325-336.

50. Lundy HF: Parental Stress, Socioeconomic Status, Satisfaction with Services, and Family Quality of Life among Parents of Children Receiving Special Education Services. Georgia State University; 2011.

51. Soresi S, Nota L, Ferrari L: Considerations on Supports That Can Increase the Quality of Life of Parents of Children With Disabilities. Journal of Policy and Practice in Intellectual Disabilities 2007, 4(4):248-251.

52. Park JJ, Turnbull AP, Turnbull HR: Impacts of poverty on quality of life in families of children with disabilities. Council for Exceptional Children 2002, 68(2):151-170.

53. Habermas J: Reason and the Rationalization of Society vol. 1. Boston: Beacon Press (originally published in German in 1981); 1984.

54. Habermas J: Lifeworld and System: A Critique of Functionalist Reason. Boston: Beacon Press (originally published in German in 1981); 1987.

55. Baur VE, Abma TA: Resident councils between lifeworld and system: Is there room for communicative action? Journal of Aging Studies 2011, 25(4):390-396.

56. Habermas J: Actions, speech acts, linguistically mediated interactions and the lifeworld. In: Philosophical Problems Today / Problèmes Philosophiques d'Aujourd'hui. Volume 1, edn. Edited by Fløistad G: Springer Netherlands; 1994: 45-74.

57. Wit de $\mathrm{M}$ : Patient participation valuable for rheumatology research: a four level responsive aluationev. Amterdam: VUmc; 2013.

58. Plot M: Communicative Action's Democratic Deficit: A Critique of Habermas's Contribution to Democratic Theory. International Journal of Communication 2009, 3 825-852.

59. Boyce W, Lysack C: Understanding the Community in Canadian CBR: Critical lessons from abroad. Canadian Journal of Rehabilitation 1997, 10(4):261-271.

60. Theron F, Davids I, Maphunye KJ: Participatory Development in South Africa. In. Pretoria: Van Schaik Publishers; 2005.

61. Higinbotham Holcombe S, Speth JG: Managing to empower : the Grameen's bank's experience of poverty alleviation. London Zed books; 1995.

62. De Staatssecretaris van Volksgezondheid WeS: Besluit van 9 juli 2014, houdende vaststelling van het tijdstip van inwerkingtreding van de Wet maatschappelijke ondersteuning 2015. In. Edited by Ministerie van Volksgezondheid WeS: Staatsblad van het Koninkrijk der Nederlanden; 2014.

63. Vreugdenhil M: Nederland participatieland? De ambitie van de Wet maatschappelijke ondersteuning (Wmo) en de praktijk in buurten, mantelzorgrelaties en kerken. Amsterdam: University of Amsterdam 2012.

64. Pham MT, Rajić A, Greig JD, Sargeant JM, Papadopoulos A, McEwen SA: A scoping review of scoping reviews: advancing the approach and enhancing the consistency. Research Synthesis Methods 2014:n/an/a.

65. Arksey H, O'Malley L: Scoping studies: towards a methodological framework. Int J Soc Res Methodology: Theory \& Pract 2005, 8(1):19 - 32.

66. Moran-Ellis J, Alexander VD, Cronin A, Dickinson M, Fielding J, Sleney J, Thomas H: Triangulation and integration: processes, claims and implications. Qualitative Research 2006, 6(1):45-59. 
67. Cameron R, Molina-Azorin J: The application of mixed methods in organisational research: a literature review. In., vol. 8. Reading: Academic Publishing Limited; 2010: pp.95-105.

68. Creswell JW: Research Design - Qualitative, Quantitative, and Mixed Methods Approaches Thousand Oaks, CA: SAGE; 2003.

69. Johnson RB, Onwuegbuzie AJ, Turner LA: Toward a Definition of Mixed Methods Research. Journal of Mixed Methods Research 2007, 1(2):112-133.

70. Corker M, Davis J, Priestley M, Watson N, Shakespeare T, Cunningham-Burley S, Barnes C: Life as a Disabled Child: A Qualitative Study of Young People's Experiences and Perspectives. In. UK: Department of Nursing Studies, University of Edinburgh; 2000.

71. Dedding C, Jurrius K, Moonen X, Rutjes L: Kinderen en jongeren actief in wetenschappelijk onderzoek: Ethiek, methoden en resultaten van onderzoek met en door jeugd: LannooCampus; 2013.

72. Beresford P: User involvement in research and evaluation: Liberation or regulation? Social Policy and Society 2002, 1( 2):95-105.

73. Collaboration UCR: An evaluation of the process and impact of patient and public involvement in the advisory groups of the UK Clinical Research Collaboration. In. London: TwoCan Associates 2009.

74. Ennis L, Wykes T: Impact of patient involvement in mental health research: longitudinal study. The British Journal of Psychiatry 2013, 203(5):381-386.

75. Teunissen G, Visse M, Laan D, de Boer W, Rutgers M, Abma T: Patient involvement in lung foundation research: A seven year longitudinal case study. Health 2013(5):320-330.

76. Vossen C: Een 10 voor patiënten participatie. In: ZonMw stimuleert gezondheidsonderzoek en zorginnovatie. Den Haag: ZonMw, VS Bfonds; 2013.

77. ZonMw, VSBFonds, PGOsupport: Participatiekompas.nl. In.; 2014.

78. Tritter JQ, McCallum A: The snakes and ladders of user involvement: Moving beyond Arnstein. Health Policy, 76(2):156-168.

79. Stoffers E, Haarsma-Wisselink A, Moser A: Werkboek Evaluatie Patiëntenparticipatie. In.: Huis voor de Zorg, Zuyd Hogeschool, Stichting Zorgconsumenten Limburg; 2012.

80. TOOLS: Patient empowerment [http://tools2use.eu/netwerkN.html] 

CHAPTER 8

Valorisation 



\section{Introduction}

"How to support my child in daily life?" is an everyday question facing parents of a child with a physical disability. The experiences of these parents formed the point of departure for this thesis. Parents were and are seen as experts in their child's life; they have many experiences in enhancing participation of their child in society, and consequently, are able to change, enable or use environments to support their child's participation at home, at school and in the community. However, by some means parents of children with a physical disability do not always benefit from each other's knowledge and sometimes miss the right support tools. Further, their stories are too little heard and understood. Working in co-creation with parents and a parent organisation following the motto "Nothing about us without us" has been thus a logical step for addressing this genuine societal problem.

In view of that, this thesis presents not only the scientific value of the studies as addressed in chapters 2-6, but also the societal value. Valorisation is the process of creating value from knowledge, by making this knowledge available and suitable for economic and social exploitation and its translation into products, services, processes or new business. This valorisation section addresses how the scientific knowledge could be transferred to and utilized in society; firstly, by looking at the relevance of the findings for actual societal developments and the role of the environment; secondly by providing examples of concrete innovative activities and products.

\section{Relevance of the findings and actual societal developments}

The collective knowledge as presented in this thesis can, most of all, serve as a means for creating awareness. Awareness about the added value of user-involvement in research and awareness about the knowledge parents hold, actions they undertake, and challenges and needs they encounter in the social and physical environment related to participation of their child with a physical disability. The knowledge of this thesis is of relevance to local authorities and their community partners, school staff, rehabilitation professionals, health insurance companies and parents. They are all faced by the challenges posed by recent societal developments and demands in the Netherlands.

\section{Parents' community participation}

In this thesis, individual experiences and perspectives from parents of a child with a disability have been gathered and brought together into collective knowledge, available for parents to use for several purposes. Many parents of a child with a disability have a 
need for contact with peers to exchange information. Contact with other parents with a child with a disability can offer support, can lead to meaningful advice and foster their community participation. It is assumable that the reforms in Dutch society will increase the need for support among parents, given that parents are increasingly expected to solve problems themselves [1]

A recent report [2] showed that parent organizations, like BOSK, have the impression that parents are frequently looking for written information on websites, either in parents' organisation magazines, or through advice forums on internet, either from people in their own social network. Furthermore, the report states that these parents are currently insufficiently able to share their experiences and in this way do not benefit from each other's knowledge [2]. Moreover, there are too few possibilities for parents to have their voices heard in the world of politics, care, education and research. Parents' community participation could rise to a higher level, where joint decision-making takes place regarding policy making or other relevant topics. This thesis provides a source of collective knowledge available for parents to learn from other parents' experiences, to reflect on their own challenges and needs and, by reading about the actions of respondents, to feel confident in being meaningful in enabling their child's participation. The explanation and description of user-involvement can encourage parents of children with a physical disability to play an active role in research or other fields of society.

\section{Local authorities and community partners}

This thesis shows examples of parents' interactions with local authorities and community partners. The Social Support Act and the Youth Act have a big impact on Dutch society and the role of the local authorities and community partners [1]. The goal of the Social Support Act is that everybody - old and young, with and without a disability, with or without problems - can join in social life. Many people can join without help, but others need help and support, or a stimulating environment. Family, friends, social networks and organisations are believed to offer their help to a significant extent [1]. The new Youth Act, active from 2015, stipulates that local authorities will be responsible for all youth care services. The new youth care system should be more efficient, coherent and cost-effective. A focus on prevention, youth's and parents' own capacities, and a better cooperation between professionals must lead to a decrease in the use of the specialised services [1].

Because of these reforms, local authorities are supposed to shift to a "need led approach" leading to many challenges [3]. They have to organize collaboration between community partners to create a uniform vision and a coherent approach to care and 
support [4]. Their employees need to develop competencies to understand the needs of clients and the social infrastructure and abilities to empower them [3]. In relation to children with a disability, employees are supposed to be capable of activating, restoring and strengthening the capacities of children, youth, parents and their social environment in order to solve problems [1].

This thesis can serve as a source of inspiration and learning for local authorities and the community partners (e.g. sport clubs, health and welfare organizations) involved in enhancing participation of children with a disability to understand the perspective of the parents on:

- $\quad$ their needs related to participation of their child with a physical disability

- $\quad$ the kind of problems their child with a physical disability experience in participation;

- the kind of problems they come across in contact with the employees;

- the kind of support they are looking for;

- how many and what kind of actions they (already) undertake to support their child with a physical disability;

- $\quad$ the lack of cooperation between stakeholders in the field of children with a physical disability;

_ $\quad$ the possibilities of involving parents as experts in policy decision-making.

\section{Inclusive education}

Parents through the findings of this thesis show their appreciation as well as their concerns with inclusive education. Inclusive education is a rather new development in the Netherlands [5]. An important facilitator in developing education that is more inclusive is the presence of curricular expertise and resources in schools. Leadership and involvement of school leaders, parental involvement, involvement of the pupils themselves, support (internal and external), a flexible curriculum and the willingness, knowledge and skills of the teaching staff are often mentioned as important facilitators for inclusive education [6]. A part of the challenge for educators is to involve parents in their daily work and to acknowledge their expertise [7]. Oberon [8] highlights the importance of creating equal partnerships between parents and the schools. Schools need to formulate how they envision parental involvement, what they expect from parents and what their own role is [9].

This thesis can serve as a source of inspiration and learning for school staff to understand needs, actions and challenges of parents with a child with a physical disability. Parents do undertake many actions to enhance participation and are experience experts. This thesis can raise awareness among school staff of the importance of accepting the perspective of parents on several levels of decision-making. 


\section{Family-centered service in paediatric rehabilitation}

Findings of this thesis highlighted parents' worries about the lack of focus of rehabilitation in the real life context in which children with a physical disability and their parents experience restrictions in participation. Family-centred service is believed to be the way forward in paediatric rehabilitation, requiring changes in the attitude and working methods of rehabilitation professionals [10]. To provide truly family-centred care that is indeed tailored to individual families, professionals in paediatric services need to make an accurate inventory of each family's specific needs and wishes [11]. Professionals adopting a family-centred model are asked to replace the role of decision-maker, agenda-setter, advice-prescriber and expert with the more challenging role of partner, listener, facilitator and consultant [12]. Further, it is of importance to consider how services can be geared towards individual preferences, as well as how to provide tools for parents to understand the impact of the environment on participation of their child with a physical disability (e.g. The Participation and Environment Measure for Children and Youth [13]). Visser-Meily et al. [14], however, concluded that despite the knowledge about the relevance of a family- centred approach little changes can be witnessed in care, partly due to the lack of awareness of professionals. The collective parents' knowledge of this thesis can be a source for rehabilitation professionals to better understand parents' strengths and raise awareness for the variety of parents' needs asking for a tailored approach.

\section{Translation of the findings in concrete innovative activities and products}

Findings of this thesis have been and will be translated into different contexts. We can present some examples of concrete activities undertaken to date.

\section{Experience Knowledge Centre development}

The intensive cooperation with the Dutch association of people with a physical disability (BOSK) and individual parents (e.g. Mrs. B. Casparie) during the thesis period led to a large national project in 2015. BOSK and Zuyd University of Applied Sciences started a Community of Practice with different stakeholders to design and deliver an Experience Knowledge Centre, aiming for empowerment of parents in supporting their child with a disability in daily life. The Experience Knowledge Centre will provide parents opportunities to share their experiences on a peer-to-peer level, create possibilities to translate individual experiences into collective knowledge and strengthen the position and involvement of parents on different societal levels. The collective knowledge about par- 
ents' actions, challenges and needs gathered in this thesis served as a rationale for this project and generated new ideas.

\section{Knowledge building: from individual experiences to collective knowledge}

Research is considered to be a bridge between individual experiences and collective knowledge [15]. However, a scientific approach takes a great deal of effort and time, and despite the relevancy and richness of the knowledge, still most of the information is not used effectively for decision-making and problem-solving purposes. The BOSK illustrated that a lot of the knowledge held by parents gets lost and is hardly used by other parents. There is an emerging need for knowledge tools that enable users to collectively create, share, browse and query their knowledge.

Most probably, one the most challenging and innovative activities emerging from this thesis is the set-up of projects to develop tools and on-line methodologies, which will convert the experiences of many parents into collective knowledge. Several faculties (Health Care, ICT, People and Business Management) of Zuyd University are involved in writing project proposals together with BOSK and Kenniscentrum Revalidatiegeneeskunde Utrecht. Providing collective knowledge to support parents in making their own decisions and developing effective self-management skills will contribute to enabling their child's participation at home, at school and in the community. This method of translating individual parents' experiences into collective knowledge will provide ways for parents to better pass on their concerns, interests and wishes to policy makers, researchers, students, educators, rehabilitation workers, and other service-users.

\section{Enabling researchers for user-involvement}

User-involvement in this thesis created awareness in researchers and parents involved in the process about the added value of user-involvement. Contacts with Dutch pioneers in this field were established during the process. It stimulated Zuyd University to choose user-involvement as one of the core principles. A new initiative called 'Enabling researchers for user involvement' was started to empower researchers at the research centres of the Faculty of Health Care and the Centre of Expertise on Innovative Care and Technology (EIZT) to involve users in research, by providing them with education and tools (e.g. master classes, workshops, coaching sessions, a matrix for user-involvement in research). Furthermore, user-involvement in this thesis attracted international attention leading to a keynote speech at the European Congress of Occupational Therapy in 2012 in Stockholm and a keynote speech at the National Finnish Research and Development symposium in Helsinki in 2014. 


\section{LITERATURE}

1. Bosscher N: The decentralisation and transformation of the Dutch youth care system. In.: Nederlands Jeugd Instituut; 2014.

2. Okma K, Naafs L, Vergeer M, Berns J: QuickScan naar de ondersteuningsbehoefte van zorgintensieve gezinnen. In. Utrecht: Nederlands Jeugdinstituut; 2014.

3. Oudenampsen DG, Nederland T: De rol van burgers in de transitie van AWBZ naar Wmo: Beleidsparticipatie, maatschappelijke participatie en maatschappelijk initiatief van burgers. In. Utrecht: Ministerie van VWS; 2013.

4. Rijnkels H, Man dS: Kantelen in de Wmo: Handreiking voor visieontwikkeling en organisatieverandering. In. Den Haag: Vereniging van Nederlandse Gemeenten; 2010.

5. Thijs A, Leeuwen vB, Zandbergen M: Inclusive education in the Netherlands. In.: Netherlands institute for curriculum development; 2008.

6. Leeuwen $v B$, Limpens $M$ : Leerlingen verschillen en dat is normaal: Ideologie en praktijk van onderwijs aan leerlingen met speciale onderwijsbehoeftes. In. Enschede: SLO - nationaal expertisecentrum voor leerplanontwikkeling; 2007.

7. Weijhrother vJ, Hoffen vZ: Ouders onmisbaar voor passend onderwijs. Zorgeloos onderwijs 2010, 12(18).

8. Eck VP, Walraven M: Pionieren in passend onderwijs: ervaringen van ouders. In. Utrecht: Oberon; 2014.

9. Vergeer MM, Felix C, Veen AM: Keuzevrijheid van ouders bij het onderwijs voor kinderen met beperkingen. In.: SCO-Kohnstamm Instituut; 2007.

10. Kuo DZ, Houtrow AJ, Arango P, Kuhlthau KA, Simmons JM, Neff JM: Family-Centered Care: Current Applications and Future Directions in Pediatric Health Care. Maternal and Child Health Journal 2012, 16(2):297 $-305$.

11. Nijhuis BJG, Reinders-Messelink HA, de Blécourt ACE, Hitters WMGC, Groothoff JW, Nakken H, Postema K: Family-centred care in family-specific teams. Clinical Rehabilitation 2007, 21(7):660-671.

12. Espe-Sherwindt M: Family-centred practice: collaboration, competency and evidence. Support for Learning 2008, 23(3):136-143.

13. Coster W, Law M, Bedell G, Khetani M, Cousins M, Teplicky R: Development of the participation and environment measure for children and youth: conceptual basis. Disability and Rehabilitation 2012, 34(3):238-246.

14. Visser-Meily A, Gorter JW, Ketelaar M, Croiset G: Meer dan de patiënt alleen. Gezinsgerichte benadering hoort in het medisch basiscurriculum. Medisch Contact 2009, 64(19):854-857.

15. Reeves A: Research as a bridge between individual experience and collective knowledge. Counselling and Psychotherapy Research 2012, 12(2):83-83. 


\section{Nederlandse samenvatting (Summary in Dutch)}



Ouders spelen een cruciale rol in het ondersteunen van participatie van kinderen [1]. Participatie, door de Wereldgezondheidsorganisatie gedefinieerd als "iemands deelname aan het maatschappelijke leven" [2], betekent voor kinderen deelname aan alledaagse activiteiten als vrijetijds-, school- en huishoudelijke activiteiten [3]. Diverse auteurs gebruiken de term sociale participatie om het belang van betrokkenheid in sociale situaties te benadrukken $[4,5]$. Participatie van kinderen in het dagelijkse leven is essentieel voor gezonde ontwikkeling, sociale en fysieke competenties, sociaalemotioneel welbevinden, en gevoel van betekenis en doel in het leven [6]. Door deel te nemen in verschillende sociale contexten vergaren kinderen de kennis en vaardigheden die nodig zijn om te kunnen samenwerken, spelen, werken en leven met andere mensen $[4,7,8]$.

Uit onderzoek blijkt dat er bij kinderen met een lichamelijke beperking een grotere kans bestaat dat ze minder participeren in alledaagse activiteiten [9]; ze nemen minder frequent deel aan bijna alle activiteiten dan kinderen zonder een lichamelijke beperking $[10,11]$, hebben minder vrienden, en voelen zich vaak sociaal geïsoleerd [12-14]. Diverse kenmerken van de omgeving zijn van invloed op participatie van kinderen met een lichamelijke beperking. Toegankelijke en ondersteunende faciliteiten, bijvoorbeeld, maken participatie mogelijk [15]. Ondersteuning van de sociale omgeving, zoals ouders, klasgenoten, leraren, wijkgenoten en vrienden, is net zo belangrijk. Vooral ouders hebben een positieve invloed op participatie op school, thuis en in de wijk van kinderen met een beperking [16]. Zij ondernemen vele acties om participatie van hun kinderen in het dagelijks leven te optimaliseren [16, 17]. Weinig informatie is beschikbaar over wat ouders van kinderen met een lichamelijke beperking doen om participatie van hun kind mogelijk te maken, waar ze tegenaan lopen, en welke behoeften zij hebben.

Het doel was om in dit proefschrift was om acties, uitdagingen en behoeften van ouders te beschrijven in relatie tot ondersteuning van participatie van hun schoolgaande kinderen met een lichamelijke beperking. Dit doel is in twee stappen behaald. Allereerst werd de literatuur geraadpleegd om na te gaan wat al bekend is over het thema (acties, uitdagingen en behoeften van ouders) en om duidelijkheid te verkrijgen over de concepten participatie en sociale participatie. Daarna werd op drie verschillende manieren bij ouders van kinderen met een lichamelijke beperking informatie verzameld over hun acties, uitdagingen en behoeften. Dit proefschrift volgt daarmee een mixed method benadering en kent de volgende studies en onderzoeksvragen: 


\section{Deel I}

\section{Scoping review}

- Wat is in de literatuur bekend over acties, uitdagingen en behoeften van ouders in relatie tot ondersteuning van participatie van hun kinderen met een lichamelijke beperking?

\section{Discussieartikel}

- Zijn participatie en sociale participatie onderscheidende concepten?

\section{Deel II}

\section{Vragenlijstonderzoek}

- Wat zijn de hoeveelheden, domeinen en prioriteiten aan behoeften bij ouders in het ondersteunen van participatie van hun schoolgaande kinderen met een lichamelijke beperking?

- Wat is de relatie tussen de hoeveelheid behoeften binnen elk domein en de grove motoriek van het kind, de gezondheidsbeleving van de ouder, de sociaaleconomische status van de familie en familietype?

\section{Dagboekonderzoek}

- Hoe beschrijven ouders hun acties, uitdagingen en behoeften in relatie tot ondersteuning van participatie van hun kinderen met een lichamelijke beperking thuis, op school en in de wijk?

\section{Interviews}

- Hoe geven ouders uiting aan hun gedachten, gevoelens en zorgen bij het reflecteren op hun acties, uitdagingen en behoeften in relatie tot ondersteuning van participatie van hun kinderen met een lichamelijke beperking thuis, op school en in de wijk?

\section{Belangrijkste bevindingen}

Deel I presenteert een overzicht van de literatuur over acties, uitdagingen en behoeften van ouders en een kritische reflectie op de concepten participatie en sociale participatie.

De scoping review over acties, uitdagingen en behoeften van ouders wordt gepresenteerd in Hoofdstuk 2. Uit dit literatuuronderzoek blijkt dat ouders van kinderen met een lichamelijke beperking een breed palet aan strategieën toepassen om hun kinderen 
te ondersteunen bij participatie. Zij ervaren diverse uitdagingen, vooral gelieerd aan knelpunten in de sociale en fysieke omgeving. De resultaten van de studie worden gepresenteerd in een voorlopig thematisch raamwerk bestaande uit twee hoofdthema's: (1) ouders maken betekenisvolle activiteiten mogelijk en ondersteunen deze, en (2) ouders ondersteunen, veranderen en gebruiken de omgeving. De meest benoemde acties betroffen "kiezen" van betekenisvolle activiteiten voor het kind, "pleiten" voor het kind, "onderwijzen" van de sociale omgeving, en "netwerken" met andere mensen. Ouders ervaren, waar het ondersteuning van participatie van hun kinderen betreft, vaak uitdagingen in de omgeving, zoals "attitudes van andere mensen", "onvoldoende ondersteuning van instanties" en "knelpunten in natuurlijke en gebouwde omgevingen". Echter, deze studie toont ook dat er nog maar weinig kennis uit onderzoek beschikbaar is over de behoeften van ouders in relatie tot het faciliteren van participatie.

De definitie van participatie van de International Classification of Functioning, Disability and Health (ICF) wordt vaak aangehaald in de literatuur, maar is tevens onderhevig aan kritiek [18-21]. Daarbij worden de concepten sociale participatie en participatie in de literatuur nogal eens door elkaar gebruikt $[22,23]$. Aangezien participatie in deze thesis een centraal concept is, heeft dat geleid tot een discussieartikel over de concepten participatie en sociale participatie, gepresenteerd in Hoofdstuk 3. De centrale vraag was of participatie, zoals gedefinieerd in de ICF, en sociale participatie onderscheidende concepten zijn. Als conclusie is geformuleerd dat een duidelijke definitie voor zowel participatie als sociale participatie nog (niet) bestaat. De ICF definitie ontbreekt het aan een helder onderscheid tussen het concept activiteit en het concept participatie. Daarnaast omvat de definitie onvoldoende de objectieve staat en de subjectieve beleving van betrokkenheid met anderen in de samenleving. Definities van sociale participatie verschillen van elkaar en onderscheiden zich onvoldoende van de ICF definitie van participatie. Aanpassing van de ICF definitie van participatie richting sociale rollen zou een aantal geconstateerde tekortkomingen oplossen. Sociale betrokkenheid zou vervolgens begrepen kunnen worden in het licht van sociale rollen. Daarmee zou een reden voor een onderscheid tussen participatie en sociale participatie verdwijnen.

Deel II bevat drie empirische studies met Nederlandse ouders van schoolgaande kinderen met een lichamelijke beperking, die neurologisch en niet-progressief van aard is (zoals Cerebrale parese of Spina bifida). De kinderen wonen thuis, zijn tussen de 4 en 12 jaar oud en volgen regulier of special onderwijs.

De eerste empirische studie, gepresenteerd in Hoofdstuk 4, beoogt een overzicht te geven van hoeveelheden, domeinen, en prioriteiten aan behoeften van ouders in relatie tot het ondersteunen van participatie van hun schoolgaande kinderen met een lichamelijke beperking. Daarnaast werd de relatie onderzocht tussen de hoeveelheid behoeften binnen elk domein en grof-motorisch functioneren van het kind, gezondheidsbeleving 
van de ouder, sociaaleconomische status van de familie en familietype. Uit het onderzoek onder 146 ouders blijkt dat er veel variatie is onder de ouders in hoeveelheid, domeinen en prioriteiten aan behoeften. Bij beschouwing van zowel de hoogste gemiddelde percentages in domeinen van behoeften, de hoogste scores voor prioriteiten als de behoeften die boven de $50 \%$ of hoger scoorden, tekent zich een patroon af van behoeften die vooral gerelateerd zijn aan omgevingsaspecten. Behoeften behorende bij de domeinen 'Wet- en regelgeving en vergoedingen', 'Vrije tijd' en 'Hulpmiddelen, aanpassingen en voorzieningen' werden het meest frequent gescoord door ouders. Alle domeinen van behoeften toonden een positieve correlatie met gezondheidsbeleving van de ouder. De domeinen 'Wet- en regelgeving en vergoedingen', 'Opvang, school en werk', 'Emotionele en psychische ondersteuning' en 'Opvoeding van mijn kind met een lichamelijke beperking' correleerden negatief met sociaaleconomische status; grofmotorisch functioneren kende een positieve correlatie met de domeinen 'Hulpmiddelen, aanpassingen en voorzieningen', 'Emotionele en psychische ondersteuning' en 'Vrije tijd'.

Hoofdstuk 5 gaat over het krijgen van inzicht in de acties, uitdagingen en behoeften van ouders in relatie tot de ondersteuning die zij bieden aan participatie van hun schoolgaande kinderen met een lichamelijke beperking thuis, op school en in de wijk. Uit de analyse van 47 dagboeken blijkt dat de acties, zoals beschreven door ouders, diverse inspanningen betreffen om participatie van hun kinderen te bevorderen. Acties zijn gericht op het ondersteunen, veranderen of gebruiken van de omgeving, of op het ondersteunen van het kind om betrokken te raken in betekenisvolle activiteiten of uitvoering ervan mogelijk te maken. De acties zijn vooral het resultaat van uitdagingen veroorzaakt door knelpunten in de sociale en fysieke omgeving. Op basis van de bevindingen uit dit onderzoek werd het voorlopige thematische raamwerk aangevuld met twee nieuwe acties (rol-opname; verandering van de fysieke omgeving), twee nieuwe uitdagingen (kiezen van de juiste activiteit thuis; maatwerkproducten) en drie nieuwe behoeften (instructies en coaching; toegankelijke producten en omgevingen; maatwerk adviezen over hulpmiddelen; aanpassingen en voorzieningen).

Het doel van de derde empirische studie was het verkrijgen van een dieper en beter begrip van gedachten, gevoelens en zorgen van ouders bij het reflecteren op hun acties, uitdagingen en behoeften in relatie tot ondersteuning van participatie van hun kinderen met een lichamelijke beperking thuis, op school en in de wijk. Hoofdstuk 6 rapporteert over deze studie. De bevindingen worden gepresenteerd in drie super-ordinate en zeven sub-ordinate thema's met subcategorieën. Uit de thema's blijkt dat ouders, reflecterend op hun acties, uitdagingen en behoeften, vooral teleurstelling ervaren over hun interactie op diverse sociale niveaus. Gevoelens en gedachten over het gebrek aan begrip van professionals, over de confrontatie met complexe systemen en over de bar- 
rières in de sociale en fysieke omgeving die participatie van hun kind belemmeren, leiden tot wensen en behoeften en motiveren ouders om actie te ondernemen. Ouders ervaren tot actie te worden gedwongen als zich situaties voordoen waarbij professionals en autoriteiten onvoldoende begrip tonen van het dagelijks leven van kinderen met een beperking en van de behoeften van deze kinderen om deel te nemen aan de maatschappij, of tekortschieten in het herkennen of erkennen van de ervaring en expertise van de ouders. Verder lieten ouders zich in deze studie uit over hun zorgen en inspanningen om geschikte vrijetijdsbesteding te vinden, en beschreven zij strategieën om zelfstandigheid in activiteiten op school en thuis te bevorderen.

Het genereren van nieuwe kennis en inzichten in de acties, behoeften en uitdagingen van ouders in het bevorderen van participatie van hun kind met een lichamelijke beperking was het doel van dit proefschrift. Onze studies laten zien dat er veel te leren valt van de ervaringen van deze ouders die vele verschillende acties uitvoeren om hun kind te ondersteunen, vele uitdagingen tegenkomen en een grote variatie aan behoeften ervaren. $\mathrm{Er}$ is een patroon te vinden in de resultaten van alle onderzoeken: de acties, uitdagingen en behoeften van ouders zijn vooral gericht op barrières in de fysieke en sociale omgeving. 


\section{LITERATUUR}

1. Patrikakou EN: The Power of Parent Involvement: Evidence, Ideas, and Tools for Student Success. In. Lincoln, IL: Center on Innovation \& Improvement, DePaul University; 2008.

2. Organization WH: Geneva: World Health Organization; 2001.

3. Organization $\mathrm{WH}$ : International classification of functioning, disability and health - children and youth version. ICF-CY 2007.

4. Koster M, Pijl S, Nakken H, Van Houten E: Social participation of students with special needs in regular primary education in the Netherlands. Int J Disabil Dev Educ 2010, 57(1):59 - 75.

5. Hjelle K, Vik K: The ups and downs of social participation: experiences of wheelchair users in Norway. Disabil Rehabil 2011, 33(25/26):2479 - 2489.

6. Law M, King G, King S, Kertoy M, Hurley P, Rosenbaum P, Young N, Hanna S: Patterns of participation in recreational and leisure activities among children with complex physical disabilities. Dev Med Child Neurol 2006, 48(5):337-342.

7. Law M: Participation in the occupations of everyday life. The American Journal of Occupational Therapy 2002, 56(6):640-649.

8. Bedell G, Dumas H: Social participation of children and youth with acquired brain injuries discharged from inpatient rehabilitation: A follow-up study. Brain Inj 2004, 18(1):65 - 82.

9. King G, Lawm M, King S, Rosenbaum P, Kertoy MK, Young NL: A Conceptual Model of the Factors Affecting the Recreation and Leisure Participation of Children with Disabilities. Physical \& Occupational Therapy In Pediatrics 2003, 23(1):63-90.

10. Imms C, Reilly S, Carlin J, Dodd K: Diversity of participation in children with cerebral palsy. Dev Med Child Neurol 2008, 50(5):363 - 369.

11. Bult MK, Verschuren O, Gorter JW, Jongmans MJ, Piskur B, Ketelaar M: Cross-cultural validation and psychometric evaluation of the Dutch language version of the Children's Assessment of Participation and Enjoyment (CAPE) in children with and without physical disabilities. Clin Rehabil 2010, 24(9):843-853.

12. Frostad P, Pijl S: Does being friendly help in making friends? The relation between the social position and social skills of pupils with special needs in mainstream education. Eur J Spec Needs Educ 2007, 22(1):15 30.

13. Blum R, Resnick M, Nelson R, St Germaine A: Family and peer issues among adolescents with spina bifida and cerebral palsy. Pediatrics 1991, 88(2):280 - 285.

14. Law M, Dunn W: Perspectives on understanding and changing the environments of children with disabilities. Phys Occup Ther Pediatr 1993, 13(3):1 - 17.

15. Welsh B, Jarvis S, Hammal D, Colver A: How might districts identify local barriers to participation for children with cerebral palsy? Public Health 2006, 120(2):167 - 175.

16. Turnbull A, Pereira L, Blue-Banning M: Parents' facilitation of friendships between their children with a disability and friends without a disability. J Assoc Persons Severe Handicaps 1999, 24(2):85 - 99.

17. Rodger S, Ziviani J: Occupational Therapy with Children: Understanding Children's Occupations and Enabling Participation: Malden: Blackwell Publishing; 2006.

18. Hemmingsson $\mathrm{H}$, Jonsson $\mathrm{H}$ : An occupational perspective on the concept of participation in the international classification of functioning, disability and health-some critical remarks. Am J Occup Ther 2005, 59(5):569 - 576.

19. Wade D, Halligan P: New wine in old bottles: the WHO ICF as an explanatory model of human behaviour. Clin Rehabil 2003, 17(4):349 - 354.

20. Ueda S, Okawa Y: The subjective dimension of functioning and disability: what is it and what is it for? Disability and Rehabilitation 2003, 25(11-12):596-601. 
21. Granlund M, Arvidsson P, Niia A, Björck-Åkesson E, Simeonsson R, Maxwell G, Adolfsson M, ErikssonAugustine L, Pless M: Differentiating Activity and Participation of Children and Youth with Disability in Sweden: A Third Qualifier in the International Classification of Functioning, Disability, and Health for Children and Youth? American Journal of Physical Medicine \& Rehabilitation 2012, 91(13):S84-S96.

22. Bowes A, McColgan G: Telecare for Older People: Promoting Independence, Participation, and Identity. Research on Aging 2012.

23. Cicerone KD, Azulay J: Perceived Self-efficacy and Quality of Life in Traumatic Brain Injury. The Journal of Head Trauma Rehabilitation 2006, 21(5):408-409. 

Appendix 1 (additional file - Chapter 4)

Frequency distribution of all item needs, top

20 needs and top 5 needs in each domain 

Day care, School and at work

The possibilities for my child to attend regular day care

Specialised day care for my child

Finding a suitable school for my child (in terms of travel time, adaptations, counselling, supportive attitude of teachers / directors)

Admission to regular education

Admission to special education

Attending a mainstream preschool, elementary or secondary school by my child

Possibilities for additional assistance for schoolwork at school or at home

The Individual Educational plan (IEP) of my child

My child's school performance

Visiting regular out of school care or extra-curricular activities at school

Possibilities for specialized out of school care

Possible job options

Appropriate job training (in terms of travel time, adjustments, counselling, supportive attitude of teachers / directors)

Possible co-ops / placements and future jobs for my child

Talk with the teacher(s) and the counsellor(s) of my child more often

Dealing with problems at school (e.g. carrying out the Individual Educational Plan, interact with people at school, quality of education, use of funds)

Suitable day program options post-secondary school (or high school)

\section{Aids, adaptations and facilities}

Options for aids

Resources or equipment for our child that are wider employable in the family (e.g. a swing that is also fun for other children in the family)

Equipment or arrangements for the whole family to go on a day trip

Try out equipment before purchasing it

Applications for equipment for my child (e.g. wheelchair, walking aid, communication aid)

Hands-on training or explanations regarding the use of an aid

Realizing small home adaptations (e.g. making icons or adjusting clothes)

Suitable/adapted toys for my child

Custom made clothing/shoes

Resources, equipment and support that are available in our community

Resources, equipment and support my child might need in the future

Funding resources and facilities

Facilities at two addresses, e.g. in the case of co-parenting

Equipment at school and the co-op/placement/work environment (e.g. special books, laptop, adjustments in the work environment) 


\begin{tabular}{lr}
\hline Domain and Need & $\%$ yes \\
\hline Funding home adjustments & 18.5 \\
The search for adapted housing & 6.8 \\
\hline
\end{tabular}

\section{Practical support at home}

Coordinating the care for my child 18.5

How to provide daily care to my child (e.g. taking a bath, dental brush, helping with eating) 19.9

As a family take care for the child with a disability properly (e.g. by following a lifting course) 28.8

Locating babysitters or respite care providers who are willing and able to care for my child for the

daytime or the evening 35.6

Practical support from family, friends and neighbours $\quad 30.1$

Care for my other children, for instance during therapy of hospital admittance of my child with disabilities

The possibilities of a personal budget

Specialized (respite) care providers at home

Specialized care provider who helps out during out-of-home activities 26

Possibilities for domestic help 19.9

$\begin{array}{ll}\text { Opportunities for supporting family care } & 11.6\end{array}$

To keep my (financial) administration right $\quad 7.5$

Accommodation options (weekends, holidays) for my child (e.g. respite care) 23.3

$\begin{array}{ll}\text { Combining the care for my child with my day job } & 26.7\end{array}$

Organizing the daily activities of the family (e.g. dressing, get ready for the taxi in time, taking care for

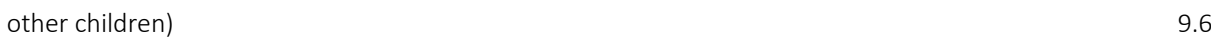

$\begin{array}{lr}\text { Placing my child in residential or assisted living } & 0.7\end{array}$

The Family

Keeping up with household duties while having a child with a physical disability

Having quality time together (e.g. having a meal together or play a game) 15.1

$\begin{array}{lr}\text { Discuss issues with my partner or spouse } & 15.8\end{array}$

$\begin{array}{ll}\text { Talking about my child with my extended family } & 17.8\end{array}$

How to help family members get along well 19.2

$\begin{array}{ll}\text { Discussing problems and problem solving } & 20.5\end{array}$

$\begin{array}{ll}\text { Learning how to support each other during difficult times } & 17.1\end{array}$

The influence of my child's disability on relationships inside and outside the family (e.g. changes in partnership, less time for other children, less time for social contacts) 36.3

Support by dividing household tasks 16.4

Recognize behavioural changes in other family members (e.g. withdrawn, aggressive, or overprotective behaviour) 23.3

Suggestions for dealing with behavioural changes in other family members 24

Reaching agreement with my partner on raising my child with a physical disability 13.7

Raising my other child(ren) 8.9

Taking good care for my other child(ren) besides caring for my child with a disability 32.2 


Domain and Need \% yes

Advice about how to mind the development of my other children (e.g. their reaction to the child with disabilities, behaviour, too much help)

Support siblings in their relationship with their brother/sister with a disability (e.g., play, make contact,

lifting, care, help, difficult behaviour)

Raising my child with a physical disability

Monitoring the development of my child

Raising my child

Parenting support in the home situation (e.g. targeted parenting advice)

Playing with my child

Appropriate daily activities or tasks for my child (e.g. family rituals)

Communicating with my child

Augmentative and alternative communication with my child (e.g. using icons, sign language, voice computer, Braille)

To provide for my child's emotional needs

To provide for my child's intellectual needs

Dealing with / supporting my child' sexual development, including sexual education, identity formation 14.4

Educate my child how to do activities/tasks

Dealing with my child's behaviour

Helping my child to deal with other family members

Educate my child how to deal with other children

Stimulate social contacts or social interaction of my child

Dealing with sleeping issues of my child

Dealing with eating problems of my child

Emotional and mental support

To share my concerns about my child with my spouse or partner

To share my concerns about my child with my family

To share concerns about my child with our extended family

To share my concerns about my child with friends

Dealing with my emotions in response to the physical disability (for example dealing with guilt, grief experience)

Support my child emotionally in the process of coping with having a physical disability

Professional support with emotional or psychological issues (psychologist, psychologist, psychiatrist) for myself

Emotional / psychological support by a professional (psychologist, psychologist, psychiatrist) for brothers / sisters

Emotional / psychological support by a professional (psychologist, psychologist, psychiatrist) for my spouse

Talk to a pastor, minister, imam, priest, rabbi or other spiritual person 


Domain and Need $\quad \%$ yes

Access to experiences of other parents having a child with a disability $\quad 52.7$

$\begin{array}{ll}\text { Peer group contact for siblings of my child with a disability } & 24.7\end{array}$

Association for Parents and Children with Disabilities $\quad 31.5$

Understanding and support from those around me $\quad 34.2$

Attend a training to empower myself (e.g. to learn to inform people about the disability of my child, or to learn to deal with reactions of others to the disability of my child) 15.1

$\begin{array}{ll}\text { Create more leisure time for myself } & 40.4\end{array}$

Create more time to spend with my spouse or partner 35.6

$\begin{array}{ll}\text { Create more time for the other child(ren) in the family } & 28.8\end{array}$

A case manager or key worker, someone who supervises the care process and is aware of the needs of

all family members $\quad 18.5$

Support in standing out for the needs of my child 17.8

Communication with professionals (e.g. authorities, therapists and doctors) 19.9

Inform others about my child

Explaining the nature and consequences of the disability or physical condition to my child 20.5

Explaining the nature and consequences of the disability or physical condition to my other children 9.6

Explaining the nature and consequences of the disability or physical condition to family members, friends, neighbours and other people

Explaining the nature and consequences of the physical condition to other children 25.3

Providing information and advices about my child to friends, family and others involved 18.5

Suggestions for volunteers (e.g. scouting leaders, trainers in a sporting club, swimming teachers) how to manage the physical condition or disability of my child 28.1

To address the extra care for my child at work (e.g. when talking to colleagues, to my boss) 12.3

Knowing how to respond when friends, neighbours, or strangers ask questions about my child's disability 15.8

Knowing how to deal with reactions of unfamiliar people

\section{Leisure time}

Finding and undertaking recreational activities for our family $\quad 37$

Continuing with 'family' hobbies (e.g. skiing, hiking, going to the beach) 30.1

Finding suitable recreational activities for my child (e.g. sports, horse riding, music, scouting) 54.1

Finding suitable activities that my child can undertake with children without a disability $\quad 50.7$

Finding suitable activities that my child can undertake with peers with a disability 46.6

Suggestions for activities that my other child(ren) can undertake with my child with a physical disability 26.7

Organizing our holidays (suitable destinations, holiday home modifications, medical facilities) 30.8

Holiday camps and holiday care for my child 20.5

An adapted, safe playground for my child in our neighbourhood 24

Transportation

Transportation options for the whole family to go out

Transportation options for my child (e.g. taxi, public transport)

Transporting my child together with other children (e.g. to go out alone with one child in the stroller 


\begin{tabular}{lr}
\hline Domain and Need & $\%$ yes \\
\hline and one child in a wheelchair at the same time) & 6.2 \\
Transport my child safely & 11.6 \\
Travel by public transport with my child (bus, train, etc.) & 26 \\
Riding the bicycle with my child & 13 \\
Transportation options for my child to and from school & 10.3 \\
Transportation during school hours (e.g. to gym class, swimming, library) & 3.4 \\
Transportation for my child to and from after school care & 4.1 \\
Transportation for my child to and from respite care & 8.2 \\
Discussing problems concerning transport of my child (e.g. travelling time) &
\end{tabular}

\section{Laws, regulations and fees}

Health insurance coverage (Which treatments are paid for by our health insurance)

The indication that we need to be eligible for 'reimbursement of exceptional medical expenses' (AWBZ) for applications via the 'Social Support Act'(WMO) and the allowance for 'disabled children living at home' (TOG)

The formal recognition that we are entitled for a reimbursement of exceptional medical expenses' (AWBZ) for applications via the 'Social Support Act' (WMO) and the allowance for 'disabled children living at home (TOG)

Information about facilities that can be requested from the Social Support Act through the office of the municipality.

Information on applying for financing for the personal budget (PGB) with which we could finance an assistant or aids for my child

Managing the personal budget and other funding options for my child

Information on applying for financing for additional support for my child with a disability in mainstream schools

Applying for the allowance for taking care of a child with a disability who lives at home

Tax deductions concerning my child's disability

Laws and regulations concerning the care allowance, a contribution from the government for the costs of health insurance

\section{Information an applying on governmental funding options that apply to us.}

Complaints procedures, e.g. where can I go with a complaint about a failed treatment or forced relocation?

"bold" - top 20 needs from all domains; "italic"- top 5 needs in each domain 

Acknowledgements 

In 2010, I started a new challenge in my life. Was there more for me to wish for? The wish of being in a PhD research project about parents of children with a physical disability, at Maastricht University, supported by Zuyd University, in cooperation with Utrecht University, University Medical Centre Utrecht, De Hoogstraat Rehabilitation, and Adelante, with Mrs. Barbara Casparie as a co-researcher, and BOSK as a partner.

\section{Four years later it is time to thank everybody who contributed to this project; some peo- ple in particular.}

My PhD team, Thanks to you for the support that you offered and for being so enthusiastic during the past four years. I am fortunate to have found people who highly value the theme of this thesis. You are all very experienced researchers and you were willing to search together for the best way to portray the experiences of parents of a child with a physical disability. Despite (or thanks to) our different backgrounds we became a team able to take innovative steps in doing research. I am grateful to you all that you so openly appreciated the idea of involving a service-user in our PhD team.

First, I would like to show my appreciation to Prof. dr. Beurskens; dear Sandra, you have a very open and innovative mind. You always see new possibilities on how to approach research and you are exceptionally talented in finding new opportunities for connections, collaboration and the practical use of knowledge. You gave me a great deal of freedom and trust. Still, at the same time, you paid a lot of attention to my health-work balance guarding that other duties would not interfere with my PhD project. In the spirit of this thesis, you truly empowered me. Some people are more than just colleagues.

Prof. dr. Smeets, dear Rob, you offered me a warm welcome to the Faculty of Health Medicine and Life Sciences, Department of Rehabilitation Medicine. You have an excellent overview on issues relevant to rehabilitation and you have such a good sense for the details of research methodology. In our project, you paid a lot of attention to the rationale of decisions. I envy the way you are open and appreciate new ideas and good arguments. My deep appreciation for all of the enabling messages I received from you in the last four years and your creative thinking about the possible financial resources for this project.

Prof. dr. Jongmans, dear Marian, you are a very driven and inspiring person with a huge knowledge in the area of paediatrics. In our team, your strong focus on the major lines led to discussions relevant to the success of the project. Furthermore, you greatly encouraged me in the development of my knowledge and skills by providing me just the right amount of challenges during our meetings. I am profoundly grateful that you were part of this journey. 
Ass. prof. dr. Ketelaar, dear Marjolijn, you have been vital to the development of this project as an expert in the area of participation of children with a physical disability and the role of parents. Your heart and mind were truly a part of this project, as you are so able to identify yourself with the position and role of parents in paediatric rehabilitation. In that perspective, I am so thankful that you kept the focus of this project on issues relevant to parents. You showed me the necessity of sharing our knowledge in the field of childhood disability; thank you for all the fantastic congress moments we have spent together.

Mrs. Casparie, dear Barbara, my research partner, inspiring and empowered mother of a child with a physical disability. Your knowledge, experiences, and ways of supporting Victoria in daily life generated many new ideas in this project. Your attention to what matters to parents and how to communicate research aims to them has been of great value in this project. Involving you as a service-user in the PhD project has been an ambitious decision; but thanks a million for saying yes to this journey. I sincerely value your passion and sense for research and you have my gratitude for your unforgettable contribution to this project. Barbara, my friend, respect en dank! Victoria, nogmaals bedankt voor je mooie tekening!

In addition, I want to express my gratitude to all the participants of our studies, members of BOSK. Participating in a survey that took 30 minutes to complete, or in a 7-day diary study taking about 15 minutes each day to complete can be very tedious. I am thankful that so many of you participated in such a committed way. My deepest respect and gratitude to parents who agreed to be interviewed in their homes and for the third time delivered information for this thesis project.

This all would not be possible without the support of BOSK! In particular my gratitude to Mr. Verheijden; dear Johannes, thank you for supporting the data-gathering process and thinking with me on how to promote this project to the members of BOSK. Mr. Klem (director of the BOSK), dear Martijn, I am very thankful that you showed such empathy to this project and saw the potential of the outcomes. I am so grateful you asked me to cooperate with you in a large national project.

My co-authors, Ramon, Meghan, Sarah, Alke and Prof. dr. Helena Hemmingsson, thank you for taking part in this thesis. Ramon, I am very grateful for your efforts of reading and re-reading all the parts of this thesis. Thank you for being my most truthful reviewer! Due to your interest in the concepts of participation, I took the opportunity to write one of the articles in this thesis together with you. Meghan, during your short stay in Europe you spent quite some time helping me out with different EndNote issues. Thanks to David we could access the XL database. Besides technical qualities, you also showed many organisational qualities (e.g. managing data) that contributed to two 
publications in this thesis. Moreover, you became a wonderful friend; thank you for all the relaxing moments I was able to spend with you. Sarah, thank you so much for joining me in the analysis of the interviews, spending hours to discussing the findings together with Barbara. I really like your personal motivation for this research area and you did such a great job on your own master thesis. Alke, we spent a few intensive weeks together, traveling all over the Netherlands to visit parents. I am very thankful to you for conducting the interviews so well. My appreciation to Prof. dr. Helena Hemmingsson for discussing the concepts of the scoping review study.

Since 2003 I am privileged to be an employee of Zuyd University, a university that encourages, stimulates and financially supports the lifelong learning wishes of their employees. Especially, thanks to the Board of Zuyd and to Frits Benjamins (director of the Faculty of Healthcare) who supported me in this decision and has shown on-going interest in my progress during all those years. Thanks also to the Occupational Therapy Department management-team, Annerie Zalmstra and Frans Schoonbrood, for your interest and support.

On this PhD journey, I am thankful to have been surrounded by very nice Zuyd colleagues being able to cope with my stress level as a part-time PhD student.

Some of them played a special role in this journey, helped shaping this thesis, facilitated data-collection and analysis or asked challenging questions. Wencke and Steffi, you both have been involved in one of the studies; Wencke, thank you in supporting the data-analysis in the diary study, and Steffi, thank you for supporting the data collection in the survey and fantastic how you completed your master thesis project.

Thanks to the members of the DenkTank Qualitative Research group and the Community of Practice Kind \& Jeugd Zuyd, who gave me the opportunity to discuss relevant topics of this thesis.

Jolien, Albine, Melanie, thank you for discussing topics of this thesis with me. Stephanie, Marja, Jacqueline, Inge and Ankie, anytime I came with a question you took time and helped me out. Thank you very much! Annette, and Helen, thanks you for helping me out with the full text articles and books; Helen, my appreciation for your language check and translation of all the parents' quotes. Bart, and Pieter, thanks for making the videohistory of user-involvement that I used in this research project and will use on different occasions.

Many thanks to Zuyd students of Occupational Therapy, Nursing, Physiotherapy and Communication \& Media Design who played a role in this project and contributed to the 
data gathering or data management process; in particular to Jaime, who made an illustration for this thesis.

My UM colleagues, thank you for giving me a warm welcome at the department of Rehabilitation Medicine and showing your interest in my project; especially my gratitude to Vera Mertens for discussing analysis options with me, and Margareth van Krevel for organizing the PhD meetings and showing interest in my progress. Thanks also to colleagues of MEMIC for data management.

Thank you very much to my assessment commission for taking time to read and assess my PhD thesis: Prof. dr. Horstman, Prof. dr. Zimmermann, Prof. dr. Jansen, Prof. dr. Gorter, and dr. Kolehmainen.

Adelante Hoensbroek, my appreciation for the financial support of this thesis project.

NetChild colleagues, many thanks for sharing your research knowledge in the area of participation with me and organizing great research meetings and discussions. My special gratitude to Maureen Bult for inviting me to be part of your participation project.

Maarten de Wit (Stichting Tools), Albine Moser (Zuyd) and Esther Stoffer (Huis voor de Zorg) thank you for giving me such great support in how to involve a service-user in the project. Maarten, I learnt so much from your experiences and knowledge in this area. I hope the four of us can continue our collaboration on service-user involvement.

In addition, my international colleagues have been wonderfully supporting me on this journey; there is no way to mention them all. Thank you for sending me nice mails and messages during this journey. My special thanks to Prof. dr. Helene Polatajko as contributor to one of the papers in this thesis. The theme of this thesis attracted some international attention; thank you dr. Lena Haglund for your trust in me to perform as one of the keynote speakers at the European Congress of Occupational Therapist in Stockholm; my gratitude to Prof. dr. May Law and Prof. dr. Jan Willem Gorter from CanChild, for inspiration, access to information, and provision of instruments; dr. Claire Craig, my dear friend, thank you for all your kind words and ways you were thinking of me; dr. Hanneke van Bruggen, my gratitude to you for enabling my international carrier.

Lieve vrienden: Barbara, Marise \& Leon, Anne-Marie \& Jo, Femke \& Leon, Anja \& Geert, Andre \& Ingrid, en Jeroen \& Bianca. In verschillende samenstellingen zijn jullie de afgelopen jaren een bron van ontspanning en plezier geweest. 
Barbara en Jolien, mijn paranimfen! Ik ben erg trots dat jullie mij willen bijstaan! Dank voor jullie samenwerking, discussies, congresbezoeken, lunches, en koffiepauzes.

Barbka \& Attila, Biserka \& Peter, Sanja \& Nace, Polona \& Janez, Nežka, Tamara, Mateja, tete \& strici z družinami, hvala za vse gurmanske užitke, kavice, pokušine vina, "slowfood" večerje, vašo družbo in pozornost, ki smo jo vedno deležni ob prihodu v Ljubljano. Prav vam gre zasluga, da 'delovne' počitnice v Sloveniji dobijo drugo dimenzijo.

Bonnie \& Gary, Jean \& Charlie, my American family I first met in 2011. Thank you for your frequent use of our Facebook page to keep in touch and for showing interest in my research work.

Joke en Anton, mijn schoonouders, dank jullie wel voor de warme ontvangt en enorme belangstelling in de afgelopen jaren. Wat fijn dat we af en toe een weekendje bij jullie konden logeren. Dankzij jullie heeft Nika dit proces zeker minder zwaar ervaren. Muriël, mijn schoonzus bedankt voor de belangstelling en de gezelligheid in de afgelopen tijd.

Mami in Ati, hvala za vse kar sta mi omogočila v življenju. Brez vaju mi tale dosežek nikoli ne bi uspel. Hvala tudi za vso skrb, ki smo jo deležni kadar pridemo na 'delovne' počitnice v Slovenijo. Zelo dobro se zavedam, da vsi ti uspehi in številni obiski kongresov brez vaju ne bi bili mogoči. Z malo slabe vesti, a vedno znova, prosim, če bi lahko prišla k Niki in ji delala družbo. Boštjan, hvala ti za vse ponujene rešitve, ki so pripomogle da je moje delo, tudi na Dobravici, nemoteno potekalo. Predvsem pa hvala, da si moj brat na katerega se vedno lahko zanesem. Tanja tudi tebi hvala za zanimanje in prijeten klepet ob kavici.

Ramon, more than anyone else, you knew what was awaiting for me. Without your encouragement and support, my PhD experience would have been very different. We are a wonderful team; a team that is able to live and work together :-)! I am very proud of us, the way we organize our life together and take care of each other; "I do not know what I would do without you, I do not know where I would be ... as you are everything to me".

Nika, ljubica moja, hvala ti, da si tako super punca. Veš kar težko mi je, ko se ne morem igrati s teboj, vedno kadar ti to želiš. SORRY! Zato pa tako bolj uživam, ob najinih skupnih potepih po mestu. Zelo sem ponosna na tebe in vedno znova me presenti, kako znaš poskrbeti za odlično družinsko vzdušje. Ti si najin sonček $($. 

Curriculum Vitae 

Barbara Piškur was born June 25, 1968 in Ljubljana, Slovenia. In 1983, she finished secondary school in Ljubljana and in 1990; she received her Bachelor of Science degree in occupational therapy. She took a job as an occupational therapist in 1990, working with children having multiple disabilities and their families. Between 1993 until 2000, she worked as an educator at the University of Ljubljana. Since 1995, she has been involved in several European projects (e.g. Development of Occupational Therapy Education in Eastern and Central Europe) and between 2000 -2003, she worked as a subcontractor for the European Network of Occupational Therapy in Higher Education (ENOTHE); between 1995 and 2001, she was a board member of ENOTHE. In 2001, she finished the European Master of Science in Occupational Therapy and one year later, she moved to the Netherlands. Since 2003, she works at Zuyd University in Heerlen. She currently combines her duties as senior educator at the Occupational Therapy department and at the Master programme Innovation in Complex Care, with the position of senior researcher at the Research Centre on Autonomy and Participation, and at the Research Centre International Relationship Management.

Barbara has been and is part of several projects; like the EU curriculum development (Euro-Education: Employability for all -EEE4all), Zuyd Innoveert, EIZT - Methodieken van Cliënten Participatie, Global Minds and Community of Practice Child and Youth project. Barbara is a member of the Advisory Board Child \& Youth of the Dutch Occupational Therapy Association and is intensively involved in different areas of practice, research and education in the field of Occupational Therapy in the Netherlands. In the field of parents' enablement, she collaborates and works with the Dutch parents' organisation BOSK.

Internationally, related to research on participation of children with a physical disability and their parents, she is cooperating with research networks and universities like NetChild (NL), CanChild (Canada), Newcastle University (UK) and Linkoping University (SE). Barbara is married to Ramon Daniëls; together they have one daughter - Nika. 
2015

Piškur B, Beurskens AJHM, Jongmans MJ, Ketelaar M, Smeets RJEM: What do parents need to enhance participation of their school-aged child with a physical disability? A cross-sectional study in the Netherlands. Child: Care, Health and Development 2015, 41(1):84-92.

2014

Piškur B, Daniëls R, Jongmans MJ, Ketelaar M, Smeets RJEM, Norton M, Beurskens AJHM: Participation and social participation: are they distinct concepts? Clinical Rehabilitation 2014, 28(3):211-220.

Klotz, S., Laumen, S., Peters, N., Steinfeld, E., Piškur, B. Hoe beschrijven ouders van kinderen met en zonder beperking de inhoud en relevantie van de Nederlandse vertaling van de PEM-CY?, Wetenschappelijk Tijdschrift voor Ergotherapie, Aflevering 3-4.

2013

Koene, I., Sanders., Staak Van Der, E., Weusten, H., \& Piškur, B. (2013). Thesis: Evaluatie van de hanteerbaarheid en betrouwbaarheid van de Nederlandse vertaling van de Participation and Environment Measure for Children and Youth, Wetenschappelijk Tijdschrift voor Ergotherapie, Aflevering 01.

Piškur, B (2013). Social participation: Redesign of education, research, and practice in occupational therapy. Scandinavian Journal of Occupational Therapy, 20 (1), 2-8.

Van den Houten J, Jansens R, Kern E, Piškur B, Schmitz S., (2013). Voortschrijdende inzichten in kinderergotherapie. Ergotherapie Magazine 4 ; 24-27.

Van den Houten J, Jansens R, Kern E, Piškur B, Schmitz S. (2013). Vraag en aanbod; op zoek naar een slagzin voor de kinderergotherapie, Wetenschappelijk Tijdschrift voor Ergotherapie, Aflevering 05.

2012

Piškur, B, Beurskens, A.J.H.M., Jongmans, M. J., Ketelaar, M., Norton, M, Frings, C, Hemmingsson, H \& Smeets, R.J.E.M. (2012). Parents' actions, challenges, and needs 
while enabling participation of children with a physical disability: a scoping review. BMC Pediatrics, 2012, 12(1):177.

Craig, C. \& Piškur, B., Student perspectives on the development and evaluation of a joint international education to promote employability in Europe, Work 41 (2012) 439-446 439.

2011

Van Zanten, E., Leurs, L., Keimes, L., Krings, A., Piškur, B. (2011). Laptop op school: een kwalitatief onderzoek naar ervaringen van leerkrachten en kinderen met fysieke beperkingen. Wetenschappelijk Tijdschrift voor Ergotherapie, nr. 4.

2010

Bult M, Verschuren O, Gorter J, Jongmans M, Piskur B, Ketelaar M: Cross-cultural validation and psychometric evaluation of the Dutch language version of the Children's Assessment of Participation and Enjoyment (CAPE) in children with and without physical disabilities. Clin Rehabil 2010, 24(9):843 - 853.

Piškur, B., Craig, C., Lindh Falk, A., Kraus, E., Van Bruggen, H. (2010). CDrom: Employability 4all: a European perspective. Modules and summary of best practices in Europe, ENOTHE, ISBN 978-90-78379-11-9.

Craig, C., Piškur, B., Lindh Falk, A., Kraus, E., Van Bruggen, H. (2010). Employability 4all: Practical Guidelines for developing a joint European module, ENOTHE, ISBN 978-9078379-12-6.

2008

Van Hartingsveldt, M., Piškur, B., en Stomph, M. (2008). Het Canadian Practice Process Framework (CPPF). Van procesmodel naar process framework, Wetenschappelijk Tijdschrift voor Ergotherapie, nr. 2.

2006

Piškur, B. en Daniëls, R. (2006). Canadian Model of Occupational Performance (CMOP) en Occupational Performance Process Model (OPPM). In: Kinebanian et al. Grondslangen van de Ergotherapie, Elsevier. 
Piškur B, Kinebanian A, Josephsson S. (2002). Occupation and well-being: A study of some Slovenian people's experiences of engagement in occupation in relation to wellbeing, Scandinavian Journal of Occupational Therapy; 9:63-70.

\section{KEYNOTE SPEECHES}

2014

Piškur, B. Keynote speech: User involvement in research: a current fashion or a must have at the National Finnish Research and Development symposium in Helsinki, November 2014.

2012

Piškur, B. Keynote speech : Social participation: Redesign of education, research, and practice in occupational therapy at the European Congress of Occupational Therapy (COTEC) in Stockholm, May 2012.

\section{CONGRESS PRESENTATIONS}

\section{4}

Piškur B, Beurskens S, Jongmans M, Smeets R, Ketelaar M, Casparie B, Verheijden J. User involvement in occupational therapy research (poster presentation). WFOT Conference, Yokohama, Japan, June 2014

Piškur, B. et al. Parents' occupations to enable child's participation in the context (oral presentation), WFOT Conference, Yokohama, Japan, June 2014

\section{3}

Piškur, B. et al. Social participation of children with a physical disability (oral presentation), Disability studies congress, Amsterdam 2013

Piškur, B. et al. Parents' influence on successful social participation of children with a physical disability (poster presentation), EACD congress UK, New Castle, 2013 
Piškur, B. Parents' influence on participation of children with a physical disability: actions, challenges and needs (oral presentation), DCD-beleidsconferentie 2013.

\section{2}

Piškur, B. Sociale participatie: de rol van de ouders (oral presentation) at the BOSK 60 jaar Jubileum Congress in Arnhem 2012.

Piškur, B. Parents' actions, challenges and needs while enabling social participation of children with a physical disability (poster presentation) at the European Congress of Occupational Therapy (COTEC) in Stockholm 2012.

Zalmstra, A., Piškur, B. Application of practice guidelines Enabling Occupation II in a Dutch community of practice (oral presentation) at the European Congress of Occupational Therapy (COTEC) in Stockholm 2012.

2011

Piškur, B. EEE4all - Innovation in education (oral presentation) on "Centrale Acties in het Leven Lang Leren Programma: inspireren en dissemineren" Utrecht 2011.

Piškur, B. et al. Oral presentation, WFOT Conference, Yokohama, Japan, June 2014

Piškur B, Beurskens S, Jongmans M, Smeets R, Ketelaar M, Casparie B, Verheijden J. User involvement in occupational therapy research. WFOT Conference, Yokohama, Japan, June 2014 


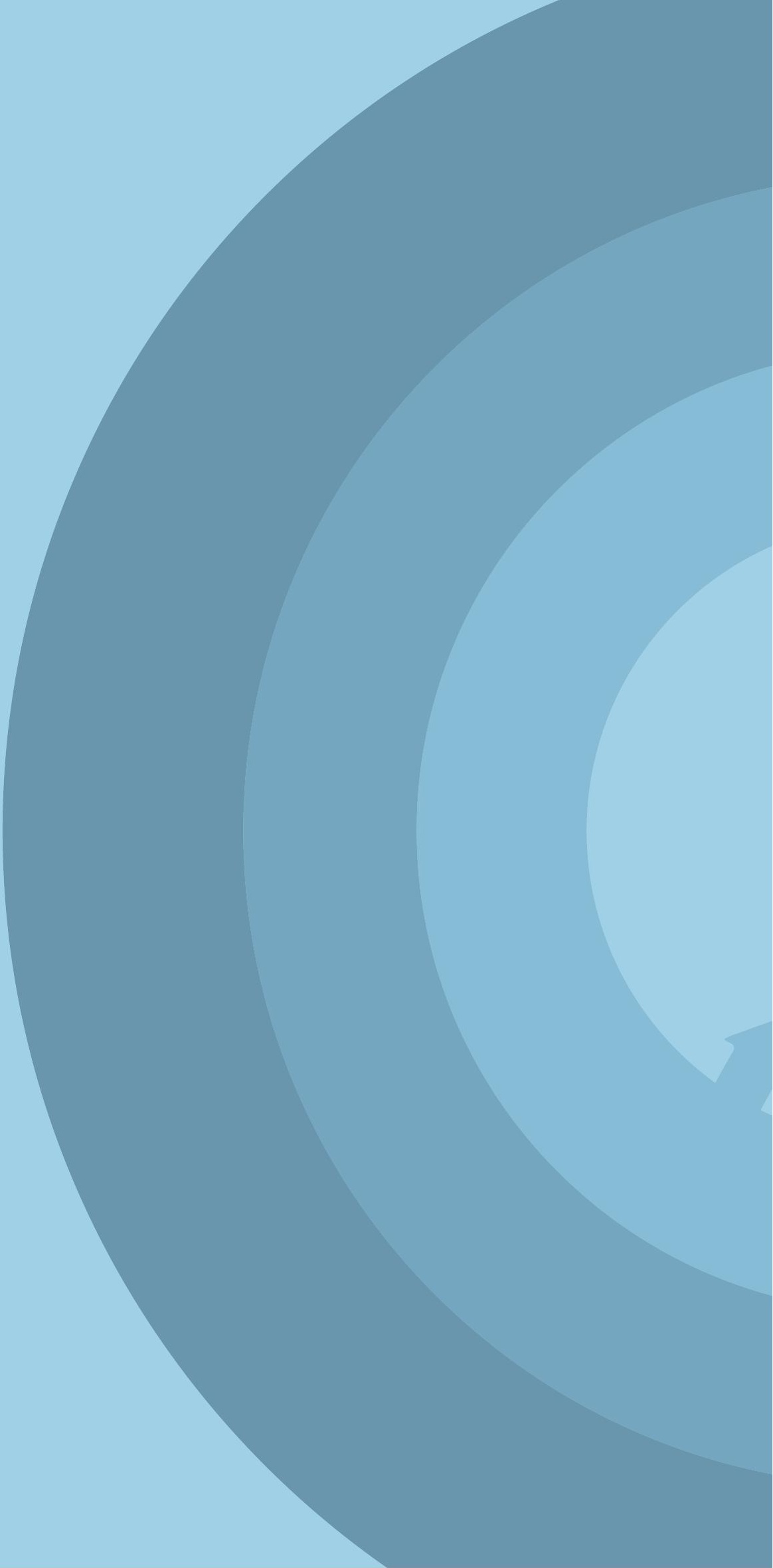

